\title{
Influência das variações de baixa frequência da Circulação de Revolvimento Meridional na concentração de clorofila-a no Atlântico Sul
}

\begin{abstract}
Dissertação apresentada ao Instituto Oceanográfico da Universidade de São Paulo como parte dos requisitos para obtenção do título de Mestre em Ciências, Programa de Oceanografia, área de Oceanografia Física
\end{abstract}

Orientador:

Profa. Dra. Olga T. Sato

São Paulo 


\section{UNIVERSIDADE DE SÃO PAULO INSTITUTO OCEANOGRÁFICO}

Influência das variações de baixa frequência da Circulação de Revolvimento Meridional na concentração de clorofila-a no Atlântico Sul

\section{Lucas Carnier Casaroli}

Dissertação apresentada ao Instituto Oceanográfico da Universidade de São Paulo como parte dos requisitos para obtenção do título de Mestre em Ciências, área de Oceanografia Física.

Versão Corrigida

Aprovado em $-1 / L$

Prof. Dr.

Prof. Dr.

Prof. Dr. 


\section{Agradecimentos}

Não sei como cheguei aqui, mas cheguei. Quero agradecer primeiramente à professora Olga. Desde 2012 quando entrei no seu laboratório sempre me tratou com cordialidade e profissionalismo. Sou muito grato por todos os ensinamentos que ela me passou ao longo desses anos. Se tive qualquer amadurecimento científico foi graças a ela. Sempre se mostrou disposta a ajudar, sempre teve paciência de explicar e com toda a cobrança sempre busca um trabalho bem feito. Obrigado professora Olga, você não é só uma professora mas uma amiga que considero muito. Indo por essa linha de professores tenho que agradecer também ao professor Paulo Polito. Professor Paulo sempre esteve disposto a explicar algo novo para minha pessoa, seja de oceanografia física, processamento de sinais ou aviões da Segunda Guerra. Também o estimo muito e o considero uma pessoa muito importante e um amigo. Agradeço aos mestres jedis: o "Tio" Ilson, sempre animado e com alto conhecimento em oceanografia e ao professor Belmiro, que apresenta a melhor didática (e melhor lousa) desse IO. Graças a eles aprendi o "ABC" da oceanografia física.

Agradeço a minha querida Luana. Flor, sem você não ia rolar esse mestrado. Você que me ajudou a me programar, criar uma rotina, me atender quando achava que não ia conseguir e ser o ombro para desabafar. Seu carinho é imensurável e sua beleza não é só física, mas sim algo muito mais profundo e único. É uma joia preciosa. Agradeço aos meus amigos desde a época do colégio que continuamos nos vendo até então, o grupo LOL. Vocês não só me apoiam nas minhas decisões loucas da vida, como são loucos o suficiente para me acharem normal. Cada um de vocês é especial para mim, são meus melhores amigos e espero que essa nossa amizade continue por MAIS DE 8000 anos, que continuemos indo JANTAR e quero que saibam que essa amizade "é tudo o que verdadeiros guerreiros desejam ter".

Para a minha família, vocês são os culpados por eu gostar tanto do mar e acabar escolher fazer um mestrado em oceanografia com interação entre a física e a biologia. Pai, você é minha maior inspiração, suas "aulas práticas" nas praias de Ubatuba me incentivaram a querer entender um pouquinho mais desse ambiente. Mãe, obrigado por sempre apoiar nas decisões seja um dia ser oceanógrafo ou no outro dia ser um cineasta ou quem sabe um dia um filósofo, sem seu apoio não seria ninguém. Vivi, você sempre foi a minha parceira de aventuras nas "piscinas naturais" no costão rochoso da praia do Félix, você foi pra biologia e eu para oceanografia. Obrigado por ser essa pessoa maravilhosa que posso contar.

Agradeço aos meus colegas da Turma $X$, sempre lembro de vocês mesmo afastados, minha "sis" Marina Hellboy, Paty boêmia, Ash com o seu café, Totó "muito louco", Léo no longboard, Jabu para discutir história, Laura parceira de mar profundo (e bandejão), Tuba sempre atrasado, Justin irritado com sotaque carioca, Ana minha amiga do coração, Mari com o seu "eaaaaaaae" e todos os demais, a lista é grande mas guardo todos no 
meu coração. Aos parceiros de laboratório: Giovana e Thaís, obrigado por tornarem meu mestrado mais alegre e divertido, Piero pelas conversas breves mais com vários insights, Marouan com suas dicas sobre Matlab e as boas conversas sobre lugares do mundo. Por fim, mas não menos importante, agradeço a Deus por ter me ajudado e estar ajudando nessa trajetória. O presente trabalho foi realizado com apoio da Coordenação de Aperfeiçoamento de Pessoal de Nível Superior - Brasil (CAPES) - Código de Financiamento 001. 


\section{Sumário}

1 Introdução 1

$1.1 \quad$ Relação da MOC na clorofila . . . . . . . . . . . . . . . . . . . . . 7

2 Materiais e Métodos 10

2.1 Clorofila-a . . . . . . . . . . . . . . . . . . . . . . 10

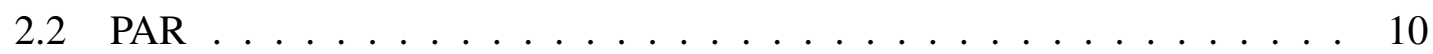

2.3 Dados de Velocidade . . . . . . . . . . . . . . . . . . . . . . 11

2.3 .1 Modelo de Reanálise Oceânica MERCATOR . . . . . . . . . . . 11

2.3 .2 Modelo ECCO . . . . . . . . . . . . . . . . 13

2.4 Dados de Nitrato $\ldots \ldots \ldots \ldots$

2.4 .1 Dados do Modelo PISCES . . . . . . . . . . . . . . . . . 14

2.4 .2 Nitrato Integrado . . . . . . . . . . . . . . . . . . . . . 15

2.5 Multi-dimensional Ensemble Empirical Mode Decomposition . . . . . . 16

$2.5 .1 \quad$ Empirical Mode Decomposition . . . . . . . . . . . . . 18

2.5 .2 Ensemble Empirical Mode Decomposition . . . . . . . . . . . 20

2.5 .3 Multi-dimensional Ensemble Empirical Mode Decomposition . . 23

2.6 Cálculo de Fluxo de Volume da MOC do Atlântico Sul . . . . . . . . . . . 24

2.7 Índices Climáticos . . . . . . . . . . . . . . . . . . 25

2.7 .1 Oscilação Antártica . . . . . . . . . . . . . . . . . . . 25

2.7 .2 El Niño - Oscilação Sul . . . . . . . . . . . . . . . 25

3 Resultados e Discussão

3.1 Apresentação dos Dados . . . . . . . . . . . . . . . . . . . . . 26

3.1 .1 Clorofila no Atlântico Sul . . . . . . . . . . . . . . 26

3.1 .2 Nitrato . . . . . . . . . . . . . . . . . 31

$3.1 .3 \quad \mathrm{PAR} \ldots \ldots \ldots \ldots \ldots$

3.1 .4 Transporte da MOC do Atlântico Sul . . . . . . . . . . . . . . 37

3.2 Aplicação do MEEMD: Clorofila, PAR e nutrientes . . . . . . . . . . . . 40

$3.2 .1 \quad$ Regiões A, B e C . . . . . . . . . . . . . . . . 42

$3.2 .2 \quad$ Nutrientes ou luz? . . . . . . . . . . . . . . . . . . . . 44

3.2.3 Nitrato integrado e concentração de clorofila: Regiões A e B . . . 46

3.2 .4 Nitrato integrado e concentração de clorofila: Região C . . . . . . 48

3.2 .5 Taxa de variação temporal . . . . . . . . . . . . . . . . . . . 49

3.3 A relação do nitrato integrado com a MOC do Atlântico Sul . . . . . . . 53

3.3 .1 Relação das regiões A, B e C com os transectos . . . . . . . . . . 55

3.4 Índices Climáticos . . . . . . . . . . . . . . . . . 66

\begin{tabular}{lll}
\hline 4 & Conclusão & 71
\end{tabular} 
5 Apêndice 76

5.1 Teste de Significância para o IMF $\ldots \ldots \ldots \ldots \ldots \ldots$

5.2 Teste de significância para as tendências decadais $\ldots \ldots \ldots$. . . . 78 


\section{Lista de Figuras}

1 Esquema da MOC, as setas vermelhas representam a circulação mais su-

\begin{tabular}{|l|}
\hline perficial forçada pelo vento; as setas azuis representam a circulação pro- \\
\hline funda forçada pelas variações de sal e temperatura. Note que nesta ima- \\
\hline gem há a representação das duas hipóteses de retorno das águas fundas \\
\hline para as águas rasas. Imagem extraída de Rahmstorf (2002). . . . . . . . . . 4 \\
\hline
\end{tabular}

2 Representação esquemática da circulação do Atlântico Sul, adaptado de

Stramma and England (1999). As principais correntes do Atlântico Sudo-

este são: Corrente das Malvinas (CM), Corrente do Brasil (CB), Corrente

do Atlântico Sul (CAS), Corrente Sul Equatorial (CSE), Corrente Norte

do Brasil (CNB). . . . . . . . . . . . . . . . . 5

3 Representação esquemática da circulação das diferentes massas d'água no

Atlântico Sul: APAN (azul), AIA (amarelo), ACAS (vermelho). Adap-

\begin{tabular}{|c|}
\hline tado dos resultados de Stramma and England (1999), extraído de Garzoli \\
\hline
\end{tabular}

and Baringer (2007). . . . . . . . . . . . . . . . . 6

4 Resolução espacial horizontal do modelo de reanálise oceânica MERCA-

TOR GLORYS2V4. Fonte: GEOMAR - Helmholtz Centre for Ocean

Research Kiel. . . . . . . . . . . . . . . . . . . . 12

5 Exemplo da grade LLC90 contendo as cinco grande faces presente no modelo ECCO. Extraído de ECCOv4r3 User Guide adaptado de (Forget et al. 2015). . . . . . . . . . . . . . . . 13

6 Esquema do modelo PISCES. As variáveis modeladas se encontram na esquerda, enquanto os demais são compartimentos. Nesta imagem só está contemplada a modelagem biológica não contendo o oxigênio nem o sis-

4tema carbonato . . . . . . . . . . . . . . . . . . . . 14

7 Mapa esquemático da localização das águas modais com suas densidades

potenciais típicas e padrão de circulação do giro subtropical e da Corrente

Circumpolar Antártica. As cores rosas são águas modais subtropicais na

porção leste das bacias oceânicas, as cores vermelhas são águas modais

subtropicais presentes nos giros e as cores em vermelho escuro são água

modal subpolar no Atlântico Norte, água modal central no Pacífico Norte

e a água modal subantártica no Oceano Austral. Extraído de Hanawa and

Talley (2001) . . . . . . . . . . . . . . . . . 16

$8 \quad$ Mapa das profundidades da isopicnal de $\sigma=26.8 \mathrm{~kg} \cdot \mathrm{m}^{-3}$. As profundidades determinadas a partir da climatologia do WOA13. As áreas cinzas são regiões onde a densidade da água de superfície é maior que a densidade de referência (próximo a região antártica) ou que não é profunda o suficiente para alcançar tal densidade. . . . . . . . . . . . . 17 
9 Ilustração esquemática do EMD. A curva $\mathrm{C}_{1}$ é uma mono-componente, as curvas amarelas $\mathrm{a}_{1}$ e - $\mathrm{a}_{1}$ são os envelopes com os máximos e mínimos e a curva vermelha $\mathrm{R}_{1}$ seria análogo a $K(t)$, uma componente com pequena variação ao longo do tempo. Fonte: Ji et al. (2014) . . . . . . . . . . . . 19

10 EEMD aplicado a uma série temporal da concentração de clorofila entre $30^{\circ} \mathrm{S}-40^{\circ} \mathrm{S}$ e $10^{\circ} \mathrm{E}-2^{\circ} \mathrm{W}$. A primeira série temporal é o dado original, as \begin{tabular}{|c|}
\hline outras curvas azuis são a decomposição da série em IMF's e a curva em \\
\hline
\end{tabular} vermelho o resíduo/tendência . . . . . . . . . . . . . . . . . . . . . 21

11 Série temporal original da concentração de clorofila (mesma que da Figura 10p sobreposta à componente da tendência de mais baixa frequência (vermelho) decomposta pelo EEMD. . . . . . . . . . . . . . . . . 22

12 Série temporal da concentração de clorofila original sobreposta a mesma série porém 40 meses mais curta (curvas superiores). IMF da componente em escala anual da série original (curvas inferiores). Todas as curvas foram levemente deslocadas para não ter sobreposição. . . . . . . . . . . 22

13 Hovmöller de três IMF's da concentração de clorofila . . . . . . . . . . . . 24

14 Regiões do Pacífico equatorial utilizada para calcular os respectivos índi-

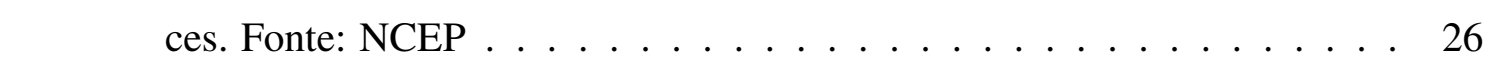

15 Média do $\log _{10}$ da concentração de clorofila entre os anos de 1998 a 2017 calculados a partir dos dados do produto GlobColour. As linhas mais cla\begin{tabular}{|c|}
\hline ras para as mais escuras correspondem às seguintes concentrações: 0,08 \\
\hline \hline $\mathrm{mg} \cdot \mathrm{m}^{-3} 0,1 \mathrm{mg} \cdot \mathrm{m}^{-3} 0,16 \mathrm{mg} \cdot \mathrm{m}^{-3} \mathrm{e} 0,25 \mathrm{mg} \cdot \mathrm{m}^{-3}$ \\
\hline
\end{tabular}

16 Localização das províncias biogeográficas South Atlantic Gyral Province (SATL) e South Subtropical Convergence Province (SSTC) para analisar a variabilidade da concentração de clorofila no Atlântico Sul a partir dos dados do Globcolour. . . . . . . . . . . . . . . . . . . . . . 28

17 Ciclo anual da concentração de clorofila nas províncias biogeográficas a

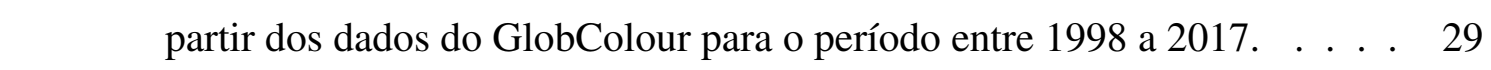

18 Histograma da concentração da clorofila nas regiões biogeográficas: a) South Atlantic Gyral Province e b)South Subtropical Convergence Province. O painel superior se refere ao histograma dos dados da província enquanto o painel inferior os dados em $\log _{10}$. As curvas em vermelho são a função densidade de probabilidade de uma distribuição log-normal (painel superior) e normal (painel inferior). . . . . . . . . . . . 32

19 Histograma do $\log _{10}$ da concentração de clorofila no Atlântico Sul. . . . . 33

20 Ciclo anual médio da concentração de nitrato integrado nas províncias \begin{tabular}{|c|}
\hline biogeográficas utilizando saída do modelo biogeoquímico PISCES entre \\
\hline
\end{tabular} os anos de 1998 a 2016. . . . . . . . . . . . . . . . . . . . . . . . . 33 
21 Média do nitrato integrado entre os anos 1998 a 2016 usando dados do modelo biogeoquímico PISCES. . . . . . . . . . . . . . . . . . 34

22 Histograma do nitrato integrado nas regiões biogeográficas: a) South Atlan-

\begin{tabular}{|c|}
\hline tic Gyral Province e b)South Subtropical Convergence Province. O painel \\
\hline superior se refere ao histograma dos dados da província enquanto o painel
\end{tabular}

inferior os dados em $\log _{10}$. As curvas em vermelho são a função densi-

\begin{tabular}{|c|}
\hline dade de probabilidade de uma distribuição log-normal (painel superior) e \\
\hline
\end{tabular} normal (painel inferior). . . . . . . . . . . . . . . . . 35

23 Média do PAR entre os anos 1998 a 2017 a partir dos dados do GlobColour 36

24 Ciclo anual do PAR nas regiões biogeográficas a partir dos dados do Glob-

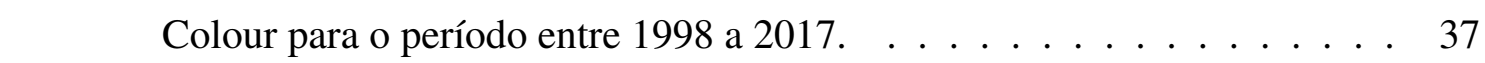

25 Histograma do PAR nas regiões biogeográficas: a) South Atlantic Gyral Province e b)South Subtropical Convergence Province. O painel superior se refere ao histograma dos dados da província enquanto o painel inferior \begin{tabular}{|c|}
\hline os dados em $\log _{10}$. As curvas em vermelho são a função densidade de \\
\hline
\end{tabular} \begin{tabular}{|c|}
\hline probabilidade de uma distribuição log-normal (painel superior) e normal \\
\hline
\end{tabular} (painel inferior). . . . . . . . . . . . . . . . . 38

26 MOC do Atlântico Sul em $34,5^{\circ} \mathrm{S}$ para os anos de 1992 a 2015 pela saída do modelo a) ECCO e b) NEMO. A linha vermelha é a tendência interanual. 39

27 Ciclo anual da anomalia da MOC do Atlântico Sul em $34,5^{\circ} \mathrm{S}, 25^{\circ} \mathrm{S}$ e $15^{\circ} \mathrm{S} 40$

28 Média anual da componente de mais baixa frequência obtida pela aplica-

ção do método MEEMD na concentração de clorofila $\left(\mathrm{mg} / \mathrm{m}^{3}\right)$. Os va-
lores em branco correspondem a valores com média de concentração de clorofila maior que $0,79 \mathrm{mg} / \mathrm{m}^{3} \ldots \ldots \ldots$. . . . . . . . . . 42

29 Mapa esquemático contendo as regiões A, B e C (retângulos pretos), a direção da tendência positiva (linha verde) e os transectos utilizados para

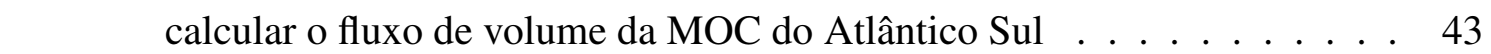

30 Séries temporais da tendência interanual da concentração de clorofila (pai\begin{tabular}{|c|}
\hline nel superior), nitrato integrado (painel do meio) e PAR (painel inferior) \\
\hline
\end{tabular}

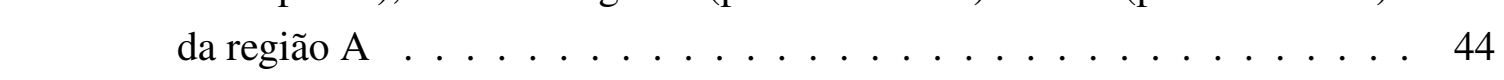

31 Similar à Figura 30 mas para a região B . . . . . . . . . . . . . . . . . . . . . . . . . 45

32 Similar à Figura 30 mas para a região $\mathrm{C} \ldots . . \ldots$. . . . . . . . 45

33 Série temporal do nitrato integrado na região A (azul) com sua tendência interanual (vermelho). . . . . . . . . . . . . . . . . . 47

34 Similar à Figura $33 \mid$ mas para o PAR. . . . . . . . . . . . . . . . . . . 48

35 Taxa de variação temporal da tendência interanual da clorofila (painel superior) e do nitrato integrado (painel inferior) para a região A . . . . . . . 49

$36 \quad$ Similar à Figura $35 \mid$ mas para a região B. . . . . . . . . . . . . . . . . . . . . 50

37 Similar à Figura $35 \mid$ mas para a região C. . . . . . . . . . . . . . 50 
38 Hovmoller da anomalia da tendência interanual da concentração de clorofila e nitrato integrado. A latitude é referência do transecto verde da Figura $29 \mid$ Uma média móvel de $1,25^{\circ}$ foi aplicada para remover qualquer ruído presente. . . . . . . . . . . . . . . . . 51

39 MEEMD da clorofila aplicado a região do giro subtropical do Atlântico Sul. As regiões em branco são valores de clorofila maior que $0,05 \mathrm{mg} / \mathrm{m}^{3} \quad 54$

40 Série temporal da MOC do Atlântico Sul nas respectivas latitudes entre

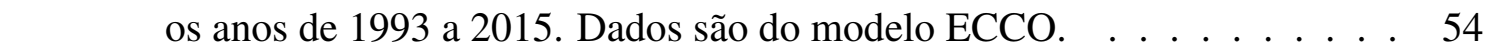

41 Série temporal da MOC do Atlântico Sul nas respectivas latitudes entre os anos de 1992 a 2015. Dados são do modelo NEMO. . . . . . . . . . . 55

42 Série temporal da tendência interanual do transporte de volume (Sv) da \begin{tabular}{|c|}
\hline MOC do Atlântico Sul em $34,5^{\circ} \mathrm{S}$ proveniente de saídas dos modelos \\
\hline
\end{tabular} ECCO (painel superior) e NEMO (painel inferior) na porção leste da bacia. 56

43 Série temporal da tendência interanual do transporte de volume (Sv) da MOC do Atlântico Sul em $25^{\circ} \mathrm{S}$ proveniente de saídas dos modelos ECCO

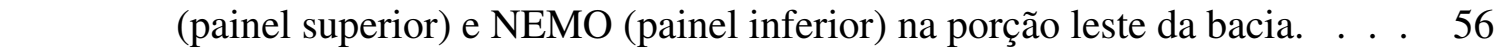

44 Série temporal da tendência interanual do transporte de volume (Sv) da MOC do Atlântico Sul em $15^{\circ} \mathrm{S}$ proveniente de saídas dos modelos ECCO

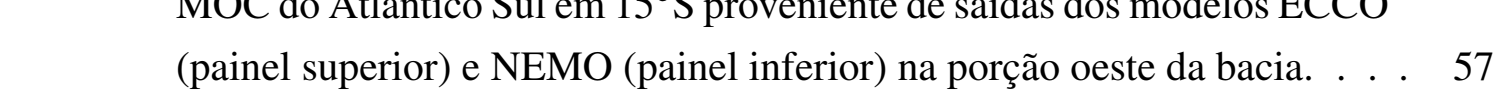

45 Taxa da tendência interanual do fluxo da MOC do Atlântico Sul no transecto de $15^{\circ}$ S. . . . . . . . . . . . . . . . . . . . . . 59

46 Taxa da tendência interanual do fluxo da MOC do Atlântico Sul no transecto de $25^{\circ}$ S. . . . . . . . . . . . . . . . . . . 60

47 Taxa da tendência interanual do fluxo da MOC do Atlântico Sul no transecto de $34,5^{\circ}$ S. . . . . . . . . . . . . . . . . 60

48 Média da anomalia da tendência interanual da concentração da clorofila (painel superior) e a sua taxa (painel inferior) próximo à região de estudo \begin{tabular}{|c|c|}
\hline de & Panassa et al. (2018). A região utilizada foi entre $1^{\circ} \mathrm{W}$ e $1^{\circ} \mathrm{E}$ e $45^{\circ} \mathrm{S}$ a \\
\hline
\end{tabular} $50^{\circ} \mathrm{S} \ldots \ldots \ldots \ldots \ldots \ldots$

49 Tendência temporal da MOC do Atlântico Sul em $34,5^{\circ} \mathrm{S}$ pelo modelo

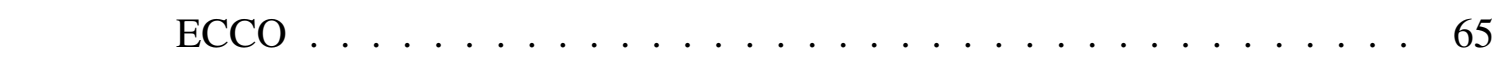

50 Tendência temporal da MOC do Atlântico Sul em $34,5^{\circ} \mathrm{S}$ pelo modelo NEMO . . . . . . . . . . . . . . . . . . . 66 
51 Teste de significância para os IMF's da MOC do Atlântico Sul (ECCO e NEMO) e dos índices climáticos. As linhas escuras contínuas se referem a um intervalo de confiança de 5\% e 95\%. As linhas tracejadas verdes, vermelhas e pretas se referem a intervalos de confiança de 70\%,50\% e 90\%, respectivamente. Os losangos azul e vermelho são IMF's da MOC do Atlântico Sul (ECCO e NEMO) e os círculos azul e magenta do ElNiño e AAO, respectivamente . . . . . . . . . . . . . . . . 69

52 Os pontos amarelos e verdes são IMF's de 1024 séries temporais de ruídos brancos. Os IMF's estão em função de sua densidade espectral média pelo seu período médio. A linha preta sólida é a curva da equação $9 \mid$ en\begin{tabular}{|l|l|l|}
\hline quanto a linha preta tracejada é a curva da equação & 10 . Os tracejados azuis
\end{tabular} \begin{tabular}{|c|}
\hline localizados na extremidade dos pontos se referem ao $5^{\circ}$ e $95^{\circ}$ percentil. \\
\hline
\end{tabular} Fonte: (Huang 2014). . . . . . . . . . . . . . . . . 77

53 Teste de significância para a tendência da concentração de clorofila na região A. Os pontos azuis são os coeficientes angulares das retas ajustadas para as séries randômicas. As linhas tracejadas se referem a valores da média $\pm 2,5$ desvios padrão. O ponto em magenta é o coeficiente angular do polinômio ajustado para a tendência. . . . . . . . . . . . . . . 79

54 Similar a Figura 53 , porém com a MOC proveniente de saídas do modelo

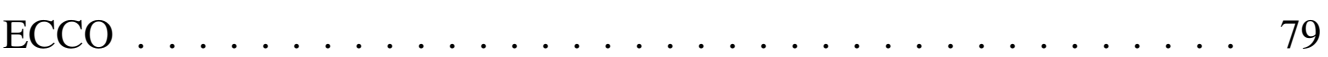

55 Similar a Figura 53 , porém com ao nitrato integrado . . . . . . . . . . 80

56 Similar a Figura 53 , porém com a MOC proveniente de saídas do modelo NEMO . . . . . . . . . . . . . . . . . . . . 80 


\section{Lista de Tabelas}

1 As cinco configurações ORCA inclusas no modelo oceânico NEMO. . . . . 12

2 Médias e os desvios padrões da clorofila, nitrato integrado, PAR em cada província biogeográfica para os anos de 1998 a 2016 (nitrato integrado) e 1998 a 2017 (clorofila e PAR). . . . . . . . . . . . . . . . . . 30

3 Tabela contendo os valores da MOC do Atlântico Sul próximo e na latitude de $34,5^{\circ}$ S. $T$ é o transporte de volume e $\sigma$ é o desvio padrão. . . . . . 41

$4 \quad$ Regiões escolhidas para análise da clorofila . . . . . . . . . . . . . 41

5 Variância relativa (em porcentagem) da componente da tendência decacal em relação à variância total do PAR e do Nitrato integrado, por região. . . 46

6 Tabela com as médias e desvios padrões da MOC do Atlântico Sul dos modelos ECCO e NEMO . . . . . . . . . . . . . . . . . . . . . . . 58

7 Tabela com os períodos de cada componente (IMF) dos índices climáticos e da MOC do Atlântico Sul por cada modelo. Os períodos estão em anos. 67

8 Resultado das correlações entre os índices climáticos e a MOC do Atlântico Sul em cada IMF. Os resultados em branco foram aqueles que não conseguiram um intervalo de confiança de $95 \%$. A defasagem é expressa em meses. . . . . . . . . . . . . . . . . . . . . . . . . 69 


\begin{abstract}
On interannual timescales the advection of heat, salt and nutrients can affect the primary production. The influence of the Meridional Overturning Circulation (MOC) over the chlorophyll concentration can be mentioned. In this study, decadal trends of PAR, integrated nitrate over the water column, chlorophyll and volume flux of the MOC were obtained using the Multidimensional Empirical Mode Decomposition method. On low frequency variations there is a relationship between the MOC volume transport with integrated nitrate over the water column in the South Atlantic, and therefore, on chlorophyll concentration. Two scenarios were identified as possible mechanisms of influence of the MOC over integrated nitrate and chlorophyll concentrations. Scenario 1 presents a direct relationship on the system MOC-integrated nitrate-chlorophyll concentration, while scenario 2 has an indirect effect, with the MOC affecting other variables that disturb the system. In this study the influence of atmospheric teleconnections on the South Atlantic MOC were also investigated. It was found evidence that the Antarctic Oscillation can affect the South Atlantic MOC on decadal timescales. It was concluded that low frequency variability on the volume flux of the MOC can alter the spatiotemporal pattern of the chlorophyll concentration on the South Atlantic.
\end{abstract}

Keywords: Meridional Overtrning Circulation, interannual variability, chlorophyll, nitrate, multidimensional empirical mode decomposition, atmospheric teleconnections, Antarctic Oscillation/El Niño-Southern Oscillation. 


\section{Resumo}

Em escalas interanuais a advecção de calor, sal e nutrientes pode afetar a produtividade primária. Pode-se citar a Circulação de Revolvimento Meridional (MOC) no impacto da concentração de clorofila. Neste estudo, a partir do método Multidimensional Empirical Mode Decomposition foram obtidos tendências decadais de PAR, nitrato integrado na coluna d'água, concentração de clorofila e fluxo de volume da MOC. Em variações de baixa frequência há uma relação entre o transporte de volume da MOC com o nitrato integrado na coluna d'água no Atlântico Sul, e consequentemente, na concentração de clorofila. Dois possíveis cenários foram identificados sobre o efeito da MOC no nitrato integrado e na concentração de clorofila. O cenário 1 apresenta uma relação direta no sistema MOC-nitrato integrado-concentração de clorofila, enquanto o efeito do cenário 2 é indireto, com a MOC afetando outras variáveis que perturbam o sistema. Neste estudo também foi analisado a influência de teleconexões atmosféricas na MOC do Atlântico Sul. Foi achado indícios da influência da Oscilação Antártica na MOC do Atlântico Sul em escalas decadais. Conclui-se que variações de baixa frequência no fluxo de volume da MOC alteram o padrão espaço-temporal da concentração de clorofila no Atlântico Sul.

Palavras-chaves: Circulação de Revolvimento Meridional, variação interanual, clorofila, nitrato, multidimensional empirical mode decomposition, teleconexões atmosféricas, Oscilação Antártica/El Niño-Oscilação Sul. 


\section{Introdução}

Fitoplâncton são organismos unicelulares que realizam fotossíntese no ambiente aquático. Estes organismos tem uma função ecossistêmica importante uma vez que são a base da cadeia alimentar no oceano, impactam a biosfera e afetam os estoques pesqueiros (Chassot et al. 2010). São responsáveis pela maior parte da produtividade primária nos oceanos, sendo assim, contemplam quase metade da produtividade primária global (Field et al. 1998). Estes organismos estão integrados na chamada "bomba biológica" na qual transporta carbono da atmosfera para o interior do oceano (Siegenthaler and Sarmiento 1993) estando envolvidos com o ciclo do carbono (Sabine et al. 2004). Desta maneira o fitoplâncton tem o potencial para contribuir com a mudança do clima sendo um modulador de quanto carbono pode ser sequestrado pela bomba biológica. O fitoplâncton também tem o potencial de afetar o balanço de radiação terrestre pela criação de núcleos de condensação de nuvens através da produção do aerossol dimetil-sulfeto (Charlson et al. 1987). O aumento na concentração de nuvens alteraria o albedo afetando a radiação de onda curta que efetivamente atinge a superfície da Terra.

Em escalas de tempo geológicas, o fitoplâncton foi importante para definir diversos balanços biogeoquímicos. Foi graças a esses organismos que o oxigênio começou a acumular na atmosfera durante o pré-Cambriano (Riding 1992). Pode-se citar que grande parte das reservas de petróleo são originárias de carbono orgânico dos blooms de fitoplâncton (Falkowski 1994). Desta maneira, entender melhor o fitoplâncton marinho significa melhorar a compreensão dos processos da biosfera, do clima e dos ciclos biogeoquímicos.

Sendo organismos fotossintetizantes, o fitoplâncton é dependente da luz para sua sobrevivência. Entretanto, a resposta fotossintética do fitoplâncton em relação à luz disponível não é constante, sendo dependente do tamanho das células, composição taxonômica e fatores abióticos tais como luz, nutrientes e temperatura (Platt et al. 2005). Dos fatores abióticos devemos considerar que as relações não são simples uma vez que forçantes físicas alteram o padrão de estratificação na coluna d'água. A estratificação limita o movimento vertical dos organismos fitoplanctônicos que, por sua vez, interfere na quantidade de radiação disponível para a fotossíntese (PAR) ou na concentração de nutrientes inorgânicos disponíveis (Prézelin et al. 1991). Sendo luz e nutrientes fatores abióticos que controlam a fotossíntese, e logo o desenvolvimento do fitoplâncton, pode-se dizer que forçantes físicas determinam a variabilidade espacial e temporal destes (Prézelin et al. 1991).

Em escalas de tempo sazonais temos uma relação direta entre estratificação da coluna d'água, profundidade da camada de mistura e clorofila-a (Lozier et al. 2011). Clorofilaa é o pigmento essencial e principal para se realizar a fotossíntese e também pode ser utilizado para se estimar a biomassa de fitoplâncton. O mecanismo de aquecimento ou 
resfriamento da coluna d'água pela superfície afeta a camada de mistura deixando-a mais ou menos estratificada. Em regiões polares, onde a coluna d'água tende a ser mais homogênea e rica em nutrientes, o aquecimento na primavera/verão faz com que a camada superior seja mais estratificada resultando em uma camada de mistura mais rasa. O fitoplâncton então consegue se manter dentro de um limite no qual consegue receber luz e realizar a fotossíntese. No outono/inverno devido ao resfriamento da superfície do oceano, as camadas superiores se tornam menos estratificadas, assim além de haver menor quantidade de luz nessa época do ano, existe o agravante das células do fitoplâncton serem transportadas para uma região mais profunda onde a há maior atenuação de luz (Longhurst 2007a).

Por outro lado, em uma região subtropical onde as águas são oligotróficas e não são limitadas pela luz, a chegada do outono/inverno faz com que a camada de mistura fique mais profunda. Isso proporciona que mais nutrientes consigam aflorar na zona eufótica e que o fitoplâncton consiga se desenvolver, tendo como consequência um aumento na concentração de clorofila-a. No verão, com o aquecimento da superfície, a água se estratifica e portanto, diminui a profundidade da camada de mistura. Isso limita a chegada de nutrientes e resulta na diminuição da concentração de clorofila-a. Portanto, em escalas sazonais vemos um mecanismo importante entre estratificação e movimentos verticais. Contudo, tal mecanismo não é observado em escalas interanuais e/ou decadais (Lozier et al. 2011). Em escalas de baixa frequência, a advecção de sal, volume, nutrientes e calor podem afetar a clorofila-a e a estratificação concomitantemente (Dave and Lozier 2015).

Estudos sobre a variabilidade dos transportes e fluxos horizontais em escalas interanuais e como afetam a clorofila são observados na literatura. Dave and Lozier (2013) mostraram que tanto a estratificação quanto a concentração da clorofila-a do Pacífico central equatorial, embora fortemente correlacionadas, tem suas respectivas variações associadas com a variabilidade da advecção em superfície. Raitsos et al. (2015) analisaram a influência do sistema de monções e suas oscilações em escalas interanuais com a circulação e como isto fertiliza o Mar Vermelho. Ayers and Lozier (2010) discorrem como mudanças na circulação afetam a concentração de nutrientes e biomassa na região de transição subtropical-subpolar do Pacífico norte, sendo que Polovina et al. (2017) levaram em conta a influência da Oscilação Decadal do Pacífico (PDO) na biota na mesma região. Polovina et al. (2008) concluiram que pelo forte gradiente de propriedades físicas, biológicas e químicas nos atóis do Havaí, a produtividade primária apresenta variação interanual e decadal. Tal variação é observada por deslocamentos meridionais nos gradientes em escalas sazonais e interanuais.

Ao se mencionar movimentos horizontais podemos citar a Circulação de Revolvimento Meridional (MOC) uma vez que esta afeta o transporte de calor e sal, altera a distribuição de massas d'água, tem controle na estratificação e está envolvida no transporte e regulagem de diversos traçadores químicos e nutrientes (Kuhlbrodt et al. 2007). 
O termo "MOC" geralmente é confundindo com o termo "circulação termohalina", embora representem fenômenos distintos. Circulação de Revolvimento Meridional implica uma circulação dentro do domínio meridional-vertical (Kuhlbrodt et al. 2007), sendo uma descrição geográfica deste movimento. Circulação termohalina, por sua vez, representa o movimento (Kuhlbrodt et al. 2007), governado por diferenças de densidade nas camadas do oceano promovidas pelas trocas de calor e sal tanto com a superfície quanto no seu interior (Rahmstorf 2002). A MOC não é forçada unicamente por variações estéricas (de densidade), uma vez que inclui a circulação governada pelos ventos. Pode-se dividir então duas grandes forçantes da MOC:

1. Uma forçante termohalina que afeta a densidade da água do mar. Esta forçante faz com que ocorra o afundamento de águas na parte boreal do Atlântico Norte e na região antártica por variações na densidade. Esta água que afunda contribui com grande parte da circulação profunda dos oceanos globais.

2. Uma forçante devido à ação dos ventos responsável pelo padrão de circulação na camada superficial do oceano.

Para fechar o ciclo é necessário ainda uma terceira forçante que implicaria na água ressurgir do fundo para a superfície. Não se tem certeza ao certo qual mecanismo responsável por isto, na literatura há duas grandes hipóteses: A primeira destas é que pela turbulência de pequena escala oriunda de ondas internas geradas por ventos e maré transportam calor da superfície para o fundo por superfícies de mesma densidade (mistura diapicnal) (Munk and Wunsch 1998). Isto faz com que massas d'águas mais profundas fiquem mais leves ressurgindo em baixas latitudes (Kuhlbrodt et al. 2007). O número calculado pela mistura diapicnal seria muito inferior ao necessário para manter o ciclo da MOC. Desta maneira a segunda hipótese afirma que a água retorna a superfície pela ressurgência antártica (Toggweiler and Samuels 1995). Tal mecanismo é explicado pela intensidade dos ventos de oeste, que por transporte de Ekman, causam uma divergência horizontal fazendo com que águas abissais cheguem à superfície. Não há um consenso em qual destes mecanismos de fato é o dominante, sendo ambos mecanismos considerados importantes. Um esquema da MOC pode ser achado na Figura 1 .

Neste estudo a área de interesse será o ramo superior da MOC na porção do Atlântico Sul. Esta bacia é de grande importância pois não só é a ligação entre dois oceanos adjacentes a leste e oeste recebendo tanto contribuição de águas frias com menor salinidade do Pacífico como águas quentes e salinas do Índico, como também seus fluxos de calor e sal afetam a formação de águas profundas no Atlântico Norte (Garzoli and Matano 2011). A circulação do Atlântico Sul é caracterizada por um giro subtropical anticiclônico, limitado ao norte pela Corrente Sul Equatorial (CSE), adjacente a um complexo sistema de correntes equatoriais, e ao sul pela Corrente do Atlântico Sul. No contorno leste próximo do continente africano as massas d'água são transportadas pela Corrente de Benguela para 

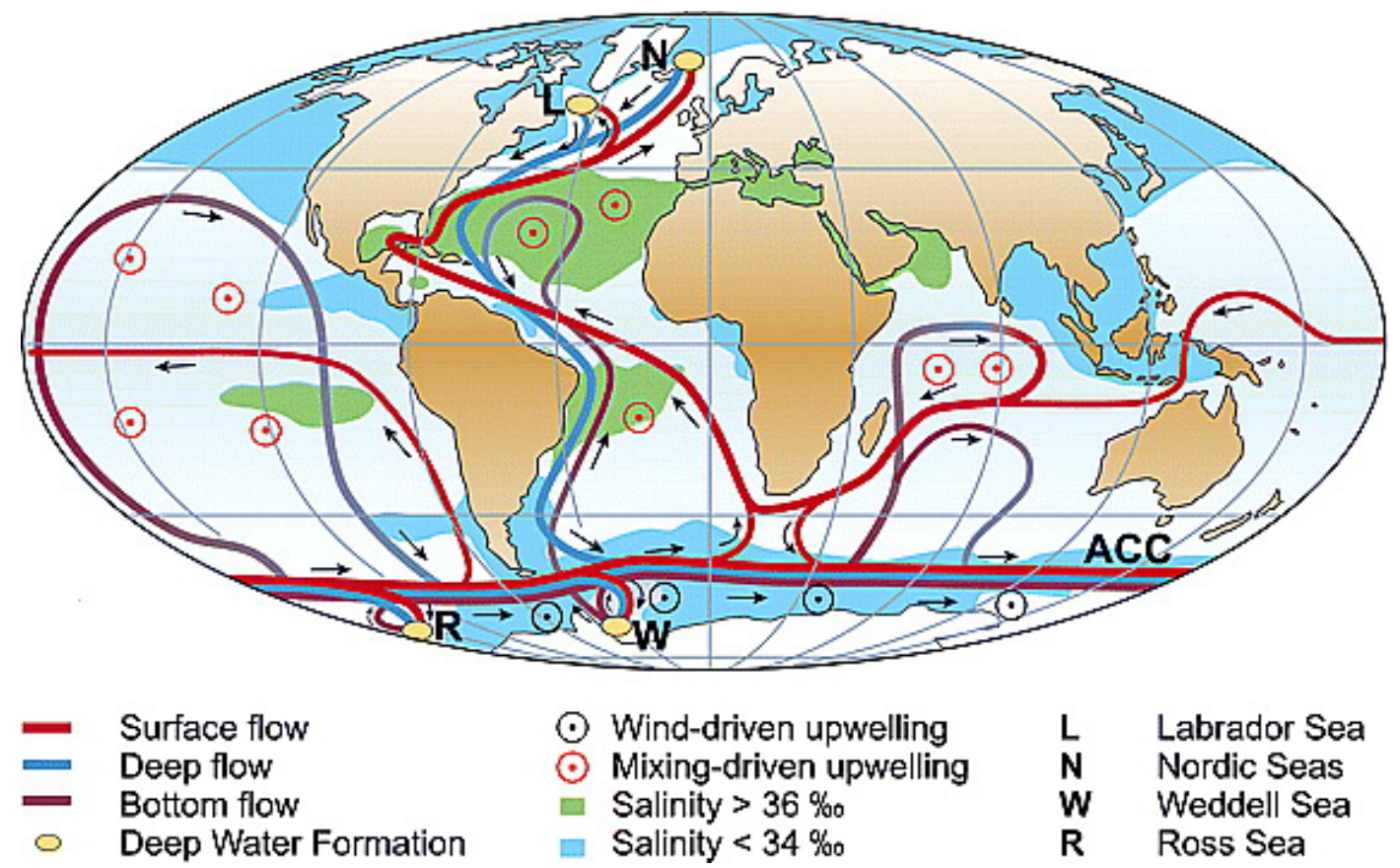

Figura 1: Esquema da MOC, as setas vermelhas representam a circulação mais superficial forçada pelo vento; as setas azuis representam a circulação profunda forçada pelas variações de sal e temperatura. Note que nesta imagem há a representação das duas hipóteses de retorno das águas fundas para as águas rasas. Imagem extraída de Rahmstorf (2002).

noroeste onde então acabam por adentrar na Corrente Sul Equatorial (CSE). Essa corrente chega até próximo a costa brasileira onde se bifurca formando para sul pela Corrente do Brasil (CB) e para norte a Corrente Norte do Brasil em superfície e a Subcorrente Norte do Brasil (SNB) (Stramma and England 1999). Esse modelo de circulação tem sido utilizado como referência para a circulação média da bacia, Figura 2,

O Atlântico Sul é marcado por temperatura e salinidade de superfície relativamente mais altas comparadas com outras bacias. Enquanto as altas na temperatura observadas nos trópicos ocorrem devido ao excesso de radiação solar nessas latitudes, a salinidade de superfície é função do balanço entre precipitação e evaporação. Este balanço é expresso pela diferença de evaporação (E) e precipitação (P): $E-P$. No Atlântico Sul tropical e subtropical ,em sua maioria, apresenta o balanço entre evaporação e precipitação positivo. Há maior evaporação sobre precipitação, favorecendo assim as altas salinidades.

Nas camadas superiores do oceano, que se estende até o começo da picnoclina, é encontrada a Água Tropical (AT). A característica desta massa d'água é apresentar temperatura e salinidade mais altas quando comparada com as demais massas d'água. A AT é definida por temperaturas maiores que $20^{\circ} \mathrm{C}$ e salinidades maiores que 36 (da Silveira et al. 2000). Sua formação se deve pela alta radiação solar e pelo balanço positivo entre evaporação e precipitação no Atlântico Sul. Abaixo da AT encontra-se a Água Central do Atlântico Sul (ACAS) contida na extensão da picnoclina. Apresenta campos de temperatura e salinidade bem definidos, variando entre $6^{\circ} \mathrm{C}$ e $20^{\circ} \mathrm{C}$ e de $34,6 \mathrm{~g} / \mathrm{kg}$ a $36 \mathrm{~g} / \mathrm{kg}$ 


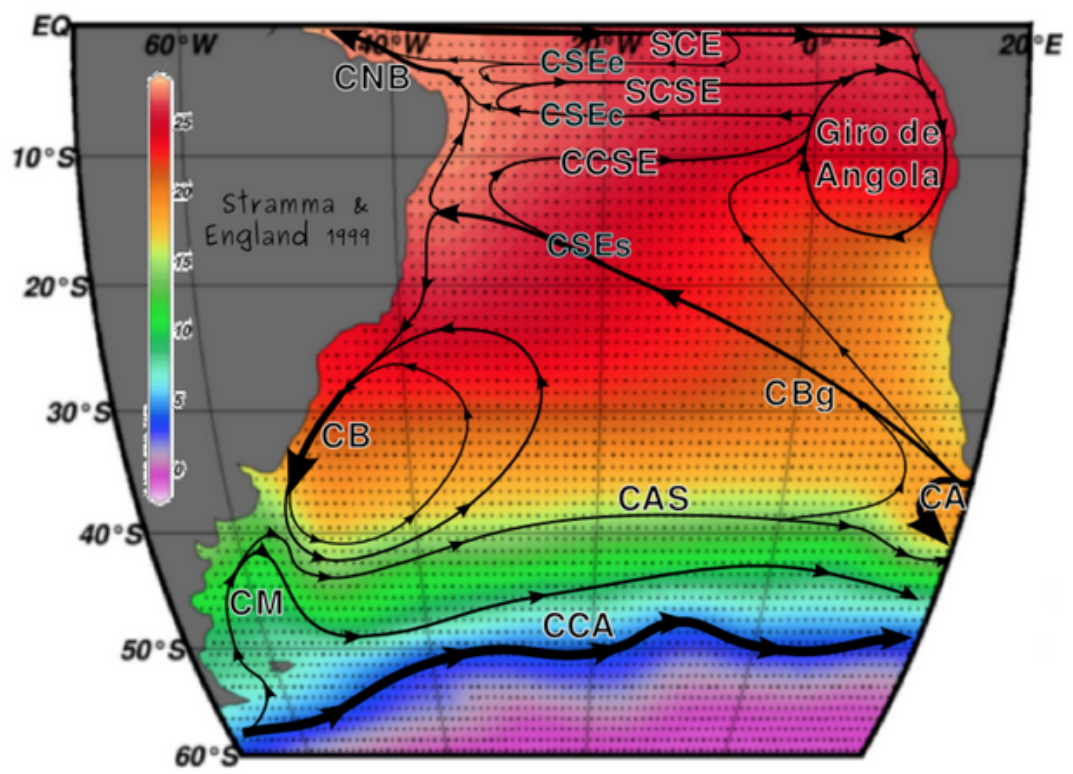

Figura 2: Representação esquemática da circulação do Atlântico Sul, adaptado de Stramma and England (1999). As principais correntes do Atlântico Sudoeste são: Corrente das Malvinas (CM), Corrente do Brasil (CB), Corrente do Atlântico Sul (CAS), Corrente Sul Equatorial (CSE), Corrente Norte do Brasil (CNB).

respectivamente (da Silveira et al. 2000). Sua formação ocorre na Convergência Subtropical recebendo águas oriundas do oceano Índico através da intrusão das Agulhas. A camada superficial contendo a ACAS e a AT é transportada pela Corrente do Atlântico Sul (CAS) onde flui para leste.

Em níveis intermediários (500-1200 m) encontra-se a Água Intermediária Antártica (AIA). Essa massa d'água tem sua transição definida nas isopicnais de $\sigma=27,1 \mathrm{~kg} \mathrm{~m}^{-3}$ nos trópicos e $\sigma=27,05 \mathrm{~kg} \mathrm{~m}^{-3}$ nos subtrópicos (Stramma and England 1999). Esse intervalo de densidades inclui temperaturas entre $3^{\circ} \mathrm{C}$ e $6^{\circ} \mathrm{C}$ e salinidades entre $34,2 \mathrm{~g} / \mathrm{kg}$ e 34,6 $\mathrm{g} / \mathrm{kg}$ (da Silveira et al. 2000), onde apresenta um mínimo de salinidade característico no diagrama TS. A região de baixa salinidade é observada a $900 \mathrm{~m}$ de profundidade próximo de $30^{\circ} \mathrm{S}$ e em $700 \mathrm{~m}$ na região equatorial (Stramma and England 1999). Sua formação ocorre próximo à Passagem de Drake no loop das Malvinas (Stramma and England 1999). Semelhantemente à ACAS, a AIA também recebe uma contribuição de águas do Índico através da Corrente das Agulhas. A trajetória da AIA também tem um trajeto análogo ao observado na Água Central do Atlântico Sul (Figura 3), porém o giro Subtropical se encontra deslocado para sul.

Em níveis profundos (1200 m a $4000 \mathrm{~m}$ ) podemos mencionar três principais massas d'águas no Atlântico Sul. A Água Profunda do Atlântico Norte (APAN) é definida entre as temperaturas de $3^{\circ} \mathrm{C}$ a $4^{\circ} \mathrm{C}$ e salinidades de $34,6 \mathrm{~g} / \mathrm{kg}$ a $35 \mathrm{~g} / \mathrm{kg}$ (da Silveira et al. 2000). Essa massa d'água tem sua origem pelo afundamento de diferentes parcelas de água no Hemisfério Norte. Porém, a medida que esses diferentes tipos d'água fluem para sul as 


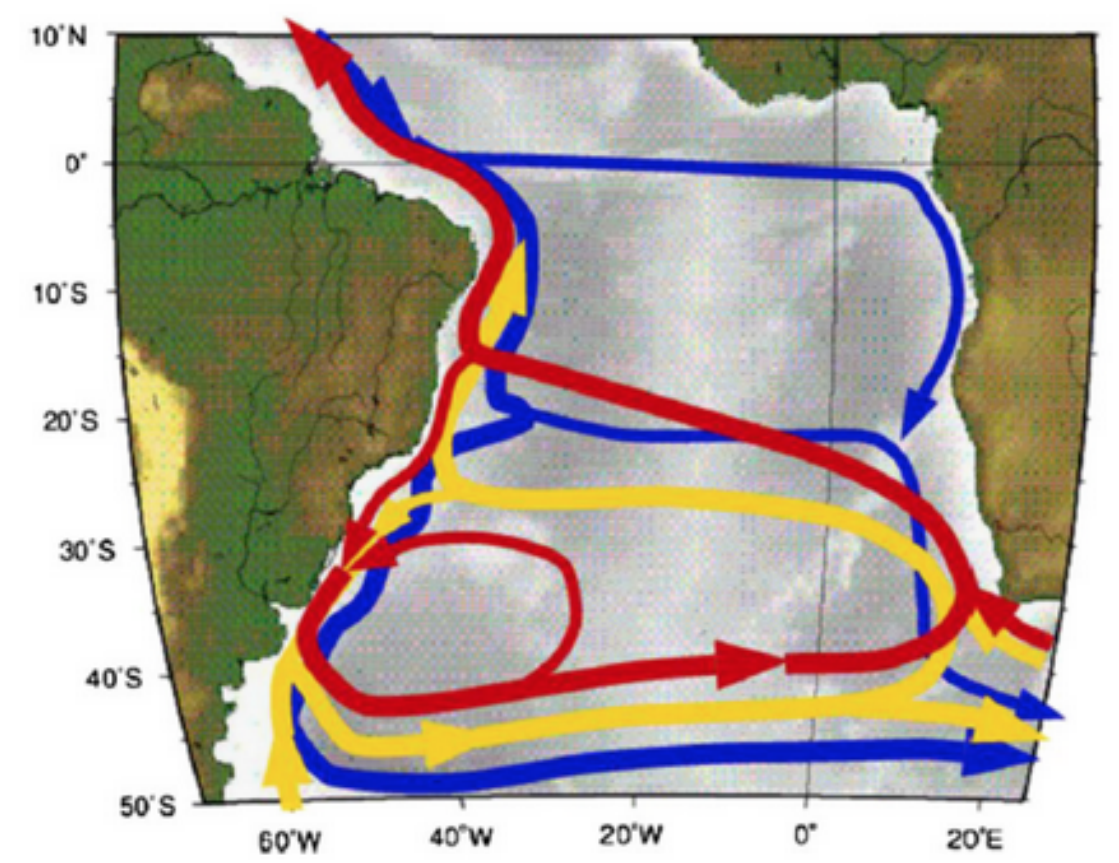

Figura 3: Representação esquemática da circulação das diferentes massas d'água no Atlântico Sul: APAN (azul), AIA (amarelo), ACAS (vermelho). Adaptado dos resultados de Stramma and England (1999), extraído de Garzoli and Baringer (2007).

suas diferenças proeminentes de sua gênese acabam por diminuir, de tal modo que no Atlântico Sul podem ser tratadas como uma única massa de água formalmente conhecida como Água Profunda do Atlântico Norte (Stramma and England 1999; Talley 2011). A profundidade da APAN é de $1200 \mathrm{~m}$ a $3900 \mathrm{~m}$ próximo ao equador e $1700 \mathrm{~m}$ a $3000 \mathrm{~m}$ na região da confluência Brasil-Malvinas (Stramma and England 1999) A APAN é transportada pela Corrente de Contorno Oeste Profunda (CCOP). A CCOP, como o nome sugere, flui próximo ao limite oeste da bacia oceânica; no Atlântico Sul essa corrente tem um fluxo resultante para sul. Próximo à costa do nordeste do Brasil, a CCOP encontra uma série de montes submarinos que afetam sua circulação fazendo que uma parte da corrente siga para leste enquanto que uma outra porção da CCOP segue para sul (Stramma and England 1999). A CCOP também tem um afastamento da borda em $20^{\circ} \mathrm{S}$ quando encontra a cadeia de montanhas Vitória-Trindade (Hogg and Owens 1999). Seu fluxo ao longo da borda segue para sul até próximo de $40^{\circ} \mathrm{S}$ na região da Convergência Subtropical onde se mistura com a densa Corrente das Malvinas e flui para leste. Nessa região, a APAN se mistura com a Água Circumpolar Profunda (ACP). Em níveis profundos, temos ainda a Água Circumpolar Profunda Superior (ACPS). Esta massa d'água tem sua origem na Água Profunda Circumpolar (APC) um corpo de água relativamente rico em nutrientes com baixa salinidade e baixa concentração de oxigênio, fluindo para leste na Corrente Circumpolar Antártica (CCA) (Stramma and England 1999). Quando a APAN se aproxima da região de confluência Brasil-Malvinas, esta penetra a APC a dividindo em dois 
ramos: Água Circumpolar Profunda Superior e Água Circumpolar Profunda Inferior.

A terceira massa d'água que se destaca em níveis profundos é a Água de Fundo Antártica (AFA). A AFA tem sua formação no Mar de Weddell e apresenta temperaturas menores que $2{ }^{\circ} \mathrm{C}$ e salinidades próximas de $34,8 \mathrm{~g} / \mathrm{kg}$. É a massa d'água com maior densidade no Atlântico Sul (Talley 2011). Seus limites de transição são $\sigma=45,9 \mathrm{~kg} \mathrm{~m}^{-3}$ no equador e $\sigma=45,87 \mathrm{~kg} \mathrm{~m}^{-3}$ próximo da Corrente do Atlântico Sul. Seu transporte é para o norte saindo da região antártica, afastando da borda em níveis mais profundos que a APAN. Próximo ao equador a AFA segue parte para leste seguindo uma porção da APAN e parte atravessa o equador indo para o Atlântico Norte (Stramma and England 1999).

\subsection{Relação da MOC na clorofila}

Estudos sobre a influência da MOC na distribuição da concentração de clorofila nos oceanos podem ser encontrados na literatura. Um dos primeiros estudos desta relação é o de Schmittner (2005) que através de modelos numéricos forçou uma interrupção na MOC através da adição de água doce no Atlântico norte. Essas simulações mostraram que se a MOC cessar, o oceano em sua maioria ficaria estratificado, limitando a concentração de nutrientes na camada fótica e levando a um colapso do fitoplâncton no oceano global. A partir desse estudo diversos outros apontaram a influência da MOC na clorofila. Hofmann et al. (2011) mostraram também por modelo que um cenário de aquecimento global levaria a um oceano mais estratificado dificultando o transporte de nutrientes em níveis intermediários para a superfície. Além disso, uma MOC do Atlântico mais fraca transportaria do Oceano Austral águas deficientes de nutriente para norte agravando ainda mais o sistema. De acordo com esse estudo, haveria uma redução de $50 \%$ da concentração da clorofila em uma projeção entre os anos 2000 a 2200.

A evolução na coleta de dados in situ e dados de satélite permitiu a combinação dos mesmos com saídas de modelos numéricos e mais estudos se desenvolveram. SanchezFranks and Zhang (2015) observaram a partir de séries temporais e saídas de modelos que a variabilidade em escalas decadais da MOC do Atlântico Norte está anticorrelacionada com deslocamentos no percurso da Corrente do Golfo mas correlacionada com a concentração de clorofila e nutriente. Os padrões de baixa frequência em larga escala apresentaram teleconexões na escala decadal com a física e biogeoquímica regional. Zhang et al. (2018) utilizando uma ferramenta matemática de decomposição de sinais conseguiram analisar a tendência espaço-temporal da clorofila no Atlântico Norte e concluíram que tal padrão na variação pode estar relacionado com a tendência da MOC do Atlântico Norte.

Sarmiento et al. (2004) e Palter et al. (2010) mostraram a dependência da clorofila nas regiões tropicais e baixas latitudes do oceano global com os nutrientes presentes na região do Oceano Austral. Este último trabalho descreveu esta associação levando em conta a variabilidade da MOC. O mecanismo por trás se dá pelo Oceano Austral ser uma região 
High Nutrient Low Chlorophyll (HNLC), isto é, é uma região que tem alta concentração de nutrientes, entretanto não tem a concentração de clorofila esperada. O motivo disto ainda é debatido dentro da comunidade científica, mas acredita-se que isto ocorra por limitação de ferro (Martin, Gordon, and Fitzwater 1990). Assim, a produção biológica não se utiliza de todos nutrientes que chegam na superfície pela ressurgência antártica, e isso faz com que estes se acumulem.

O transporte de volume das camadas superiores causado pela ação dos ventos (transporte de Ekman) de oeste na região antártica acarreta em um deslocamento dessa água rica em nutrientes para norte, até o ponto de formação da Água Intermediária Antártica (AIA) e Água Modal Subantártica (SAMW). Estas águas afundam e levam alta concentração de nutrientes em níveis intermediários, sendo a SAMW menos densa que a AIA. Essa água modal e a AIA fazem parte do ramo superior da MOC, e são transportadas próximo da região do Oceano Austral em direção ao equador. A SAMW, a medida que é transportada pela MOC sofre influência das grandes ressurgências na parte leste das bacias oceânicas e mistura diapicnal, até conseguir chegar em superfícies mais rasas na camada fótica. Esses nutrientes são utilizados pelo fitoplâncton formando matéria orgânica, que por sua vez é parcialmente remineralizada em profundidades menores do que a subducção da SAMW (Williams, Roussenov, and Follows 2006) permanecendo na camada fótica. Desta maneira, parte destes nutrientes transportados pela SAMW conseguem recircular em camadas mais rasas e permanecem alimentando os giros subtropicais. Esse mecanismo alimenta de $33 \%$ a $75 \%$ da produtividade primária tropical entre $30^{\circ} \mathrm{N}$ a $30^{\circ} \mathrm{S}$ (Palter et al. 2010) com uma escala espacial de menos de 40 anos para todo o nutriente ser utilizado neste espaço. Palter et al. (2010) ainda afirmam que os nutrientes da SAMW alimentam primeiro a produtividade primária ao sul de $20^{\circ} \mathrm{S}$. Este mecanismo conseguiu explicar o resultado em diversos estudos variando de tópicos desde a biogeoquímica do Atlântico norte a estudos paleoclimáticos (Marinov et al. 2006, Moore et al. 2009; Anderson et al. 2009) e levando a formulação de outros estudos pelo desdobramento desse mecanismo (Ayers and Strutton 2013; Panassa et al. 2018; Palter et al. 2011).

Dado este cenário, o presente estudo tem como hipótese as seguintes premissas:

1. A clorofila-a no Atlântico sul é influenciada em escalas interanuais pela MOC do Atlântico Sul, sendo que os padrões de distribuição espaço-temporal são reflexos da variabilidade de baixa frequência da MOC do Atlântico Sul.

2. A MOC sofre influência de fenômenos remotos através de teleconexão atmosférica, dentre eles vamos estudar o El Niño e a Oscilação Antártica (AAO).

Com estas duas hipóteses pretende responder as seguintes perguntas:

- A clorofila-a do Atlântico sul é influenciada pela MOC do Atlântico Sul?

- Se sim, há alguma forçante climática que afete a mesma? 
- Essa influência na clorofila ocorre pelo mesmo mecanismo descrito por Palter et al. $(2010)$ ?

- Qual a escala de tempo que isto ocorre? Quais os padrões espaciais?

Como objetivos específicos podemos citar:

- Obter séries temporais mensais de mapas da concentração de clorofila-a, nitrato integrado na coluna d'água e PAR para o Atlântico Sul. Quantificar a média e desvio padrão desses parâmetros na bacia, bem como a variabilidade temporal e espacial.

- Através da utilização de modelos numéricos, estimar o transporte de volume da MOC através de determinadas latitudes no Atlântico Sul.

- Aplicar a metodologia Multidimensional Ensemble Empirical Decomposition (MEEMD) para decompor as séries temporais em questão e extrair a componente que expressa as variações interanuais de cada parâmetro.

- Obter mapas da tendência interanual de concentração de clorofila, nitrato integrado na coluna d'água e PAR.

- Calcular as taxas das tendências interanuais da MOC do Atlântico Sul em $15^{\circ} \mathrm{S}$, $25^{\circ} \mathrm{S}$ e em $34,5^{\circ} \mathrm{S}$, concentração de clorofila e nitrato integrado.

- Correlacionar o transporte de volume da MOC com índices do El Niño e da Oscilação Antártica em diversas frequências intrínsecas ao fenômeno físico.

Este estudo está estruturado da seguinte forma, na seção 2 temos a descrição do Material e Métodos onde é descrito a origem dos dados deste estudo e os cálculos utilizados, além do método adaptativo de decomposição utilizado: o Multidimensional Ensemble Empirical Decomposition (MEEMD). Na seção 3 temos os Resultados e Discussão onde é descrito o que foi observado das análises e o porque de apresentar o padrão achado, sendo que em uma primeira parte se faz uma análise inicial dos dados, em seguida é aplicado o MEEMD na série temporal da clorofila-a onde seu padrão espaço-temporal é investigado, seguido de uma apresentação do resultado da tendência da MOC do Atlântico Sul com as tendências das variáveis biogeoquímicas e uma discussão no que estes implicam, e por fim, uma correlação é feita entre as diversas componentes interanuais da MOC do Atlântico Sul com as diferentes componentes interanuais de dois índices climáticos (El Niño e AAO). Na seção 4 temos a conclusão seguido do apêndice na seção 5 e das referências bibliográficas. 


\section{Materiais e Métodos}

\subsection{Clorofila-a}

Os dados de clorofila utilizados neste trabalho foram obtidos a partir do projeto Globcolour, vinculado a Agência Espacial Europeia (ESA). Os dados são produzidos a partir da combinação de diversas medidas de cor do oceano oriundos de diferentes satélites (merged product) com o intuito de fornecer uma série contínua de mapas globais de concentração de clorofila-a. A junção desses dados de diferentes sensores garante uma maior continuidade dos dados, melhora a cobertura espacial e temporal e garante uma redução em ruídos (Maritorena and Siegel 2005; Barrot, Mangin, and Pinnock 2010).

A clorofila-a utilizada neste estudo é de águas do caso-1, isto é, águas em que as propriedades óticas inerentes são dominadas majoritariamente pelo fitoplâncton (Matsushita et al. 2012), águas do caso-1 são associadas na maior parte do tempo a águas do oceano aberto, longe do continente. O produto de águas do caso-1 do projeto Globcolour foi calculado utilizando dados dos satélites MODIS-Aqua, SeaWifs, VIIRS e MERIS (Barrot, Mangin, and Pinnock 2010) e os dados de cada satélite foram combinados utilizando uma média ponderada dentre os sensores e o método GSM, que se utiliza das radiâncias normalizadas de cada sensor para estimar a concentração clorofila (Maritorena and Siegel 2005; Shi et al. 2015). Os dados utilizados neste estudo são mensais, com cobertura global e com resolução espacial de 1/4 , cobrindo o período de 1998 a 2017.

\subsection{PAR}

PAR é um acrônimo em inglês para radiação fotossinteticamente ativa. É uma medida que exprime o quanto de luz está disponível para o organismo realizar fotossíntese. É definido como as radiâncias observadas no topo da atmosfera dentro do intervalo de 400 $\mathrm{nm}$ a $700 \mathrm{~nm}$ (Frouin and Pinker 1995), contemplando assim a maior parte do espectro eletromagnético visível. As unidades do PAR são mol de fótons por metro quadrado por dia (mol de fótons $\cdot \mathrm{m}^{-2} \cdot \mathrm{dia}^{-1}$ ). Assim como a clorofila-a, o PAR é um dado de cor, e desta maneira, foi obtido também pelo projeto Globcolour. Os dados de PAR são oriundos dos satélites MODIS-Aqua, SeaWifs e VIIRS e são combinados através de uma média ponderada (Maritorena and Siegel 2005). O PAR utilizado neste estudo tem resolução temporal mensal, com uma distribuição global, resolução de 1/4 entre os anos de 1998 a 2017. 


\subsection{Dados de Velocidade}

\subsubsection{Modelo de Reanálise Oceânica MERCATOR}

Neste estudo foram utilizadas saídas do modelo de reanálise oceânica global MERCATOR GLORYS2V4. A reanálise é baseada no modelo oceânico Nucleus for European Models of the Oceans versão 3.1 (NEMOv3.1). O modelo oceânico NEMO se utiliza de um conjunto de configurações do oceano global para definir a resolução espacial do modelo. Esse conjunto de configurações tem o nome de ORCA. O usuário desse modelo pode alterá-las para conseguir a grade que lhe mais convém para as suas necessidades. $\mathrm{O}$ NEMO inclui 5 configurações ORCA pré-definidas no seu sistema (Tabela 11). Estas configurações são definidas pelo valor da resolução espacial em graus no Equador terrestre. O MERCATOR GLORYS2V4 (referido neste estudo como NEMO) apresenta uma grade ORCA com resolução espacial de $1 / 4^{\circ}$ com uma malha de 1442 pontos de longitude por 1021 de latitude. Essa resolução espacial é projetada para permitir a definição de perturbações de mesoescala. A resolução da grade (Figura 4) é de $27 \mathrm{~km}$ no Equador, $22 \mathrm{~km}$ próximo a região da Corrente do Golfo e $12 \mathrm{~km}$ na região Ártica e Antártica apresentando 75 níveis verticais, com resolução de $1 \mathrm{~m}$ próximo da superfície e $200 \mathrm{~m}$ em profundidades acima de 3000 m, sendo 24 níveis nos primeiros 100 m (Gilles Garric 2017; Garric and Parent 2013). A batimetria do modelo é baseada em um conjunto de dados que modelam a topografia terrestre e a batimetria, esse tipo de modelo se chama Global Relief Model. No MERCATOR GLORYS2V4 há o uso de dois Global Relief Models: o ETOPO1 e o GEBCO8. O ETOPO1 foi desenvolvido pela National Geophysical Data Center, sendo um melhoramento do ETOPO2v2 por sua menor resolução espacial de 1 minuto de arco (Amante and Eakins 2009). O ETOPO1 recebe dados de outros Global Relief Models como também de medidas de batimetria, conseguindo uma grade global. $\mathrm{O}$ General Bathymetric Chart of the Oceans (GEBCO) é um conjunto de dados batimétricos dos oceano. Está associado com a International Hydrographic Organization (IHO) e o Intergovernmental Oceanographic Commission (IOC) da UNESCO. O GEBCO8 apresenta uma resolução espacial de 30 segundos de arco, sendo que o conjunto de dados foi gerado a partir de dados de coleta de navios interpolados com dados de satélite (Becker et al. 2009). No modelo MERCATOR GLORYS2V4 o ETOPO1 foi utilizado para a batimetria de profundidades acima de $300 \mathrm{~m}$ e o GEBCO8 para profundidades menores que $200 \mathrm{~m}$, existindo uma interpolação entre 200 e $300 \mathrm{~m}$.

$\mathrm{O}$ modelo é forçado na atmosfera pelos produtos de reanálise do ERA-Interim do $\mathrm{Eu}$ ropean Centre for Medium-Range Weather Forecasts (ECMWF). Este produto assimila dados de diversas variáveis que podem afetar a atmosfera (temperatura, vento, umidade, ozônio, pressão na superfície, umidade e temperatura do solo, cobertura de neve, ondas de superfície no oceano, etc) e a partir dessas variáveis são utilizadas para inicializar um modelo de previsão de tempo (Dee et al. 2011). O modelo de previsão permite extrapolar in- 
Tabela 1: As cinco configurações ORCA inclusas no modelo oceânico NEMO.

\begin{tabular}{|c|c|c|}
\hline Resolução Horizontal & Número de pontos (longitude) & Número de pontos (latitude) \\
\hline 4 & 92 & 76 \\
2 & 182 & 149 \\
1 & 362 & 292 \\
0.5 & 722 & 511 \\
0.25 & 1442 & 1021 \\
\hline
\end{tabular}

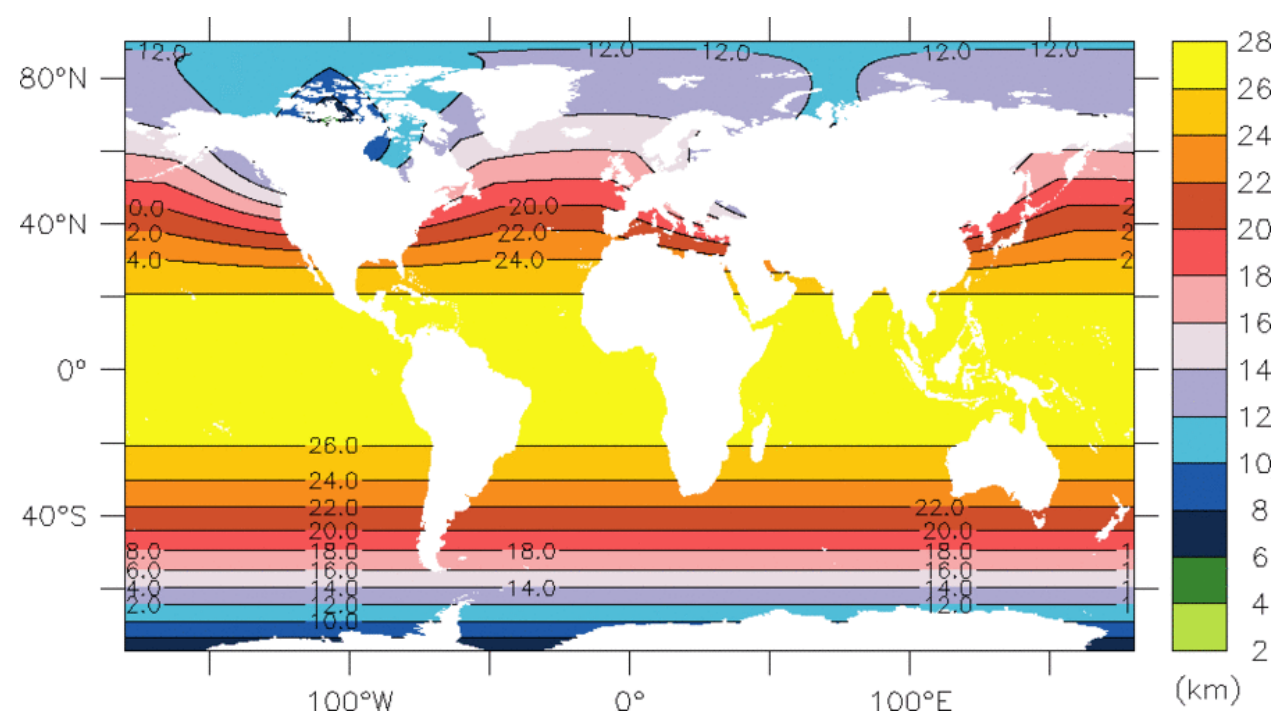

Figura 4: Resolução espacial horizontal do modelo de reanálise oceânica MERCATOR GLORYS2V4. Fonte: GEOMAR - Helmholtz Centre for Ocean Research Kiel.

formações de parâmetros observados localmente para parâmetros não-observados (como precipitação, fluxos turbulentos, campos de radiação, propriedades de nuvens, umidade do solo, entre outros) e observar a evolução destes no tempo (Dee et al. 2011). O modelo assimila dados de satélite de temperatura da superfície do mar e altimetria, perfis in situ de temperatura e salinidade e concentração de gelo marinho. A assimilação de dados se utiliza de uma técnica baseada em um filtro de Kalman de baixa ordem (Gilles Garric 2017; Garric and Parent 2013). As saídas são apresentadas na forma de médias mensais contemplando os anos de 1993 a 2015.

Como saída do GLORYS2V4 temos as seguintes variáveis:

- Temperatura potencial e salinidade da água do mar

- Velocidade zonal e meridional da água do mar.

Outras variáveis inclusas são altura da superfície do mar acima do geoide e relacionadas ao gelo marinho (porção da área, espessura, velocidade zonal e meridional). Para este estudo foram utilizadas as velocidades da reanálise, em especial, a velocidade meridional para o cálculo do transporte de volume em determinadas latitudes ao longo da bacia do Atlântico Sul. 

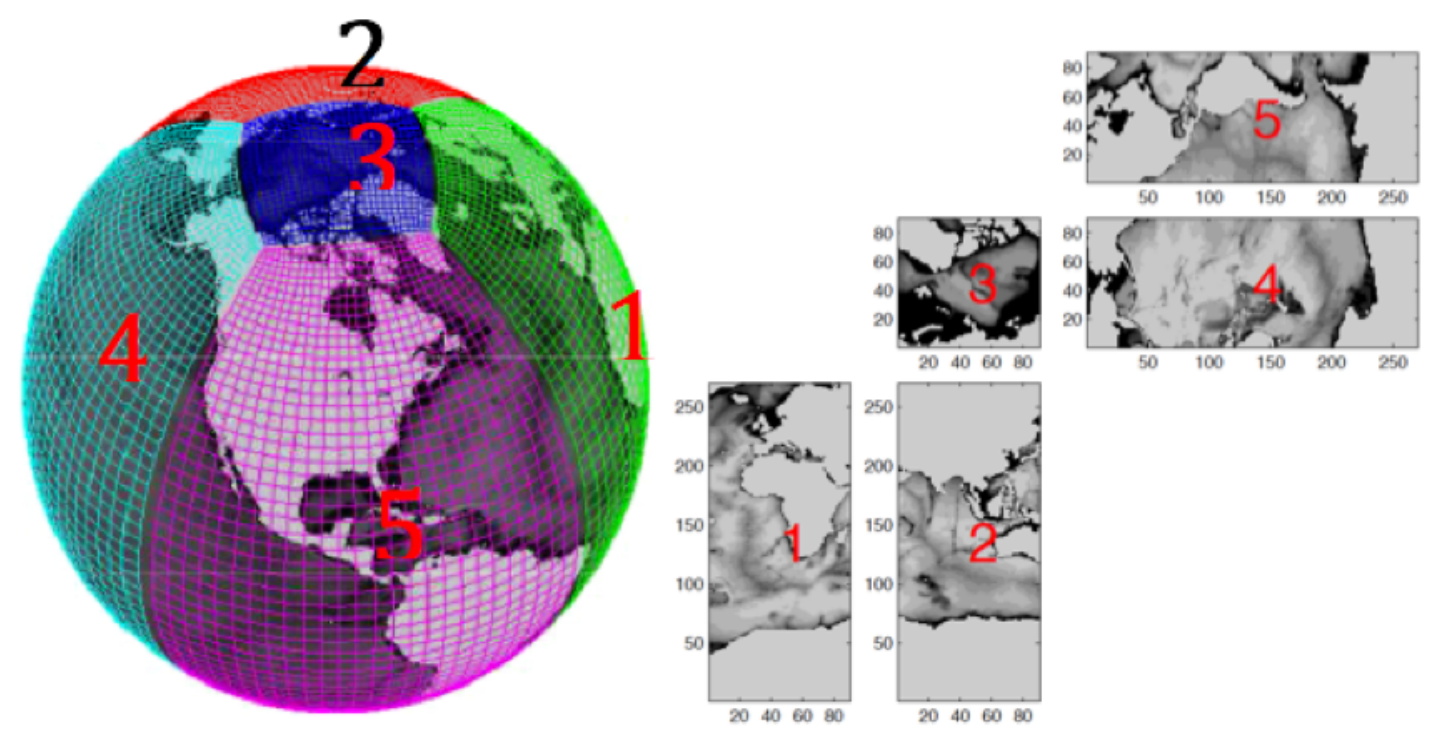

Figura 5: Exemplo da grade LLC90 contendo as cinco grande faces presente no modelo ECCO. Extraído de ECCOv4r3 User Guide adaptado de (Forget et al. 2015).

\subsubsection{Modelo ECCO}

Estimating the Circulation and Climate of the Ocean, ECCO, é um consórcio que surgiu inicialmente dentro do projeto World Ocean Circulation Experiment (WOCE) para integrar dados de modelos de circulação geral dos oceanos (GCM) com dados observacionais. Neste estudo foi utilizado saídas do modelo ECCO version 4 release 3 (ECCOv4r3) que assimila dados do modelo oceânico do Massachusets Institute of Technology (MITgcm) com dados observacionais de diferentes plataformas: nível do mar (TOPEX-Poseidon, Jason-1, Jason-2, Geosat-Follow-On, CryoSat-2, ERS-1/2, ENVISAT, SARAL/AltiKa), perfis de temperatura e salinidade (flutuadores Argo, XBT, CTD, Elefantes-marinhos com perfiladores oceanográficos, Ice-Tethered Profilers), temperatura da superfície do mar (AVHRR, AMSR-E), salinidade da superfície do mar (Aquarius), concentração de gelo marinho (SSM/I DMSP-F11,-F13 e SSMIS DMSP-F17), pressão no fundo do oceano (GRACE), climatologia de TS (World Ocean Atlas 09) e topografia dinâmica média (DTU-13) (Fukumori et al. 2017). Semelhante ao GLORYS2V4, o ECCO é forçado na atmosfera pelo ERA-Interim do ECMWF, apresenta uma resolução horizontal com máxima de $22 \mathrm{~km}$ e mínima de $110 \mathrm{~m}$ e possui uma profundidade máxima de $6145 \mathrm{~m}$. Conta com uma grade do tipo LLC90 (Lat-Lon-Cap 90), isto é, contém uma grade simples de latitude e longitude entre $70^{\circ} \mathrm{S}$ e $57^{\circ} \mathrm{N}$ e uma "tampa" no Ártico, sendo que a grade é dividida em cinco grandes faces ao longo do globo (Figura 5) (Forget et al. 2015).

O período coberto pelo modelo inclui a "era de altimetria de satélite", de 1992 a 2015. Foram utilizados dados mensais de velocidades meridionais para o cálculo de transporte da MOC em determinadas latitudes do Atlântico Sul. 


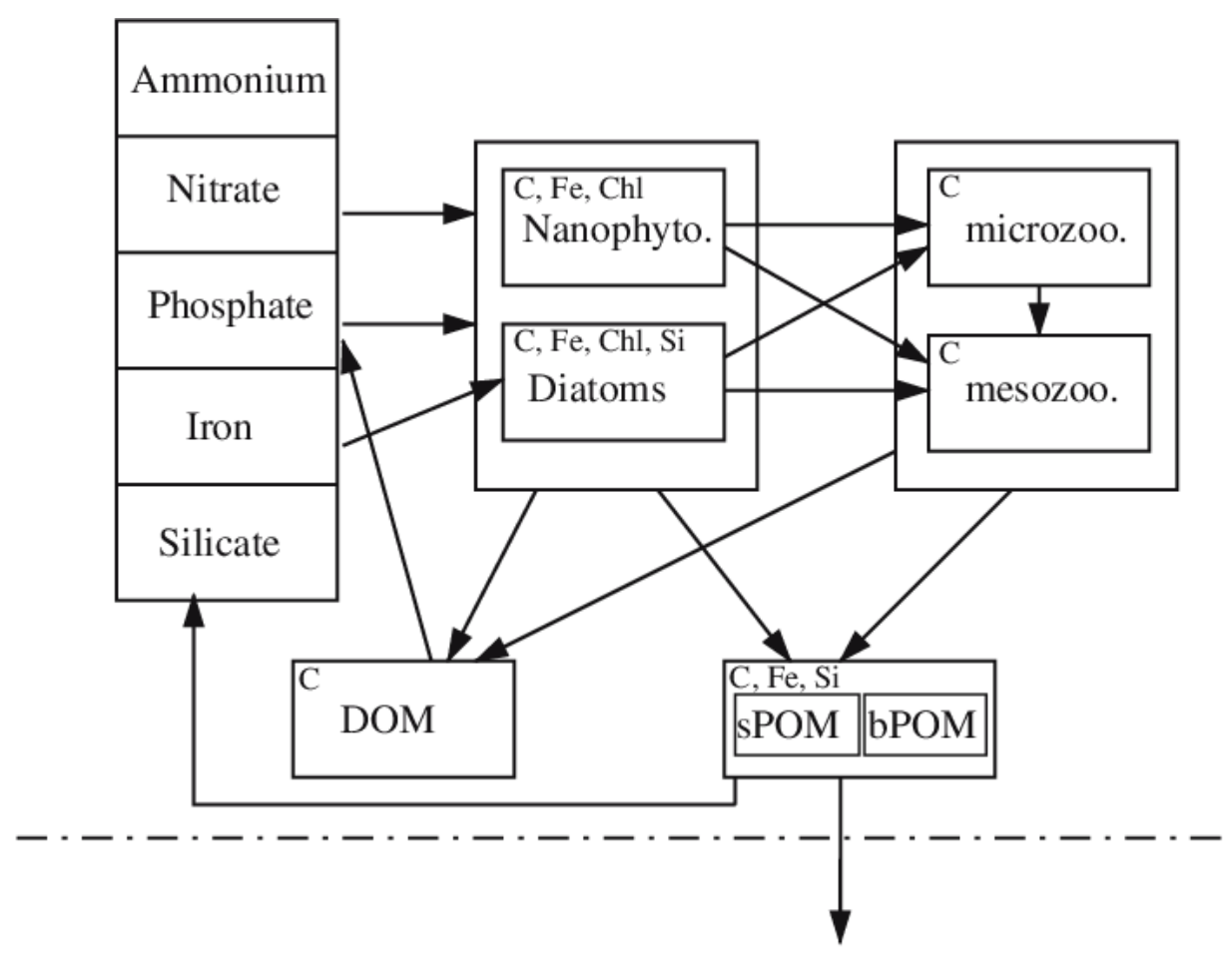

Figura 6: Esquema do modelo PISCES. As variáveis modeladas se encontram na esquerda, enquanto os demais são compartimentos. Nesta imagem só está contemplada a modelagem biológica não contendo o oxigênio nem o sistema carbonato.

\subsection{Dados de Nitrato}

\subsubsection{Dados do Modelo PISCES}

Dados de nitrato provenientes do produto global biogeoquímico do tipo hindcast (sem assimilação de data) conhecido como GLOBAL REANALYSIS BIO 001029 (GRB) foram utilizados neste estudo (Aumont 2005). O GRB é uma simulação biogeoquímica que se utiliza do modelo PISCES (NEMO 3.6 - PISCESv2). Esse modelo segue a linha de modelos biogeoquímicos denominados Monod models (Aumont 2005), em referência a equação matemática que leva o nome do cientista Jacques Monod. Esse modelo assume que a razão de Redfield, isto é a razão estequiométrica entre carbono, nitrogênio e fósforo na biomassa do fitoplâncton e nos pools de nutriente no oceano, é constante e que o crescimento do fitoplâncton depende da concentração externa de nutrientes (Aumont 2005). PISCES é um modelo de complexidade intermediária contendo 24 compartimentos (onde se encontram as variáveis químicas modeladas: sedimento, matéria orgânica dissolvida, matéria orgânica particulada, zooplâncon, fitoplâncton, entre outros (Figura 6). O modelo contém variáveis prognósticas e leva em conta ciclos biogeoquímicos do oxigênio e carbono e os principais nutrientes que limitam o crescimento do fitoplâncton: nitrato, amônia, fosfato, ácido silícico e ferro (Aumont and Bopp 2006; Perruche et al. 2013; Perruche, Paul, and Drévillon 2018). O modelo também contempla 4 tipos funcionais de 
plâncton baseado no tamanho (Aumont 2005):

- Para o fitoplâncton,

- o grupo pequeno, representando o nanofitoplâncton;

- o grupo grande, representando as diatomáceas.

- Para o zooplâncton,

- o grupo pequeno, representando o microzooplâncton;

- o grupo grande, representando o mesozooplâncton.

O modelo biogeoquímico PISCES é acoplado com um modelo físico de circulação, Mercator FREEGLORYS2V4, assim as variáveis biogeoquímicas são governadas pela velocidade das correntes e por campos de difusividade simulados pelo modelo oceânico físico. O Mercator FREEGLORYS2V4 é semelhante ao modelo de reanálise GLORYS2V4 (que foi utilizado neste estudo), sua diferença se dá por também ser como o GRB um modelo do tipo hindcast (Perruche, Paul, and Drévillon 2018; Perruche et al. 2013). Este modelo oceânico físico é forçado na atmosfera pelo ERA-Interim do ECMWF. A batimetria se utiliza do ETOPO1 para regiões profundas (planície abissal) e GEBCO1 para regiões rasas (plataforma continental e talude). A grade é regular e global $\left(180^{\circ} \mathrm{W}-180^{\circ} \mathrm{E}\right.$, $90^{\circ} \mathrm{N}-89^{\circ} \mathrm{S}$ ) com resolução de $1 / 4^{\circ}$ (Perruche et al. 2013; Perruche, Paul, and Drévillon 2018).

O PISCES se utiliza para as condições iniciais o World Ocean Atlas 2013 (WOA13) (Garcia et al. 2013a; Garcia et al. 2013b) para nitrato, fosfato, silício e oxigênio, o GLODAPv2 para carbono inorgânico dissolvido e alcalinidade, e saída de modelos de rodadas climatológicas para ferro e carbono orgânico dissolvido (Perruche et al. 2013; ; Perruche, Paul, and Drévillon 2018). Leva em conta fontes externas de nutrientes como poeira atmosférica, rios, descarga de sedimentos e $\mathrm{CO}_{2}$ atmosférico (Perruche et al. 2013; ; Perruche, Paul, and Drévillon 2018). Antes de ser publicamente distribuído, o modelo passa por um processo de avaliação de qualidade em que se compara sistematicamente a saída do modelo por todo o período que abrange com dados de climatologia do WOA13 e de clorofila de satélites em escalas mensais e anuais (Perruche, Paul, and Drévillon 2018). Neste estudo foram utilizados os produtos mensais de nitrato do modelo PISCES. A escolha se deve ao fato do nitrato ser limitante para o crescimento do fitoplâncton no oceano subtropical/tropical (Bristow et al. 2017).

\subsubsection{Nitrato Integrado}

Para podermos analisar o nitrato em mapas bidimensionais semelhantemente ao que foi feito para a análise da clorofila, o nitrato foi integrado verticalmente. O limite de integração escolhido foi baseado na densidade da Água Modal Subantártica (SAMW), uma 
vez que é essa água modal que contém os nutrientes que irão fertilizar o oceano tropical/subtropical e é transportada pela MOC do Atlântico Sul (Palter et al. 2010; Sarmiento et al. 2004). A SAMW apresenta uma faixa de densidade dependendo de sua localização

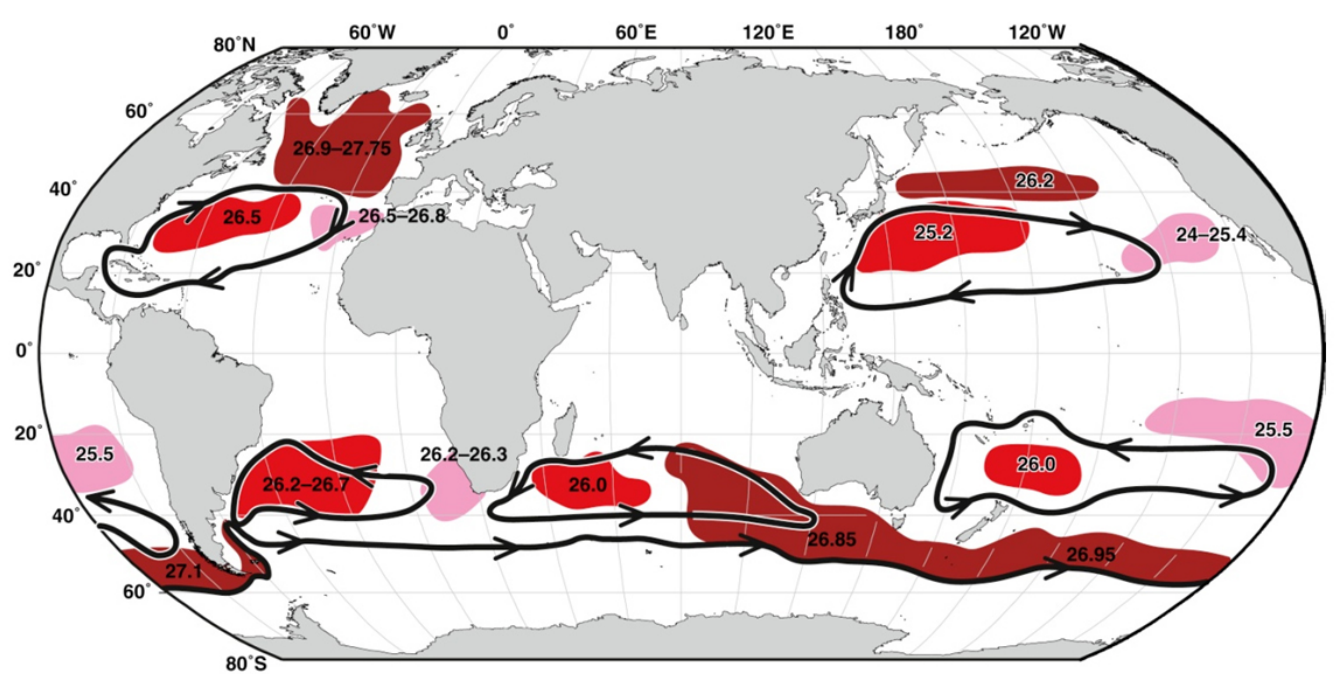

Figura 7: Mapa esquemático da localização das águas modais com suas densidades potenciais típicas e padrão de circulação do giro subtropical e da Corrente Circumpolar Antártica. As cores rosas são águas modais subtropicais na porção leste das bacias oceânicas, as cores vermelhas são águas modais subtropicais presentes nos giros e as cores em vermelho escuro são água modal subpolar no Atlântico Norte, água modal central no Pacífico Norte e a água modal subantártica no Oceano Austral. Extraído de Hanawa and Talley (2001)

geográfica, variando de $\sigma=26.5 \mathrm{~kg} \cdot \mathrm{m}^{-3}$ na porção sudoeste do Atlântico Sul e ficando mais densa a medida que se afasta para oeste chegando a $\sigma=27.1 \mathrm{~kg} \cdot \mathrm{m}^{-3}$ a oeste da Passagem de Drake, sendo nesta região precursora da AIA (Figura 7) (McCartney 1977; Hanawa and Talley 2001; Cerovečki et al. 2013). Desta maneira, foi selecionada a profundidade da densidade no núcleo da SAMW $\left(\sigma=26.8 \mathrm{~kg} \cdot \mathrm{m}^{-3}\right)$ como limite de integração vertical. Com a densidade escolhida, foi feita uma grade contendo as diversas profundidades na isopicnal de $26.8 \mathrm{~kg} \cdot \mathrm{m}^{-3}$ utilizando a climatologia de densidade do WOA13 (Figura 8).

\subsection{Multi-dimensional Ensemble Empirical Mode Decomposition}

Multi-dimensional Ensemble Empirical Mode Decomposition (MEEMD) é uma ferramenta matemática voltada para o processamento de sinais utilizada para determinar as frequências instrínsecas a séries temporais. O MEEMD é baseado no Empirical Mode Decomposition (EMD) e no Ensemble Empirical Mode Decomposition (EEMD), ambos descritos a seguir. 


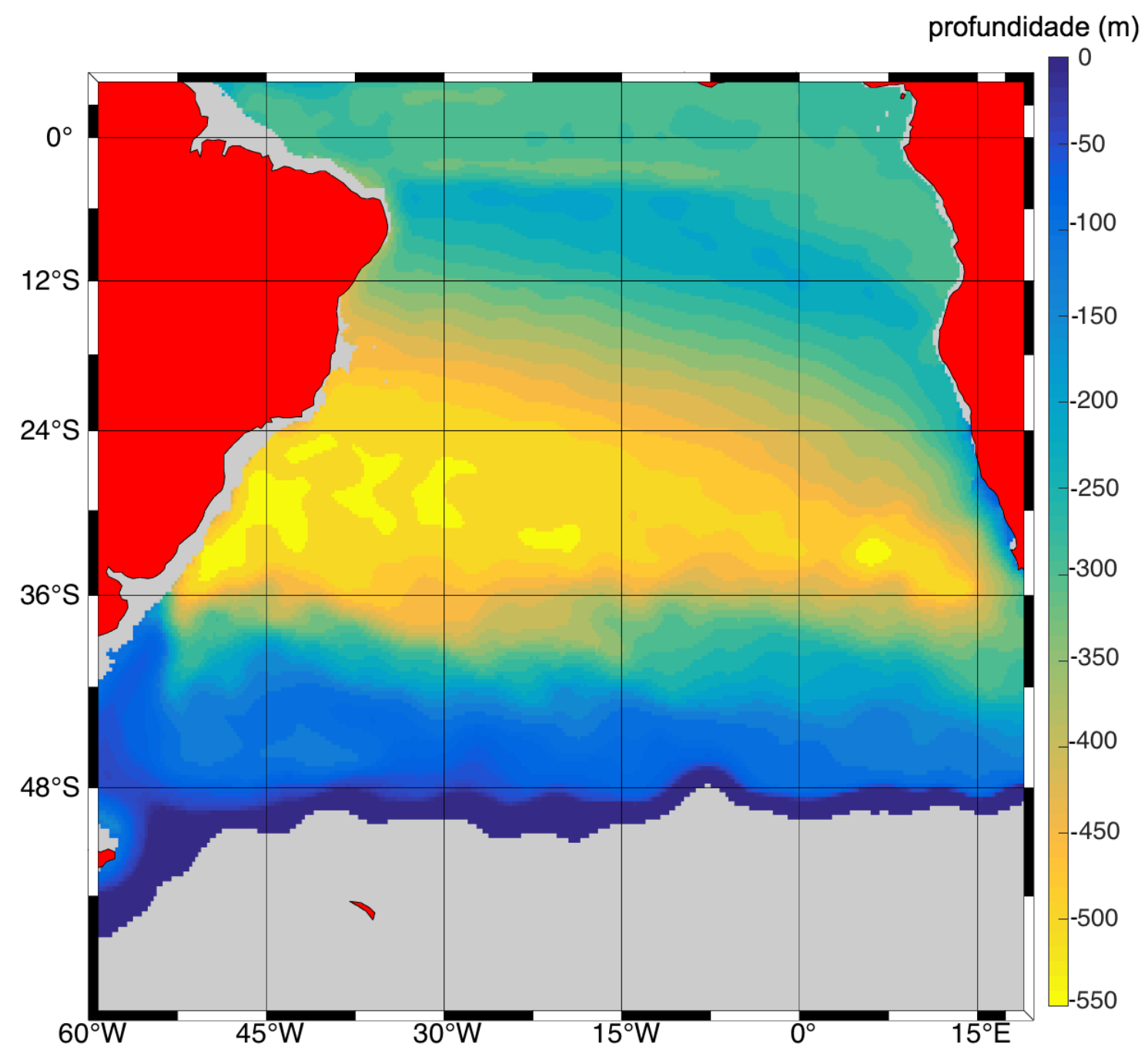

Figura 8: Mapa das profundidades da isopicnal de $\sigma=26.8 \mathrm{~kg} \cdot \mathrm{m}^{-3}$. As profundidades determinadas a partir da climatologia do WOA13. As áreas cinzas são regiões onde a densidade da água de superfície é maior que a densidade de referência (próximo a região antártica) ou que não é profunda o suficiente para alcançar tal densidade. 


\subsubsection{Empirical Mode Decomposition}

A análise espectral de Hilbert é uma análise de processamento de sinais que consegue analisar o sinal em função da amplitude e frequência pelo tempo (Time-Frequency Domain analysis) (Huang et al. 1998). Para isso é necessário a frequência instântanea do sinal (equação (1)), como consequência um método foi desenvolvido para calculá-las: o Empirical Mode Decomposition (EMD) (Huang et al. 1998). O EMD decompõe uma série temporal em diferentes componentes intrínsicas ao sinal, chamados Intrinsic Mode Functions (IMF).

Podemos definir a frequência instantânea como:

$$
\omega=\frac{d \theta(t)}{d t}
$$

sendo $\omega$ a frequência instantânea e $\theta$ a fase oscilatória. $O$ conceito de frequência instantânea implica que em um dado instante de tempo $t$, pode-se definir uma frequência $\omega$. Isto fez criar então o conceito de "mono-componente", que em qualquer instante de tempo existe uma frequência instantânea única, definida e positiva (Huang 2014). Um sinal mono-componente pode ser expresso como um produto entre uma amplitude dependente do tempo e um sinal portador (carrier) oscilatório variando sua frequência instantânea.

Desta maneira temos uma função mono-componente (MC) descrita por (Huang et al. 1998):

$$
M C=A(t) * \omega(t),
$$

onde $A(t)$ é a amplitude em função do tempo $t$ e $\omega$ é a frequência instantânea. Dentro da mono-componente podemos selecionar os envelopes de amplitude $A(t)$ e $-A(t)$, criando assim uma curva unindo os máximos e mínimos locais (Figura 9). Supondo que temos uma componente $K(t)$ que apresenta uma pequena variação ao longo do tempo, se somarmos $M C+K$ teremos assim uma série temporal delimitada pelos envelopes $K(t)+A(t) \cdot \omega(t)$ e $K(t)-A(t) \cdot \omega(t)$ que acompanham a nova curva suavizada dos máximos e mínimos desta função (Figura 9). Indo pelo caminho contrário dada uma série da forma $M C(t)+K(t)$, se selecionarmos as curvas que unem os máximos e mínimos da função, conseguimos achar $K(t)$ e separar a série temporal $M C(t)$ da componente de pequena variação $K(t)$; este é o princípio do EMD.

$\mathrm{O}$ algoritmo utilizado para aplicação do EMD para uma série temporal $Y(t)$ segue os seguintes passos sendo chamado de sifting (Wu and Huang 2009):

1. Assumir que $Y_{1}(t)=Y(t)$;

2. Determinar os máximos e o mínimos de $Y_{1}(t)$;

3. Obter uma curva contendo os máximos (envelope superior $e_{\max }$ ) e com os mínimos (envelope inferior $e_{\min }$ ) através de um spline cúbico; 


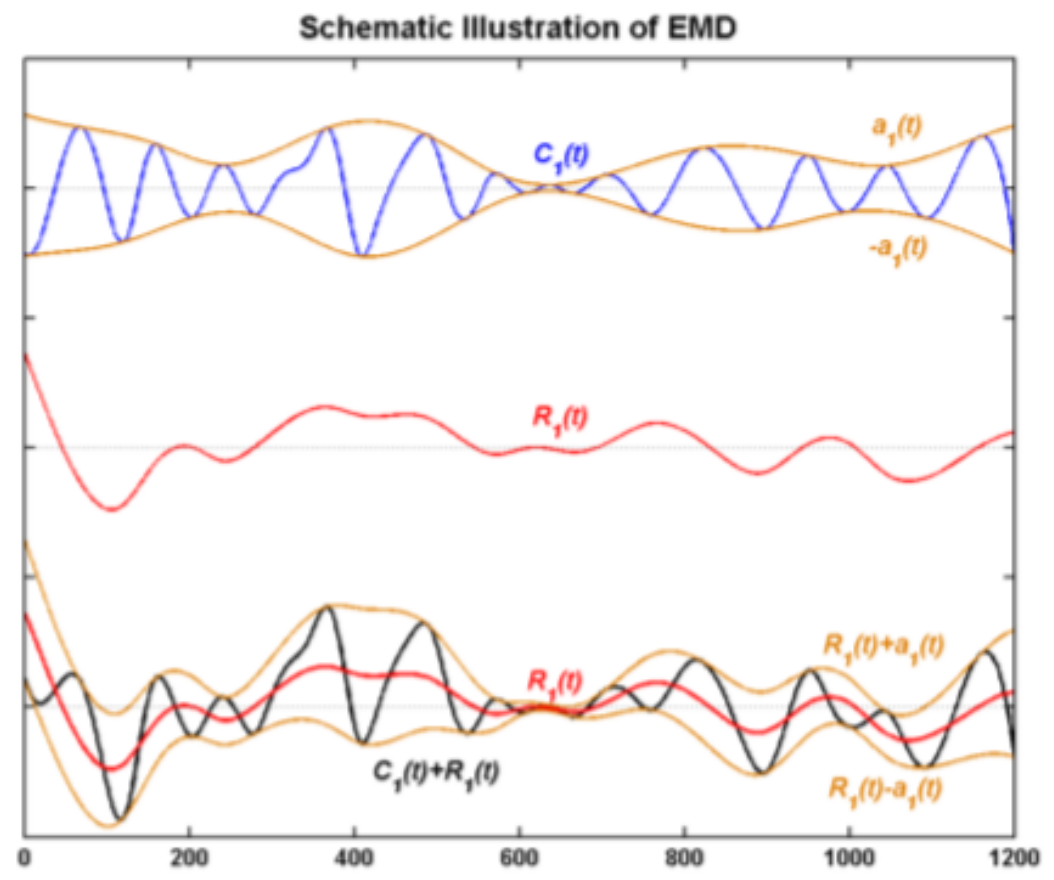

Figura 9: Ilustração esquemática do EMD. A curva $C_{1}$ é uma mono-componente, as curvas amarelas $\mathrm{a}_{1} \mathrm{e}-\mathrm{a}_{1}$ são os envelopes com os máximos e mínimos e a curva vermelha $\mathrm{R}_{1}$ seria análogo a $K(t)$, uma componente com pequena variação ao longo do tempo. Fonte: Ji et al. (2014)

4. Determinar a média local, ou seja:

$$
m(t)=\frac{\left[e_{\max }(t)+e_{\min }(t)\right]}{2}
$$

onde $m(t)$ é a curva simétrica entre os envelopes de máximo $\left(e_{\max }\right)$ e mínimo $\left(e_{\min }\right)$.

5. Analisar o quanto $m(t)$ é simétrico com relação a $e_{\max }$ e $e_{\min }$ examinando sua proximidade de zero através de um critério.

Dois critérios são utilizados para parar o processo de sifting. O primeiro é através de um teste de convergência de Cauchy, em que se analisa a diferença entre dois sifting sucessivos, se for menor que um limite estabelecido pelo usuário, o processo de sifting finaliza (Huang et al. 2003). O outro é o $S$ stoppage criteria (critério S),o sifting finaliza quando o mesmo número de passagens por zero ou pontos extremos são o mesmo número de $S$ sifting sucessivos (Huang et al. 2003). A escolha de $S$ também é feita pelo usuário.

Se o valor apresenta tal simetria o processo finaliza, caso contrário, temos $Y_{1}(t)=Y(t)-$ $m(t)$ e $Y_{1}(t)$ passa entre os processos (2) a (5). Através do sifting conseguimos os IMF's, estes satisfazem duas propriedades (Huang et al. 1998): 
1. O número de extremos tem que ser igual ao número de vezes em que a função cruza o zero, diferindo apenas por um.

2. O valor médio definido pelo envelope de máximos e envelope de mínimos deve ser zero em qualquer ponto da função.

O IMF é subtraído da função $Y(t)$, a série temporal restante é definida como resíduo. O EMD termina se não houver mais nenhuma componente oscilatória (IMF's) neste resíduo, caso se fizer presente o resíduo passa pelos processos (2) a (5) do sifting. O número de IMF's geralmente segue $\log _{2} N$, sendo $N$ o número de dados na série. Desta maneira, o EMD decompõe a série em vários IMF's e uma componente residual monotônica ou com apenas um extremo. Assim uma série temporal $Y(t)$ é dada por (Wu et al. 2007):

$$
Y(t)=\sum_{i=1}^{n} C_{j}+K_{n}
$$

sendo $Y(t)$ a série temporal, $C_{j}$ as componentes oscilatórias (IMF's) e $K_{n}$ uma curva residual sem componentes oscilatórias (tendência). O Empirical Mode Decomposition é uma função adaptativa levando em conta extremos locais da função e não se utilizando de nenhuma base definida à priori, e, portanto podendo ser utilizada em séries temporais cuja variabilidade é não-linear e não-estacionária.

\subsubsection{Ensemble Empirical Mode Decomposition}

É comum encontrar em registros de dados coletados a presença de ruídos, seja por valores anômalos relacionados a grandeza medida devido à superposição de perturbações introduzidas por outros processos que ocorrem simultaneamente ou por erros sistemáticos. O EMD está sujeito à incertezas quando aplicada em séries temporais ruidosas. Dada sua característica de ser um método que leva em conta pontos extremos locais da função, um ruído pode afetar a decomposição dos IMF's, principalmente no que diz respeito as suas frequências, colocando escalas demasiadamente diferentes em uma mesma componente ou ainda a mesma escala em diferentes IMF's. Esse problema recebe o nome de scale/mode mixing.

Este problema foi contornado pela utilização de um método conhecido como Noise Assisted Data Analysis (NADA) (Wu and Huang 2009). Adiciona-se um ruído branco em toda a série temporal uniformemente. Consegue-se então separar em diferentes IMF's o ruído branco mais o sinal; isto é feito em várias iterações, em cada iteração se adiciona um ruído branco diferente (Equação 5 ).

$$
Y_{i}(t)=Y(t)+W_{i}(t)
$$

onde $Y$ é a série temporal e $Y_{i}$ é a série temporal mais um ruído branco $W_{i}$ (Wu and Huang 


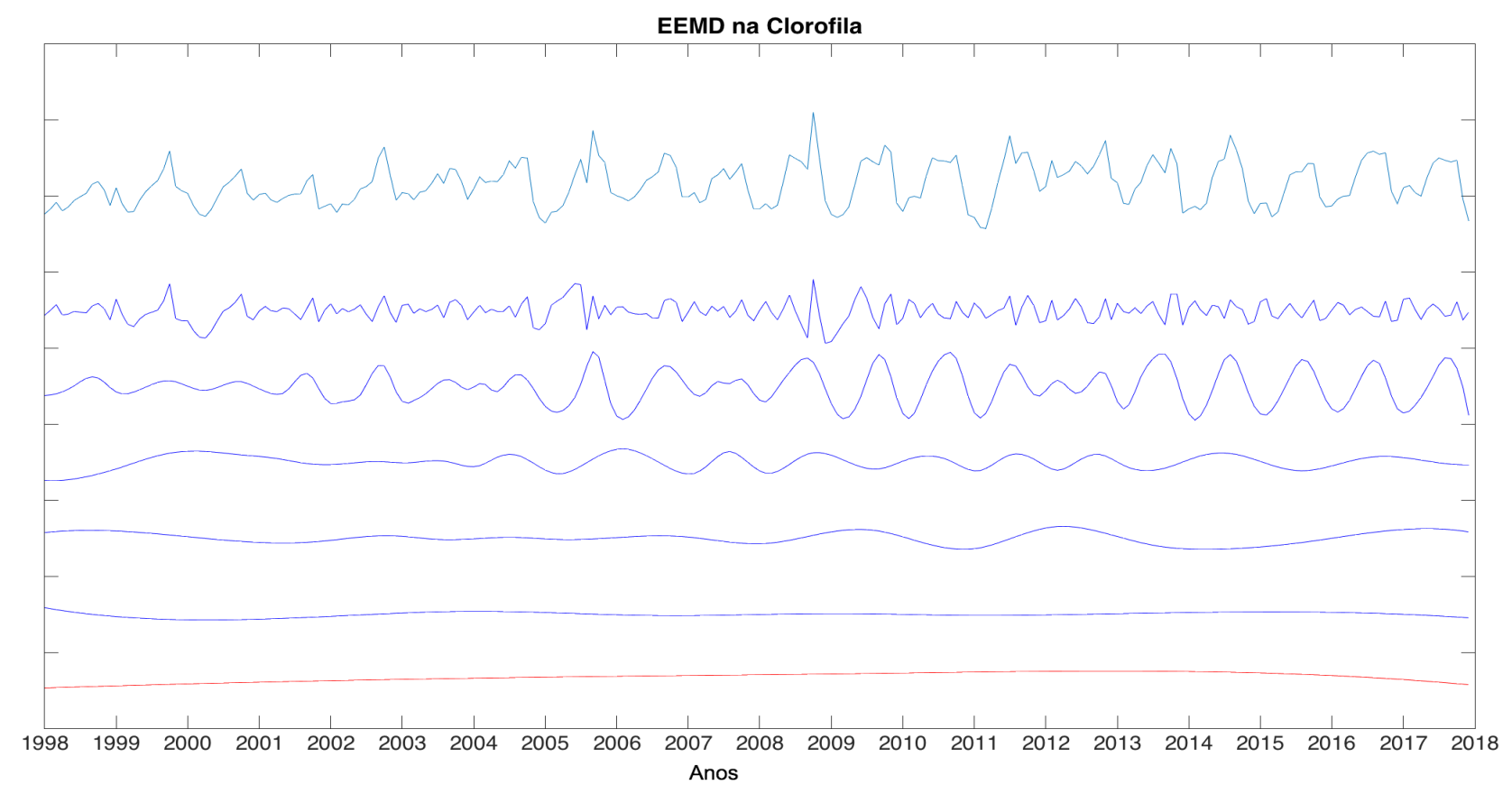

Figura 10: EEMD aplicado a uma série temporal da concentração de clorofila entre $30^{\circ} \mathrm{S}$ $40^{\circ} \mathrm{S}$ e $10^{\circ} \mathrm{E}-2^{\circ} \mathrm{W}$. A primeira série temporal é o dado original, as outras curvas azuis são a decomposição da série em IMF's e a curva em vermelho o resíduo/tendência

2009). Cada iteração da equação 5 resulta em séries temporais diferentes, e consequentemente ao aplicar o EMD, em diferentes IMF's. Após um certo número de iterações da equação 5, as diferentes séries temporais são decompostas pela análise do EMD e uma média dos IMF's das diferentes séries temporais $Y_{i}$ é realizada. Esse processo resulta na preservação do sinal e a remoção das frequências não desejadas (ruído) evitando o problema de mode mixing, além da propriedade do ruído branco ser cancelado no cálculo da média (Wu and Huang 2009). O algoritmo lógico por trás do EEMD segue os seguintes passos:

1. Adicionar um ruído branco na série;

2. Decompor a nova série em IMF's;

3. Repetir as etapas 1 e 2 diversas vezes, pois sempre há um ruído branco diferente;

4. Obter as médias do conjunto dos diferentes IMF's relacionados.

O número de iterações na equação 5 é escolhida pelo usuário. Wu and Huang (2009) recomendam que o número seja da ordem de $10^{2}$. Tanto o EMD quanto o EEMD são métodos que levam em conta a variação do parâmetro investigado em um instante de tempo localizado. Assim, mesmo com adição de novos dados na série, as componentes já calculadas para um tempo específico não são alteradas. Como pode-se observar na Figura 12 percebemos que mesmo com séries temporais com diferentes comprimentos os dados referentes aos mesmos períodos não se alteram, uma vez que a subsequente evolução de 


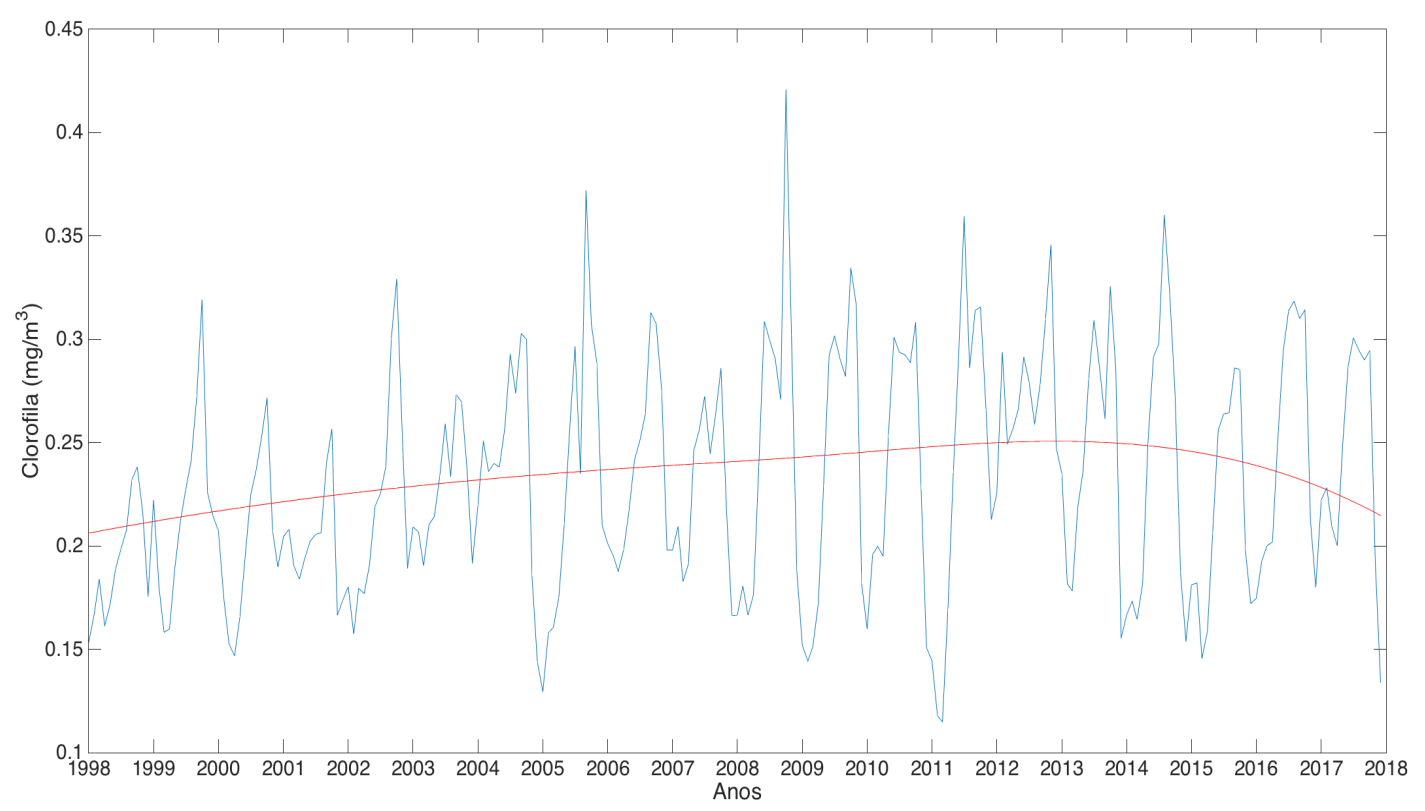

Figura 11: Série temporal original da concentração de clorofila (mesma que da Figura 10) sobreposta à componente da tendência de mais baixa frequência (vermelho) decomposta pelo EEMD.

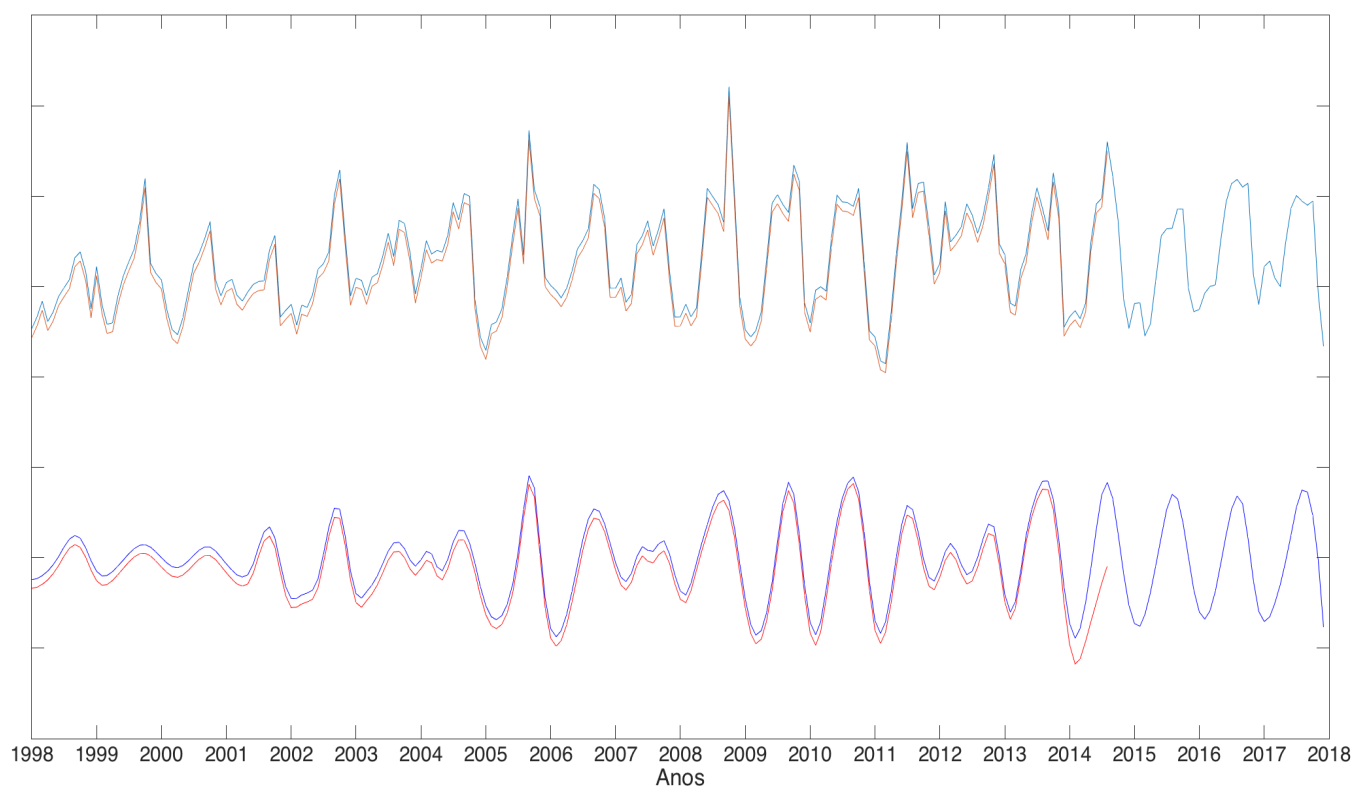

Figura 12: Série temporal da concentração de clorofila original sobreposta a mesma série porém 40 meses mais curta (curvas superiores). IMF da componente em escala anual da série original (curvas inferiores). Todas as curvas foram levemente deslocadas para não ter sobreposição. 
um sistema físico não pode alterar acontecimentos pretéritos (Ji et al. 2014).

\subsubsection{Multi-dimensional Ensemble Empirical Mode Decomposition}

EMD e EEMD são métodos adaptativos que conseguem lidar com a decomposição de séries temporais levando em conta suas variações no tempo, mas não no espaço. Por esta razão o Multi-dimensional Ensemble Empirical Mode Decomposition (MEEMD) foi elaborado lidando com a série temporal em uma estrutura espaço-temporal. Como o EMD e o EEMD são técnicas que analisam a variabilidade levando em conta os extremos da função, se a grandeza se propaga espacialmente, é possível identificá-la por pontos de máximos e mínimos em regiões adjacentes (Wu, Huang, and Chen 2009).

Para poder fazer uma análise espacial se utiliza os seguintes passos:

1. Decompor a série temporal utilizando o EEMD em cada ponto da grade espacial;

2. Juntar os n-ésimos elementos de cada $\operatorname{IMF}\left(C_{n}\right)$ e o resíduo $\left(K_{n}\right)$ dentro de toda a grade, formando uma estrutura espacial-temporal coerente em diferentes frequências.

O MEEMD se mostra como uma ferramenta eficaz para decompor uma série temporal de uma variável composta por uma combinação de sinais de diferentes frequências em componentes que se propagam coerentemente no tempo e no espaco. Temporalmente, esse método herda do EMD/EEMD a capacidade de representar a componente em um período específico e, portanto, não é alterado com adição de novos dados conforme já mencionado acima. Como resultado, é possível obter uma grade em que se consegue observar tanto sinais estáticos quanto propagantes, como pode ser observado na Figura 13. permitindo assim uma análise espacial. Outro ponto passível de nota é que analisando esta Figura podemos perceber que as diferentes escalas não se influenciam espacialmente, mostrando o padrão espacial em diferentes frequências de maneira independente.

O MEEMD já foi utilizado diversas vezes nos mais variados campos da ciência, atuando por exemplo, desde ciências da saúde (Pachori 2008) até processamento de som em vozes (Schlotthauer, Torres, and Rufiner 2009), em especial ao que se refere esse estudo, já foi utilizado em ciências atmosféricas e oceanográficas (Ji et al. 2014; Zhang et al. 2018; Franzke 2014; Hu et al. 2012; Zhu, Huang, and Wu 2012; Misra et al. 2014)

Neste estudo o MEEMD foi aplicado aos dados de clorofila, nitrato integrado e PAR, se utilizando da componente residual como evolução espaço-temporal da variável. Para se compreender a evolução espaço-temporal da clorofila, a anomalia das tendências da clorofila-a foi calculada. 


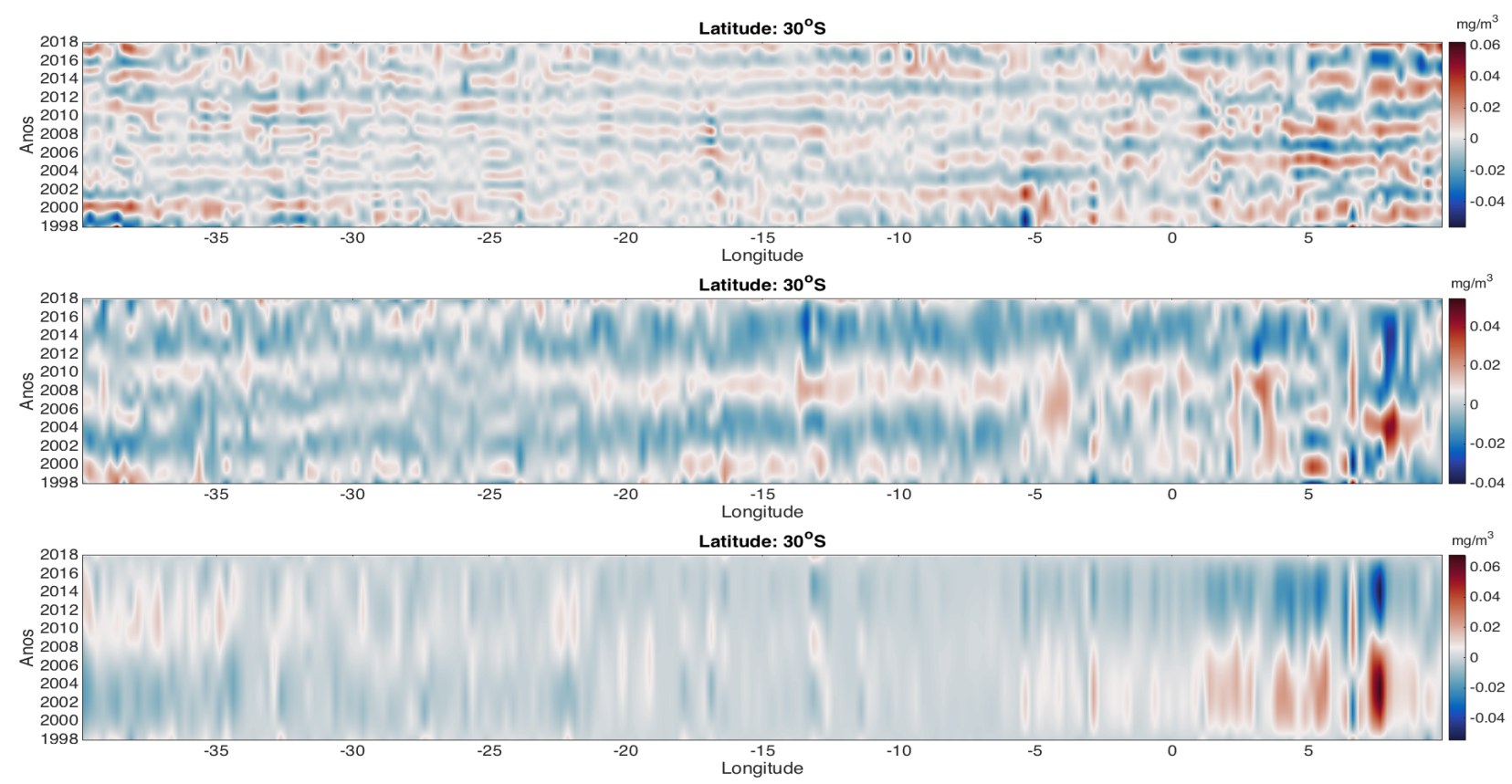

Figura 13: Hovmöller de três IMF's da concentração de clorofila

\subsection{Cálculo de Fluxo de Volume da MOC do Atlântico Sul}

Para o cálculo de fluxo de volume da MOC no Atlântico Sul foi calculado o máximo cumulativo transportado para norte integrado zonalmente da superfície ao fundo, sendo análogo a dizer o máximo de fluxo para norte na camada superior (Garzoli et al. 2013; Dong et al. 2009; Dong et al. 2011). A equação do transporte de volume pode ser descrita como:

$$
T=\int_{z 1}^{z 2} \int_{x 1}^{x 2} V d x d z
$$

onde, $V$ é o campo de velocidade meridional, $z 1$ e $z 2$ as profundidades da superfície e do fundo, e $x 1$ e $x 2$ os limites de integração zonal da bacia.

Para o cálculo da MOC os limites de integração zonais são pelas extremidades da bacia, isto é, no Atlântico Sul, delimitado pelos continentes sul-americano e africano. Entretanto, o fenômeno aqui estudado se relaciona muito mais com o transporte por parte das correntes de borda leste, onde ocorrem as grandes ressurgências e consegue aflorar os nutrientes presentes na Água Modal Subantártia (SAMW) transportados pela MOC (Palter et al. 2010). Desta maneira em vez de integrar zonalmente toda a bacia, a integral expressa na equação 6 é calculada somente na porção leste, levando em conta a presença da Dorsal Mesoatlântica como divisória pelo seu possível efeito topográfico. A MOC do Atlântico Sul tem uma orientação sudeste-noroeste (Figura 11), em resposta ao padrão de circulação observado no oceano superior do Atlântico Sul (Stramma and England 1999; Schmid 2014, Garzoli and Matano 2011). Isto resulta em a MOC cruzar a bacia, saindo da parte leste e indo para a porção oeste. Assim, em regiões tropicais mais próximas do 
Equador os limites de integração zonais foram dados pela borda oeste (também divididos pela Dorsal).

\section{7 Índices Climáticos}

Índices climáticos foram utilizados neste estudo para analisar possíveis influências de processos oceânicos remotos através de teleconexões atmosféricas na MOC. Dentre os diversos índices climáticos que poderiam ter potencial de afetar a MOC do Atlântico Sul, dois foram escolhidos. O primeiro é a Oscilação Antártica (AAO). Sua escolha foi baseada pelo seu efeito nos ventos de oeste na região subpolar, que por sua vez alteram a ressurgência antártica, afetando assim diretamente a concentração nutrientes que adentram na Água Modal Subantártica (SAMW) e AIA (Água Intermediária Antártica) e que serão transportados pela MOC do Atlântico Sul (Thompson et al. 2011; Marshall 2003; Panassa et al. 2018). Além disso, a AAO pode afetar o vazamento das Agulhas, que traz águas do Oceano Índico no Atlântico Sul (Biastoch and Böning 2013; Beal et al. 2011; Marini, Frankignoul, and Mignot 2011). O outro índice estudado é o El Niño - Southern Oscilation (ENSO). As teleconexões associadas a este processo podem interferir no padrão de ventos do Atlântico Sul (no caso, no padrão Dipolo Subtropical do Atlântico Sul) e, assim, afetar a circulação da MOC no Atlântico Sul (Rodrigues, Campos, and Haarsma 2015).

\subsubsection{Oscilação Antártica}

Os índices da Oscilação Antártica foram obtidos do National Centers for Environmental Prediction (NCEP) e são calculados através de uma análise de EOF nas médias mensais de anomalias de altura em $700 \mathrm{hPa}$ (Mo 2000). Os índices então são calculados projetando médias diárias e mensais da anomalia de altura de $700 \mathrm{hPa}$ no modo principal desta EOF. Os dados são normalizados pelo desvio padrão do índice mensal contemplado entre os anos de 1979 a 2000. Para este estudo foram utilizados índices mensais de 1979 até 2018.

\subsubsection{El Niño - Oscilação Sul}

Para o ENSO o índice adotado foi o Niño3.4. Esse índice foi obtido através da agência governamental do Estados Unidos National Oceanic and Atmospheric Administration (NOAA) dentro do departamento de Earth System Research Laboratory (ESRL). O Niño 3.4 se refere a região delimitada pelo mesmo número dentro do Pacífico equatorial (ver Figura 14). O índice é calculado pelos seguintes passos (Trenberth 2016): calcular a média da temperatura da superfície do mar (TSM) dentro da região 3.4 (Figura 14). Depois o valor da média é subtraído pela climatologia mensal de TSM da mesma região, obtendo uma série temporal de anomalia. A série de anomalia é suavizada com uma média móvel de 5 meses e normalizada pelo seu desvio padrão. 


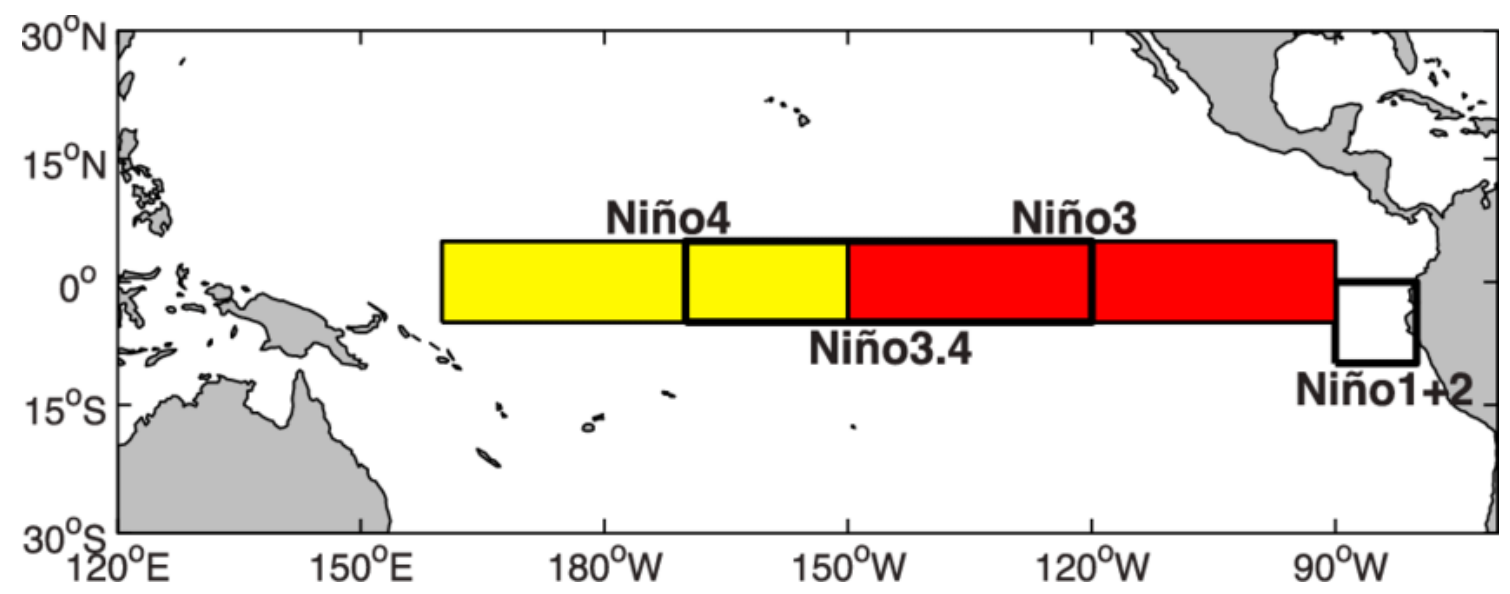

Figura 14: Regiões do Pacífico equatorial utilizada para calcular os respectivos índices. Fonte: NCEP

\section{Resultados e Discussão}

\subsection{Apresentação dos Dados}

A região de estudo envolve a bacia do Atlântico sul, e contempla desde a região equatorial até o começo da região antártica. Fatores que afetam a clorofila na escala de bacia são temperatura, variabilidade na radiação luminosa, ventos, correntes, entre outras variáveis contendo diferentes estruturas ecológicas (Longhurst 2007b; Longhurst 2007c). Na subseção a seguir os dados serão apresentados para entendermos com sua distribuição varia no tempo e no espaço.

\subsubsection{Clorofila no Atlântico Sul}

A média da concentração de clorofila no Atlântico Sul ao longo do período estudado pode ser observada na Figura 15. O padrão de distribuição espacial na bacia mostra uma região com baixa concentração de clorofila no centro do giro subtropical, e concentrações mais altas ao longo das margens continentais. As altas concentrações ao redor do giro ocorrem porque:

1. No lado leste da bacia, como nas demais bacias, encontramos uma região de ressurgência costeira devido aos padrões de circulação atmosférica de larga escala. Como resultado da influência dos ventos ocorre um transporte de Ekman que advecta águas da superfície próximo às costas em direção ao oceano aberto. Por continuidade águas em subsuperfície ressurgem na superfície. A corrente associada nessa região é a a Corrente de Benguela.

2. Concentrações relativamente altas são observadas na região relativamente próxima ao Equador também por resposta à ação do vento. Por transporte de Ekman ocorre 
divergência das águas na superfície em direção aos polos ocasionando então a ressurgência equatorial.

3. Na porção mais austral da área de estudo vemos também alta concentração por diversos fatores. Há a influência dos ventos de oeste que resulta em uma ressurgência antártica. Além disso, as características termohalinas da coluna d'água permitem uma baixa estratificação e uma camada de mistura mais profunda.

Esses fenômenos permitem que águas em regiões mais profundas com maior concentração em nutrientes alcancem níveis mais rasos, chegando na zona fótica. Sendo o giro subtropical limitado por nitrato (Bristow et al. 2017), com luz e nutriente o fitoplâncton pode sobreviver e realizar fotossíntese. Devido a variação espacial, optamos em dividir

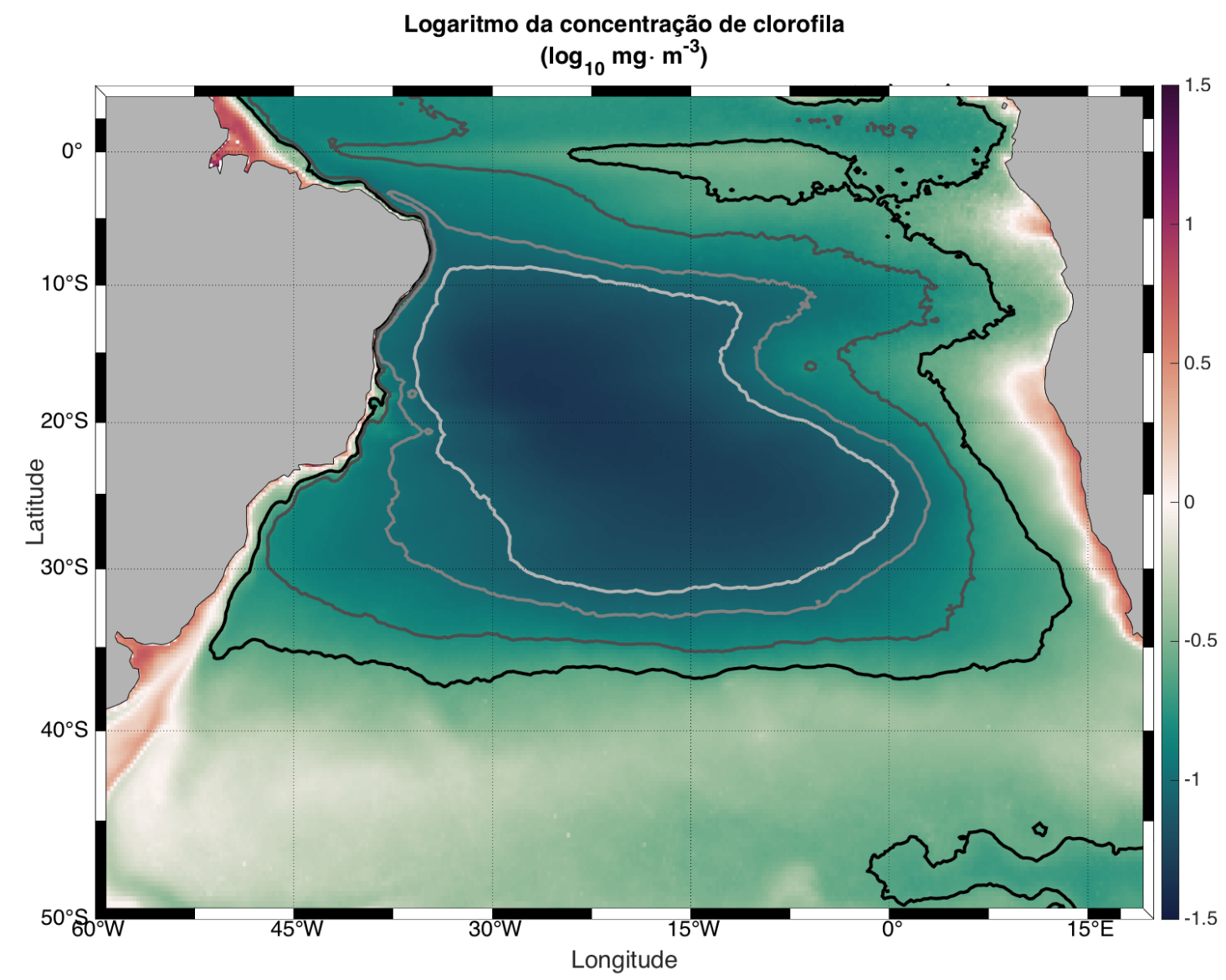

Figura 15: Média do $\log _{10}$ da concentração de clorofila entre os anos de 1998 a 2017 calculados a partir dos dados do produto GlobColour. As linhas mais claras para as mais escuras correspondem às seguintes concentrações: $0,08 \mathrm{mg} \cdot \mathrm{m}^{-3}, 0,1 \mathrm{mg} \cdot \mathrm{m}^{-3}, 0,16 \mathrm{mg} \cdot \mathrm{m}^{-3}$ e $0,25 \mathrm{mg} \cdot \mathrm{m}^{-3}$.

a área de estudo em sub-regiões para uma primeira análise da variabilidade da clorofila e as demais variáveis associadas a biogeoquímica (PAR e nitrato integrado), uma vez que a bacia pode apresentar diferentes biomas (Longhurst 2007c).

Dentro da área de estudo duas províncias biogeográficas foram escolhidas (Figura 16). A primeira é a South Atlantic Gyral Province (SATL) (Longhurst 2007d) escolhida por sua 


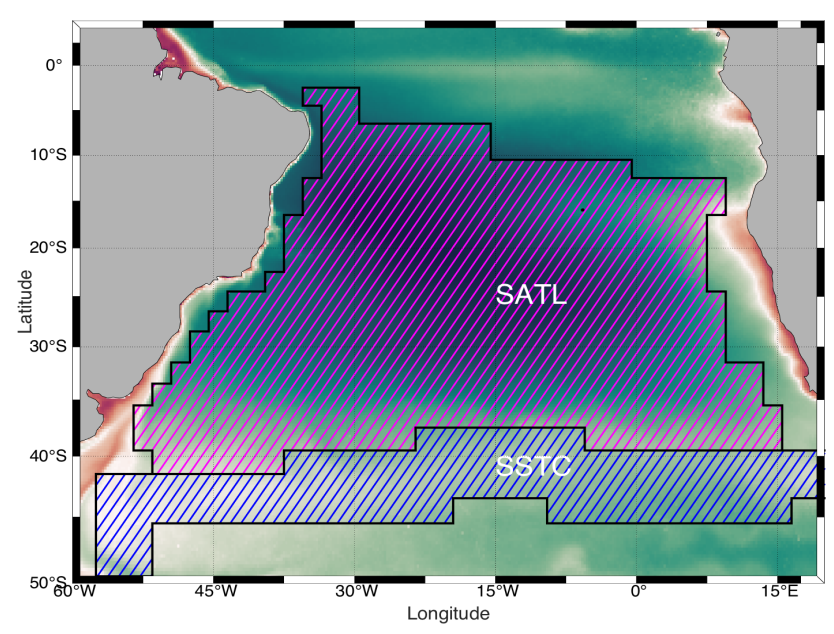

Figura 16: Localização das províncias biogeográficas South Atlantic Gyral Province (SATL) e South Subtropical Convergence Province (SSTC) para analisar a variabilidade da concentração de clorofila no Atlântico Sul a partir dos dados do Globcolour.

extensão contemplar maior parte da área deste estudo e a segunda é a South subtropical Convergence Province (SSTC) pela dinâmica dos ventos de oeste e ser uma região que contempla a formação da Água Modal Subantártica (SAMW) (Longhurst 2007a). Fica digno de nota que não será incluso neste estudo as altas concentrações de clorofila-a nas regiões costeiras, pois estamos interessados em processos inerentemente oceânicos.

Analisando o ciclo anual da concentração de clorofila na província SATL (Figura 17) vemos o mínimo em Fevereiro e o máximo em Outubro. Tal padrão sazonal está correlacionado com a profundidade da camada de mistura e os processos físicos que a regem. No começo do inverno austral, o oceano nesta província começa a perder calor para a atmosfera, isto ocorre de tal maneira que em Julho ocorre uma perda uniforme de calor desde $10^{\circ} \mathrm{S}$ a $45^{\circ} \mathrm{S}$ (Longhurst 2007d). Na porção mais ao norte da província há a influência da Zona de Convergência Intertropical, que apresenta no inverno ventos mais fortes e maior altura de onda ajudando a afundar a camada de mistura entre o Equador até $25^{\circ} \mathrm{S}$. Este padrão da camada de mistura se perpetua durante a primavera austral a medida que o oceano começa lentamente a se aquecer e estratificar a coluna d'água. No final do inverno e começo da primavera também há influência de ondas de instabilidade tropical relacionado à divergência devido a ação dos ventos alíseos na porção mais norte da província (Longhurst 2007d). A medida que a primavera austral termina e o verão se aproxima o oceano começa a receber mais calor, estratificando a água e diminuindo a profundidade da camada de mistura e, consequentemente, menos nutrientes chegam na zona fótica. Em escala de bacia podemos citar um outro processo que relaciona a variabilidade da clorofila em função da temperatura da superfície do mar (TSM) (Longhurst 2007d). Há um máximo de TSM na província no final de Fevereiro relacionado com um máximo de área da região oligotrófica, já quando o mínimo de TSM é observado temos o máximo 
de concentração de clorofila (Longhurst 2007d). Isso está de acordo com a Figura 17. conseguimos ver o mínimo na concentração de clorofila em Fevereiro com o máximo de concentração de clorofila no inverno (quando ocorre mínimo da TSM).

O ciclo anual da concentração de clorofila na província SSTC apresenta um mínimo no inverno austral (Junho a Agosto) e máximo no verão. Este padrão segue a influência dos fatores abióticos na produtividade primária. No inverno essa região recebe uma menor irradiância solar o que afeta diretamente a fotossíntese exercida pelo fitoplâncton. Adicionalmente, o oceano apresenta uma menor estratificação e alta mistura convectiva devido a ação dos ventos e perda de calor oceânico para a atmofera o que resulta em média em organismos do fitoplâncton removidos da zona fótica, agravando ainda mais a produtividade primária de forma deletéria (Longhurst 2007a). Esta província apresenta um alto gradiente horizontal de nitrato. Isso ocorre porque a SSTC contempla em seu domínio a linha de rotacional zero da tensão de cisalhamento do vento, sendo então o limite norte do transporte de Ekman das águas subantárticas ricas em nutriente e o limite sul do giro subtropical, pobre em nutrientes (Longhurst 2007a). A medida que a camada de mistura começa a estratificar na primavera devido ao aumento da incidência solar, há um aumento na produtividade primária. Este aumento se sucede a medida que a água se aquece e estratifica conseguindo ter uma maior estabilidade da coluna com a maior parte dos nutrientes das águas subantárticas sendo utilizados. No outono o oceano ao perder calor para a atmosfera, a camada de mistura se aprofunda concomitantemente à diminuição na irradiância solar, o que causa um decaimento na produtividade primária até seu mínimo no inverno.
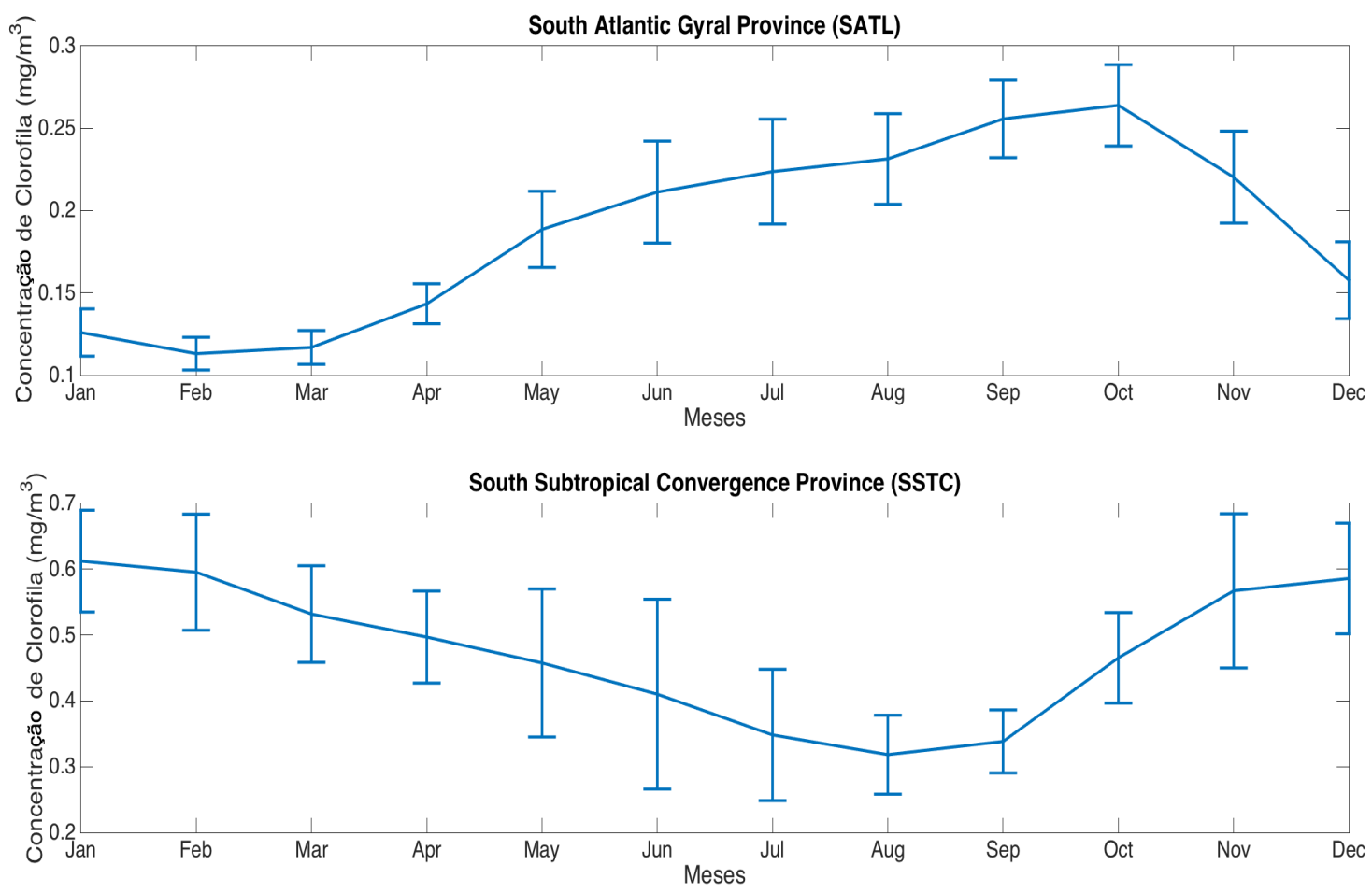

Figura 17: Ciclo anual da concentração de clorofila nas províncias biogeográficas a partir dos dados do GlobColour para o período entre 1998 a 2017. 
Tabela 2: Médias e os desvios padrões da clorofila, nitrato integrado, PAR em cada província biogeográfica para os anos de 1998 a 2016 (nitrato integrado) e 1998 a 2017 (clorofila e PAR).

\begin{tabular}{|c|c|c|c|c|}
\cline { 2 - 5 } \multicolumn{1}{c|}{} & \multicolumn{2}{c|}{ SATL } & \multicolumn{2}{c|}{ SSTC } \\
\cline { 2 - 5 } \multicolumn{1}{c|}{} & Média & Desvio Padrão & Média & Desvio Padrão \\
\hline Clorofila $\left(\mathbf{m g} / \mathbf{m}^{3}\right)$ & 0,15 & 0,11 & 0,47 & 0,15 \\
\hline Nitrato Integrado $\left(\mathbf{m m o l}^{\mathbf{2}} \mathbf{\mathbf { m } ^ { 2 }}\right)$ & 480,1 & 489,2 & 2020,2 & 487,5 \\
\hline PAR (mol de fótons/m $/ \mathbf{d i a})$ & 40,5 & 5,5 & 27,9 & 2,1 \\
\hline
\end{tabular}

As médias e o desvio padrão da concentração de clorofila em cada província estão expressas na Tabela 2. A média da região SSTC é é aproximadamente três vezes maior que a média da SATL, isto se deve primeiramente que a SSTC é uma alta zonal permanente de clorofila (Longhurst 2007d), enquanto a província SATL contempla em seu domínio a parte central do giro subtropical, onde se encontra as menores concentrações de clorofila. Com relação ao desvio padrão, a SATL apresenta um valor comparável com a sua média. O gradiente meridional de clorofila nesta província é alto comparado com a outra província; há um mínimo localizado na região central enquanto uma concentração maior nas margens norte (resultado da influência da divergência equatorial), leste (parte da ressurgência da corrente de Benguela) e sul (limite com a alta da província SSTC), esta variação dá um alto desvio padrão encontrado no domínio.

A função densidade de probabilidade da concentração de clorofila em base logarítmica para ambas províncias são mostradas na Figura 18 . Ao analisarmos a distribuição dos valores de concentração de clorofila, Figura 18 painéis superiores, observamos que não se trata de uma distribuição normal. Portanto, a estatística convencional para o cálculo de média e desvio padrão não pode ser aplicada. É usual no caso da clorofila utilizar a distribuição do logaritmo da concentração com o intuito de promover uma função densidade de probabilidade que siga os padrões de distribuição normal ou gaussiana, Figura 18. painéis inferiores. Na SATL, a maior densidade de probabilidade está relacionada com baixas concentrações. Essa distribuição reflete grande parte da região oligotrófica do Atlântico Sul sendo que apenas nas regiões marginais que encontramos os maiores valores. Na província SSTC, a distribuição se aproxima de uma distribuição bimodal, com a probabilidade maior quando $\log _{10}(C)=-0,4$ e a outra aproximadamente $\log _{10}(C)=-0,2$. Esse segundo máximo na probabilidade pode ser um reflexo da grande concentração de clorofila encontrada nos períodos do verão uma vez que a partir de Outubro até Fevereiro já se tem valores maiores que $0,5 \mathrm{mg} / \mathrm{m}^{3}$ (ver Figura 17 ).

Vale ressaltar que mesmo com a aplicação do logaritmo nos dados de clorofila, não foi obtida uma curva normal na província SATL, reflexo da distribuição espacial da concentração da clorofila descrito acima. Adicionalmente a isto, vemos pela figura do histograma de clorofila-a do Atlântico Sul (Figura 19) que há limitação por parte do sensor, uma vez que há uma queda brusca após valores menores que $\log _{10}(C)=-1,25$. Desta maneira, há 
ressalvas ao se analisar quantitativamente a média e desvio padrão da província SATL. Qualitativamente, no entanto, essa província correspondeu com o observado na literatura (Longhurst 2007d) e apresentou um histograma coerente com a distribuição espacial contemplada.

\subsubsection{Nitrato}

O ciclo anual médio da concentração de nitrato integrado verticalmente em cada província seguiu um padrão esperado dada a variação sazonal da profundidade da camada de mistura e o padrão da clorofila na Figura 20. Na província SATL, o nitrato teve seu máximo no inverno austral (Julho) e mínimo no fim do verão (Fevereiro). Como mencionado na seção anterior, é observada uma perda de calor uniforme na superfície do oceano entre $10^{\circ} \mathrm{S}$ e $45^{\circ} \mathrm{S}$ no mês de Julho (entre $-100 \mathrm{~W} / \mathrm{m}^{2}$ a $-125 \mathrm{~W} / \mathrm{m}^{2}$ ) (Longhurst $2007 \mathrm{~d}$ ) causando assim uma coluna d'água menos estratificada devido à mistura convectiva, e coincidindo com o máximo observado nesse mês na Figura 20. A medida que chega a primavera e há um aumento da produtividade primária (Figura 17) os nutrientes na camada fótica vão sendo utilizados, explicando a queda após o inverno. Este valor chega no seu mínimo em Fevereiro, onde a coluna d'água se torna mais estratificada e com uma concentração menor de nutrientes ao que se tinha antes na camada de mistura ser formada. Este mínimo coincide com o mínimo de clorofila (ver Figura 17). Com menor produtividade primária e uma perda de calor do oceano a medida que se avança no outono e inverno, a concentração de nitrato integrado aumenta (aumentando também a clorofila até seu máximo em Outubro, a queda que segue pode ser explicada na queda da concentração de nitrato integrado a partir de Setembro) até atingir seu máximo em Julho de novo.

De maneira análoga ao descrito acima, pode-se explicar o padrão encontrado no nitrato integrado na província SSTC. Na Figura 20 vemos um mínimo de nitrato integrado no final do outono austral, seguido de um súbito aumento até o máximo em Agosto; este comportamento é resultante do aumento da profundidade da camada de mistura concomitantemente com uma diminuição na produtividade primária (Figura 17). De Agosto a Outubro a concentração de nutrientes apresenta um máximo por um equilíbrio entre um aumento da produtividade primária com o começo da estratificação da coluna d'água que ainda recebe altas concentrações de nitrato devido a influência das águas subantárticas (Longhurst 2007a). Continuando a estratificação e o seguido aumento da produtividade primária, a concentração de nutrientes começa a cair, chegando no mínimo do mês de Maio. 


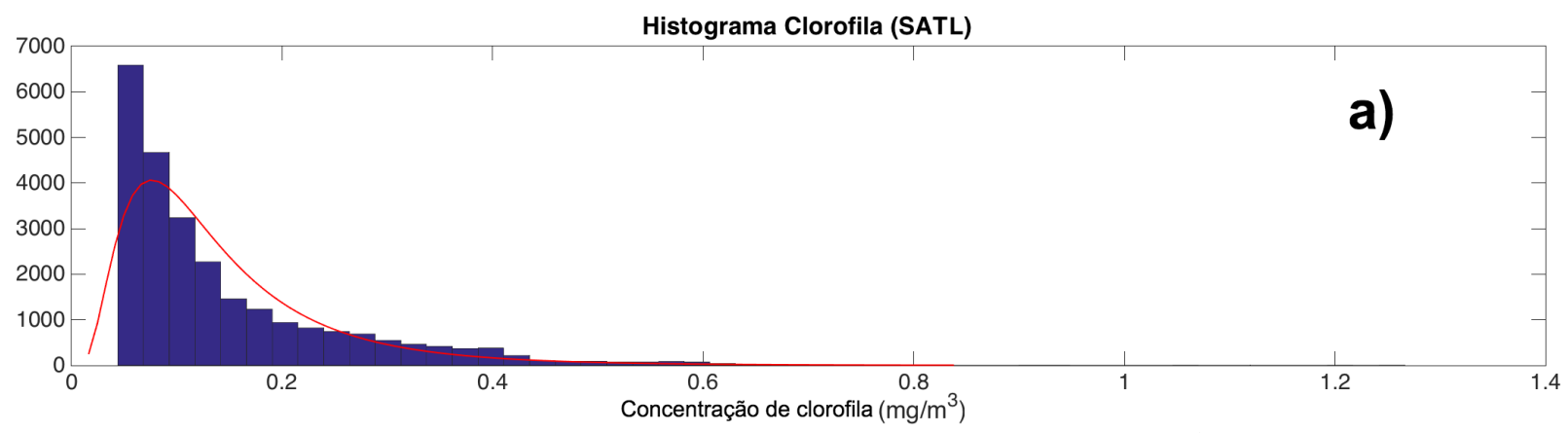

Histograma $\log _{10}$ Clorofila (SATL)
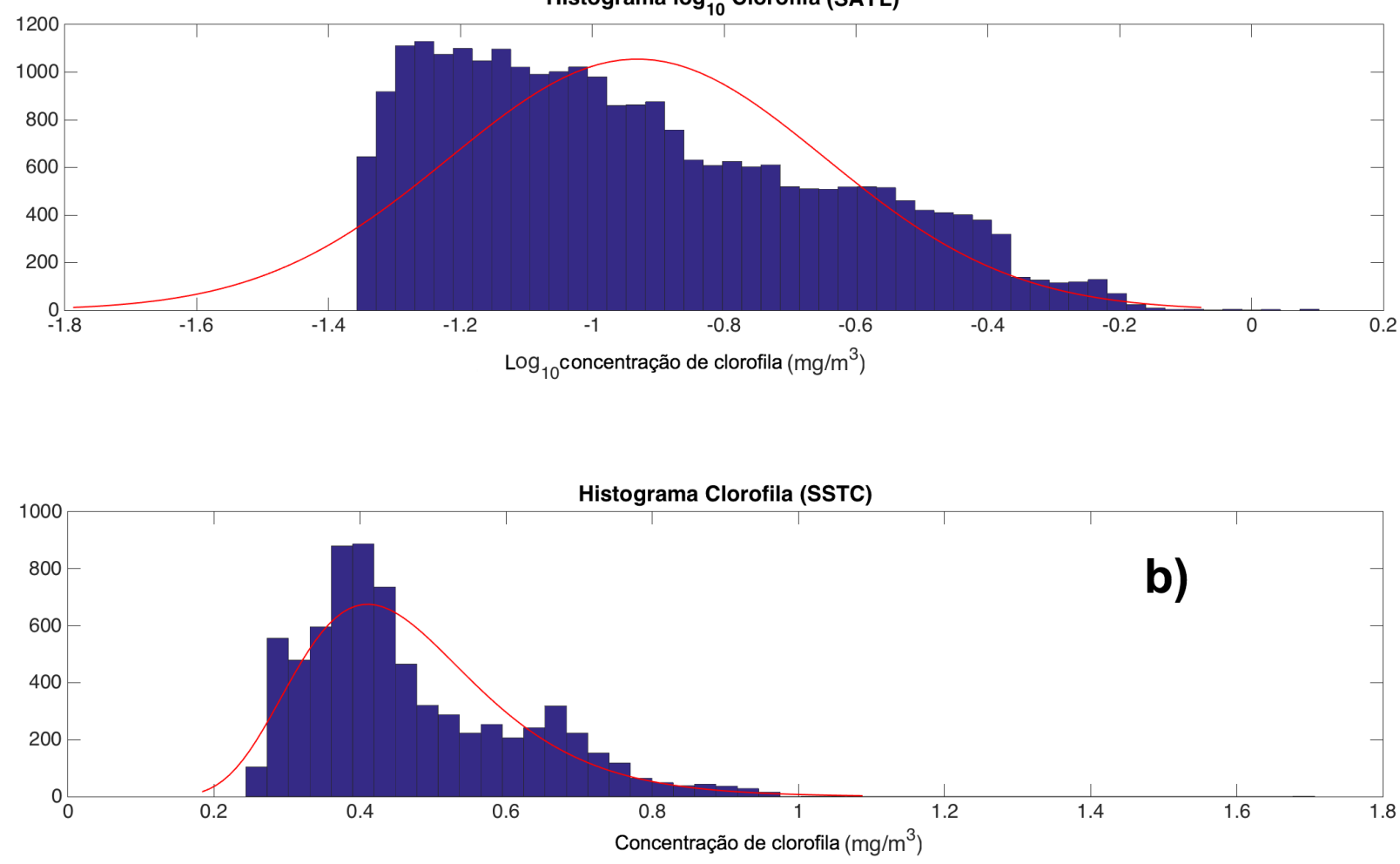

Histograma $\log _{10}$ Clorofila (SSTC)

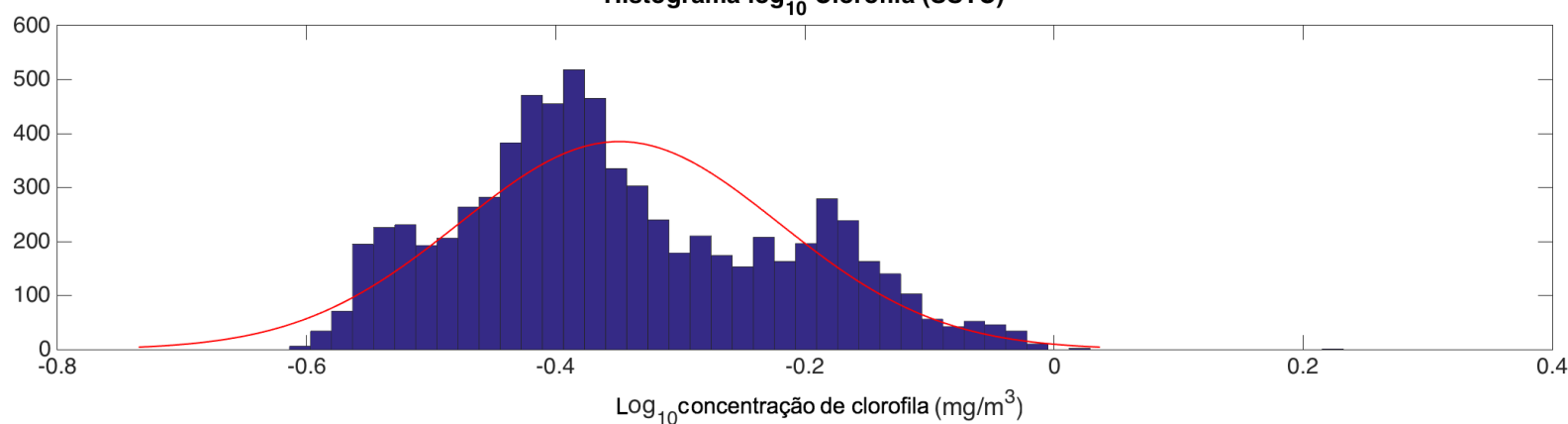

Figura 18: Histograma da concentração da clorofila nas regiões biogeográficas: a) South Atlantic Gyral Province e b)South Subtropical Convergence Province. O painel superior se refere ao histograma dos dados da província enquanto o painel inferior os dados em $\log _{10}$. As curvas em vermelho são a função densidade de probabilidade de uma distribuição log-normal (painel superior) e normal (painel inferior). 


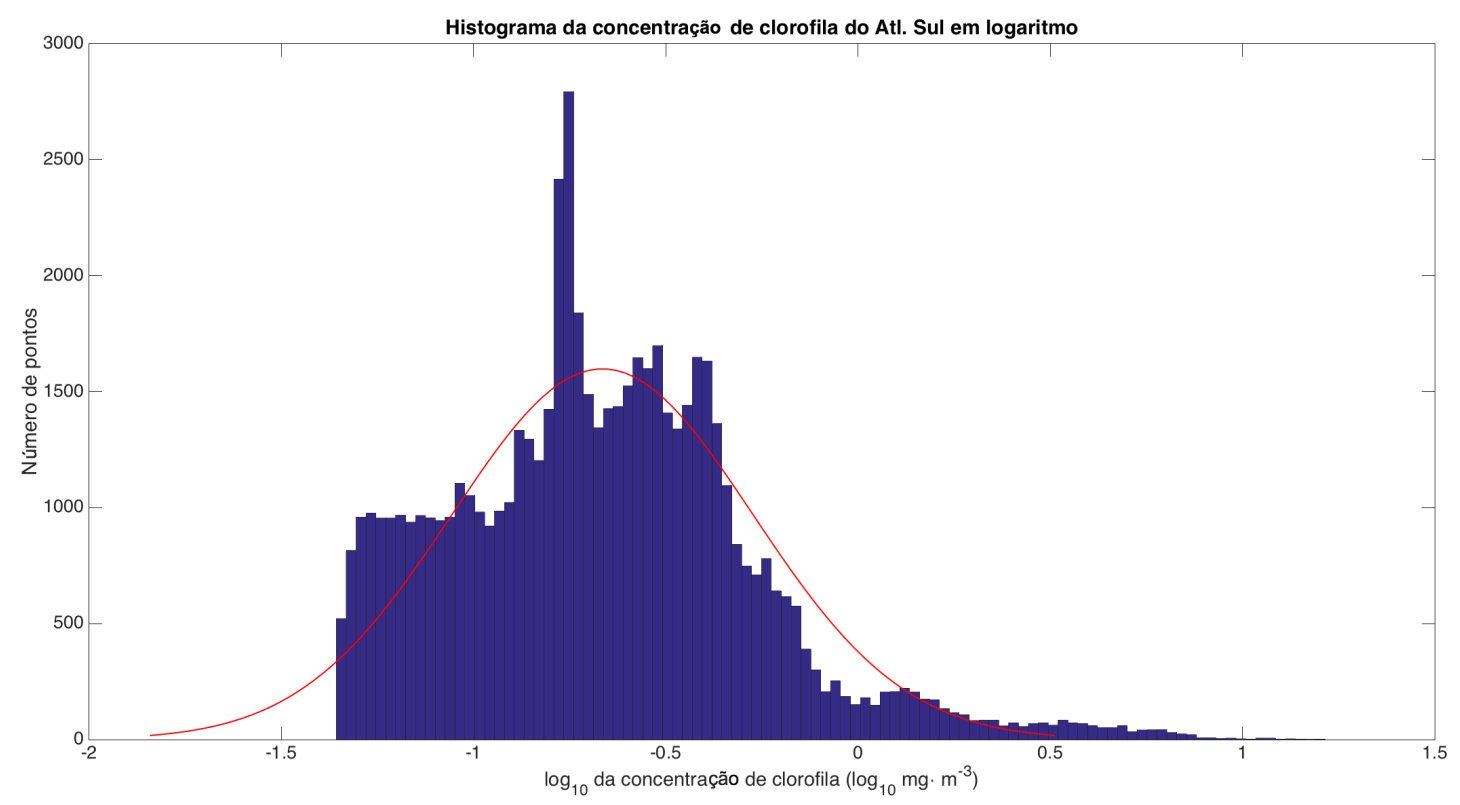

Figura 19: Histograma do $\log _{10}$ da concentração de clorofila no Atlântico Sul.
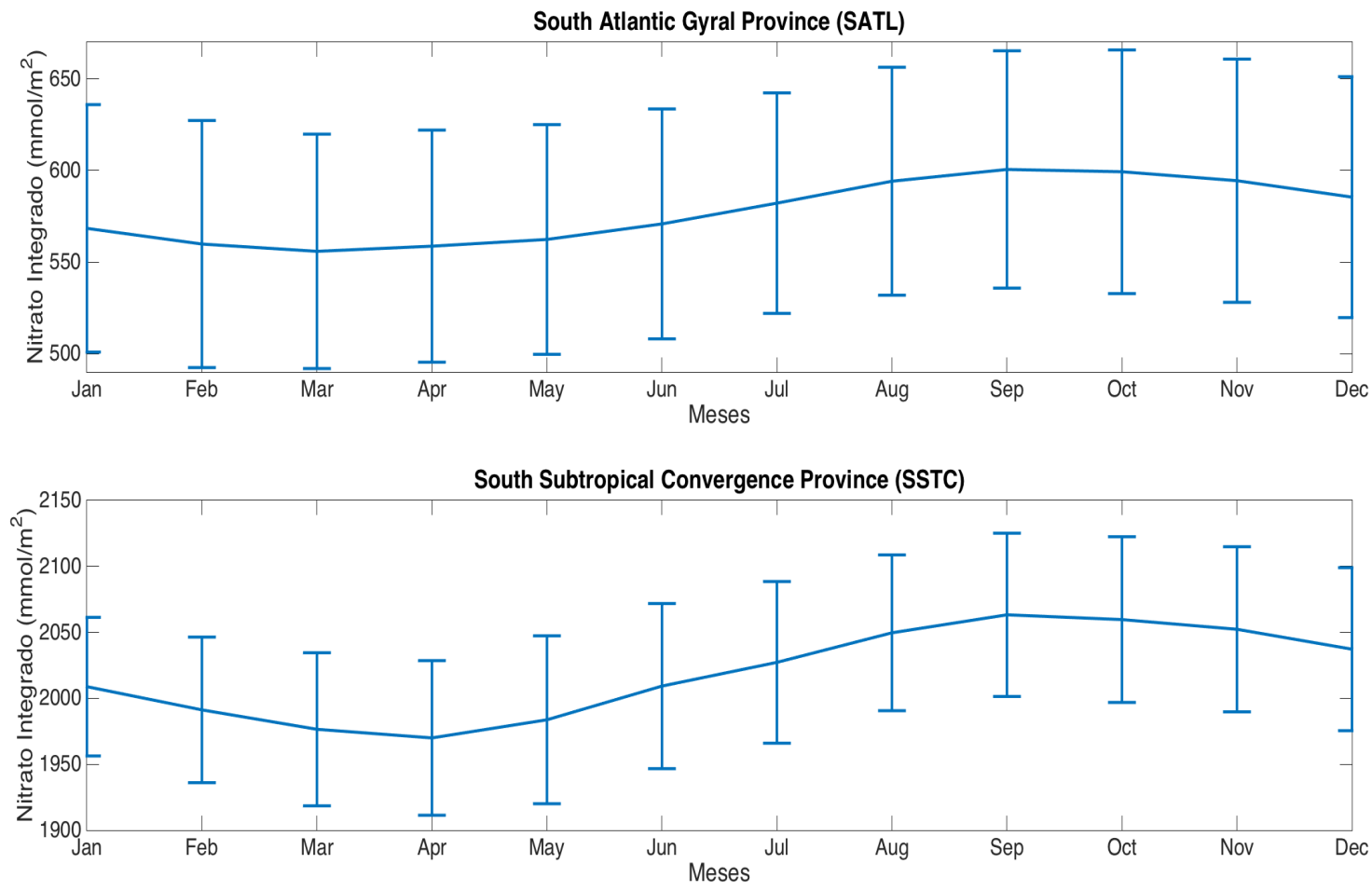

Figura 20: Ciclo anual médio da concentração de nitrato integrado nas províncias biogeográficas utilizando saída do modelo biogeoquímico PISCES entre os anos de 1998 a 2016.

As médias e desvio padrão do nitrato integrado apresentam o mesmo padrão que a da concentração de clorofila apresentaba na Tabela 2. A província SATL contém o centro do giro subtropical, que é altamente estratificado e apresenta concentrações baixas de nitrato em superfície, ao mesmo tempo que marginalmente há valores maiores (Figura 21), dife- 


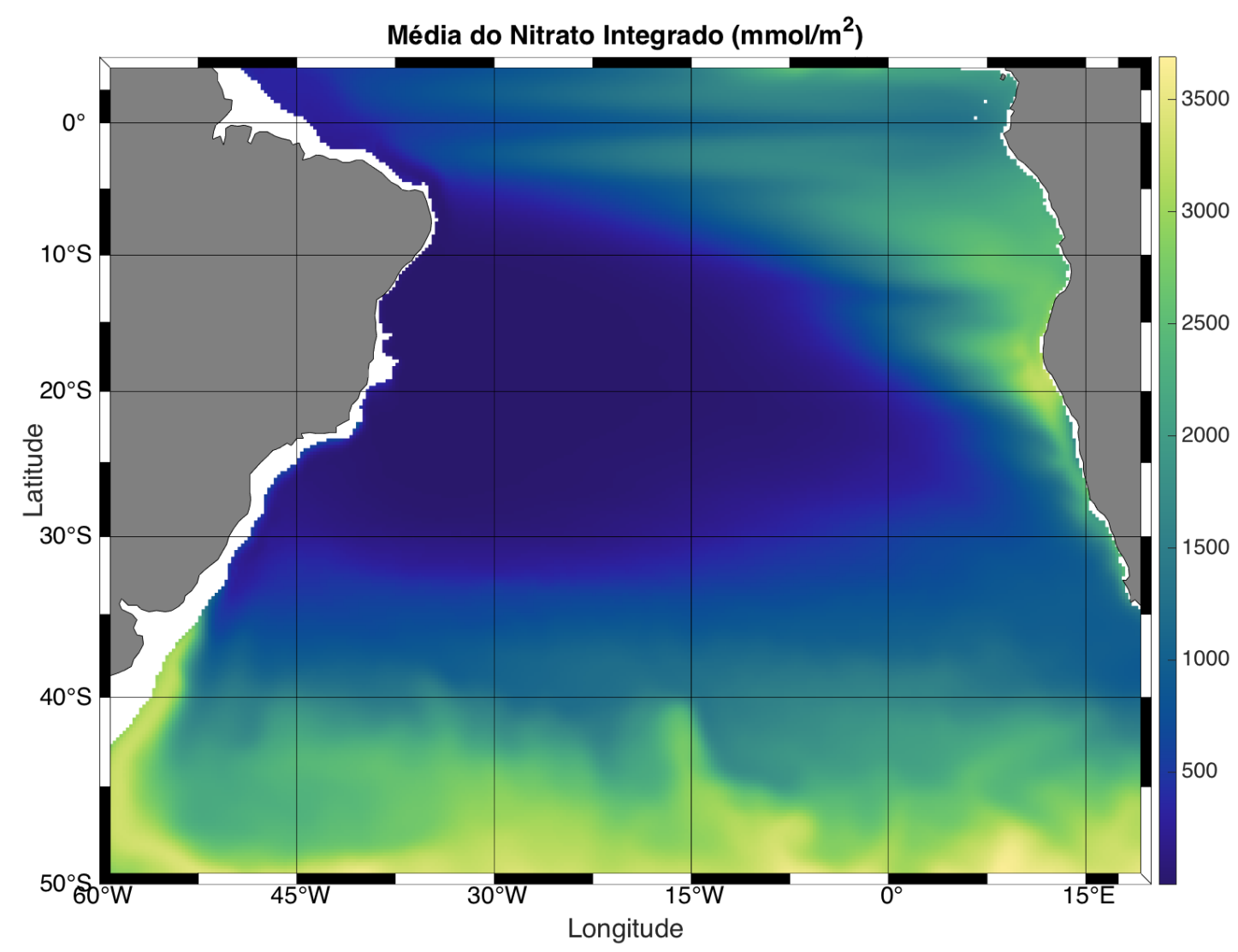

Figura 21: Média do nitrato integrado entre os anos 1998 a 2016 usando dados do modelo biogeoquímico PISCES.

rente da província SSTC que recebe altas concentrações de águas subantárticas. Assim, vemos uma média da região SATL sendo 4,2 vezes menor do que a média estimada em SSTC (Tabela 2). Esta discrepância de valores achados em SATL (Figura 21), explica o porque de um valor alto de desvio padrão com relação a sua média, análogo ao que é visto na clorofila na mesma província (Tabela 2). Dada esse alto gradiente na concentração de nitrato integrado foi observado na distribuição dos dados um padrão semelhante a uma distribuição log-normal (Figura 22). Os menores valores com maiores frequências e uma queda abrupta sentido aos valores de concentração mais altos. Ao aplicar o $\log _{10}$ nos dados de nitrato integrado foi obtido uma distribuição com alta frequência de valores de nitrato integrado menores conforme esperado. Os valores da província SSTC, por sua vez, não se assemelharam a uma distribuição log-normal, então não foi preciso a conversão dos dados em logaritmo (Figura 22). 

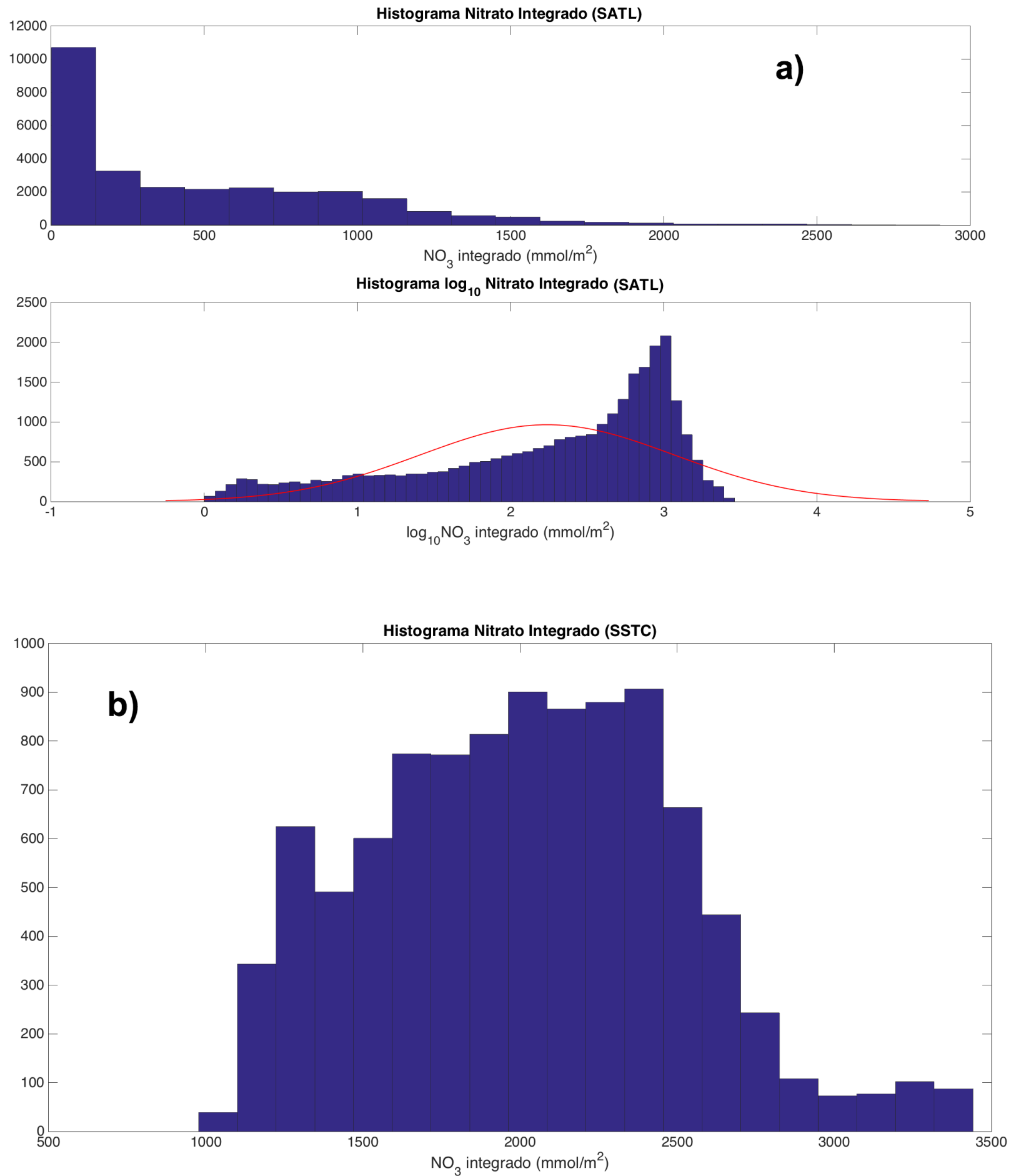

Figura 22: Histograma do nitrato integrado nas regiões biogeográficas: a) South Atlantic Gyral Province e b)South Subtropical Convergence Province. O painel superior se refere ao histograma dos dados da província enquanto o painel inferior os dados em $\log _{10}$. As curvas em vermelho são a função densidade de probabilidade de uma distribuição lognormal (painel superior) e normal (painel inferior). 


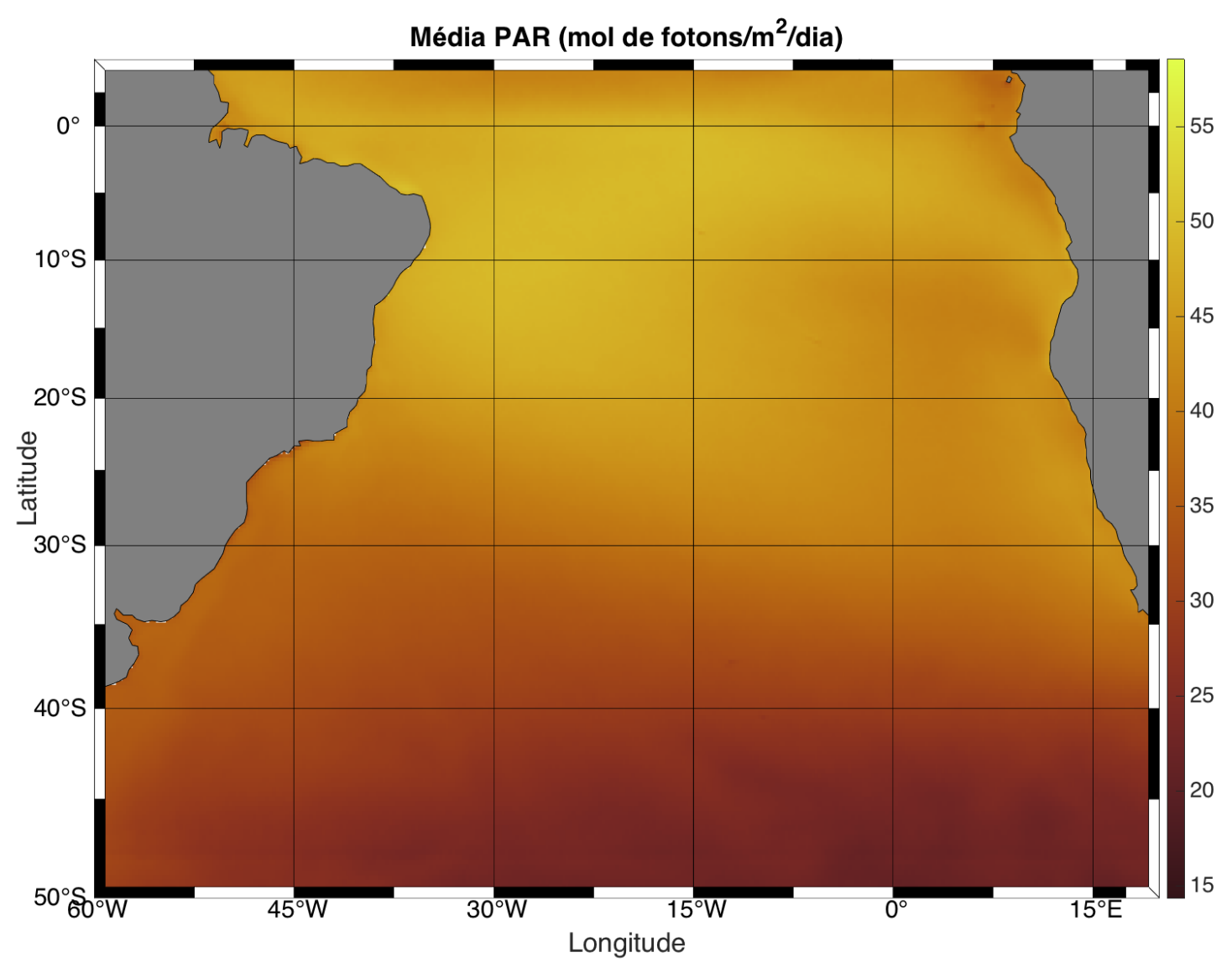

Figura 23: Média do PAR entre os anos 1998 a 2017 a partir dos dados do GlobColour

\subsubsection{PAR}

O PAR em cada província seguiu o padrão de sazonalidade esperado (Figura 24). O máximo ocorre no verão e o mínimo no inverno. Tal estrutura é obviamente regulada pela incidência de raios solares sobre a superfície da Terra. O que diferencia uma província de outra é a escala do PAR. Localizada mais ao norte que a SSTC, a SATL tem a maior parte de sua província em uma região tropical e subtropical, onde a incidência solar é maior do que a SSTC (Figura 23), este fator faz com que o PAR em cada província tenha distribuições únicas. A distribuição dos dados em cada província pode ser observada na Figura 25. Pela província SATL estar na região tropical e subtropical, onde há alta incidência solar, há uma distribuição levemente homogênea dos dados, com uma média de $40 \mathrm{~mol}$ de fotons $/ \mathrm{m}^{2} / \mathrm{dia}$. Em contrapartida, pela localização mais austral da região SSTC a característica é de um clima mais temperado onde a amplitude do ciclo anual da temperatura da superfície do mar é maior que a de regiões de mais baixas latitudes. 

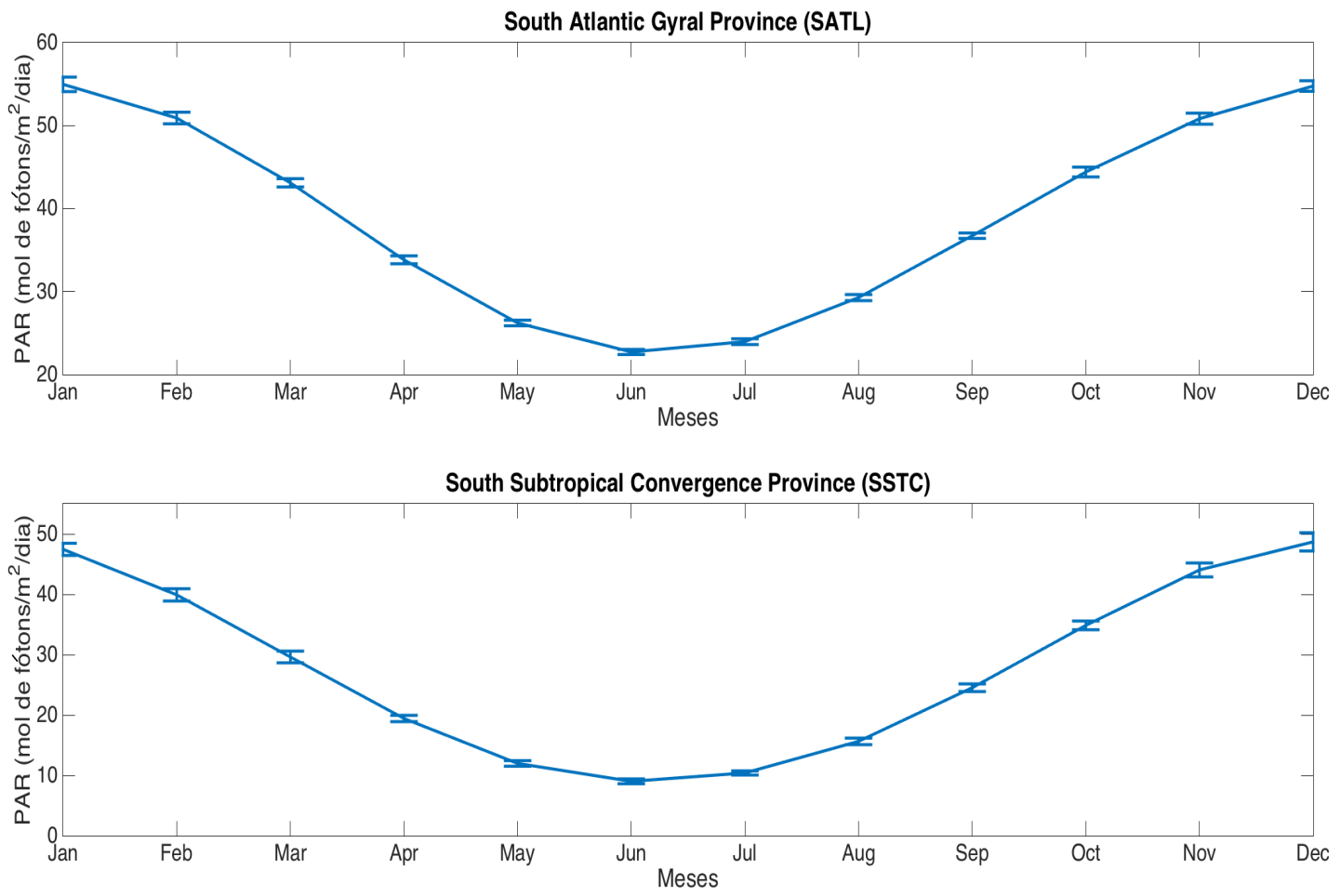

Figura 24: Ciclo anual do PAR nas regiões biogeográficas a partir dos dados do GlobColour para o período entre 1998 a 2017.

\subsubsection{Transporte da MOC do Atlântico Sul}

O transporte da MOC do Atlântico Sul foi estimado em $34,5^{\circ} \mathrm{S}$, onde há diversos estudos próximo desta latitude de seu fluxo de transporte de volume e fluxo de calor meridional (Garzoli et al. 2013, Garzoli and Baringer 2007; Dong et al. 2009; Dong, Goni, and Bringas 2015; Dong et al. 2011). A série temporal da MOC do Atlântico Sul foi calculada para cada um dos modelos utilizados: enquanto o ECCO produziu um transporte de volume da MOC com média mais baixa $(15,55 \pm 2,3 \mathrm{~Sv})$, o modelo NEMO se manteve com uma média de 19,88 $\pm 3,5 \mathrm{~Sv}$ (Figura 26). Entretanto, ambos os transportes calculados não são diferentes dentro da margem de erro apresentada na Tabela 3. Ambas as médias ficaram próximas do valor da MOC do Atlântico Sul encontrados em diferentes estudos na região (Tabela 3).

O ciclo anual da MOC do Atlântico Sul (Figura 27) varia com a latitude. Ambos os modelos concordaram na fase e amplitude do ciclo anual da $\mathrm{MOC}$ em $15^{\circ} \mathrm{S}$ e $25^{\circ}$ mas ficaram fora de fase em $34,5^{\circ} \mathrm{S}$. Majumder, Schmid, and Halliwell (2016) obtiveram um resultado semelhante, utilizando dados Argo, dados de altimetria e saídas de modelos para determinar o ciclo anual da MOC em diversas latitudes. A latitude de $35^{\circ} \mathrm{S}$ apresentou defasagem entre o transporte de volume da MOC usando dados Argo e altimetria com os de modelos. A diferença seria que nessa latitude existem complexos sistemas dinâmicos: na borda oeste, a confluência entre as Corrente do Brasil e Corrente das Malvinas e na 

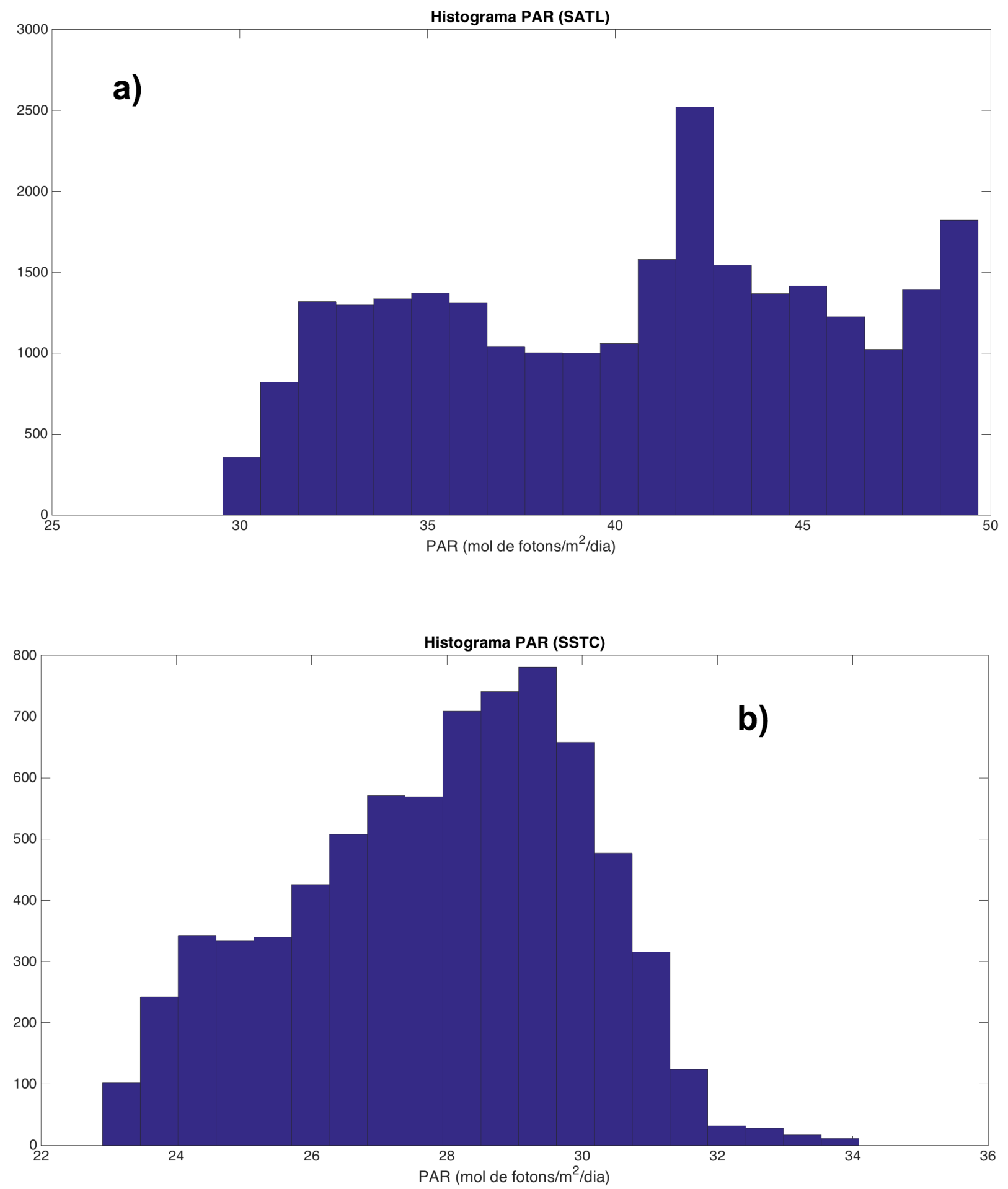

Figura 25: Histograma do PAR nas regiões biogeográficas: a) South Atlantic Gyral Province e b)South Subtropical Convergence Province. O painel superior se refere ao histograma dos dados da província enquanto o painel inferior os dados em $\log _{10}$. As curvas em vermelho são a função densidade de probabilidade de uma distribuição log-normal (painel superior) e normal (painel inferior). 


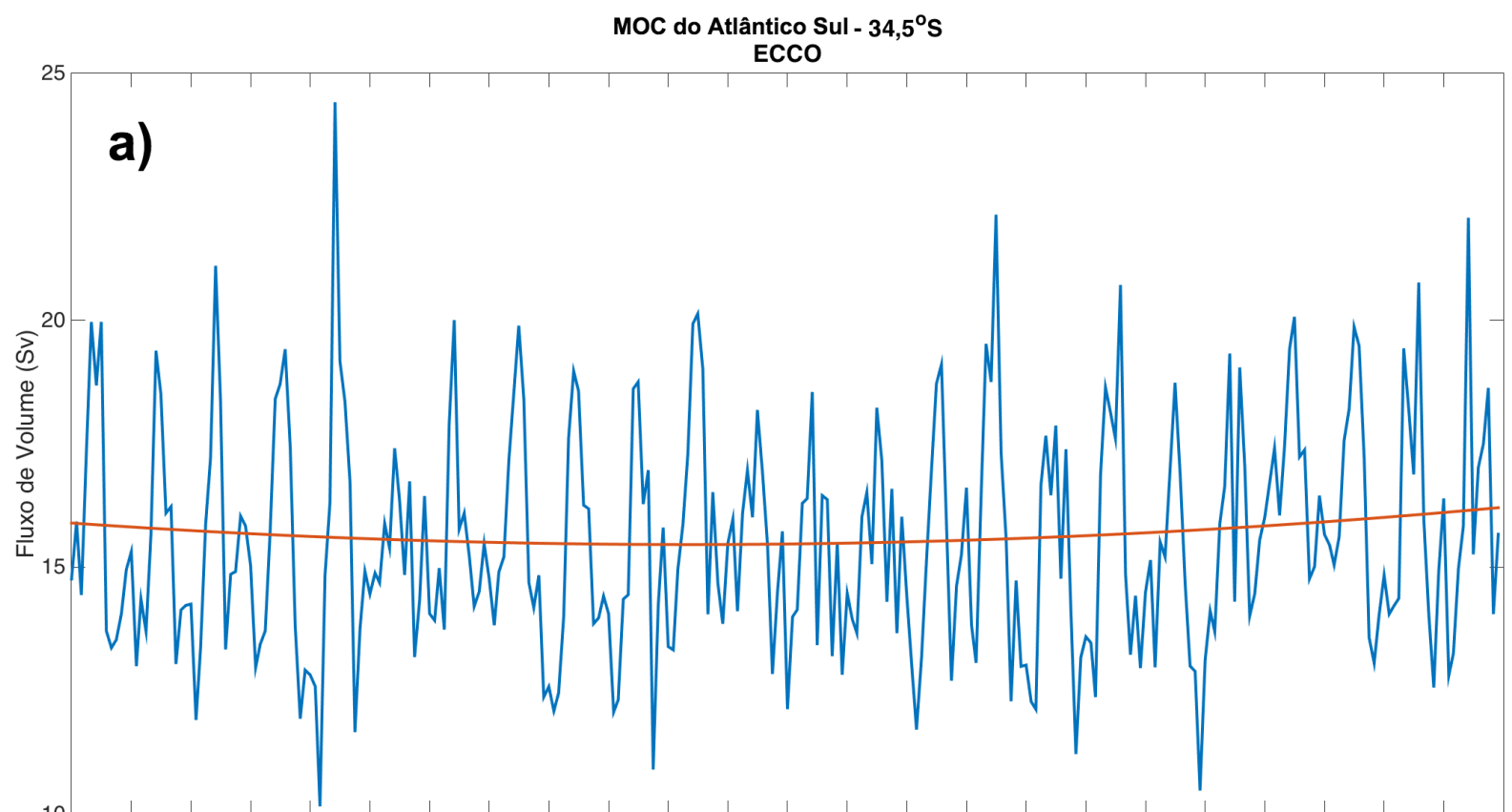

${ }_{1992}^{10} 199319941995199619971998199920002001200220032004200520062007200820092010201120122013201420152016$

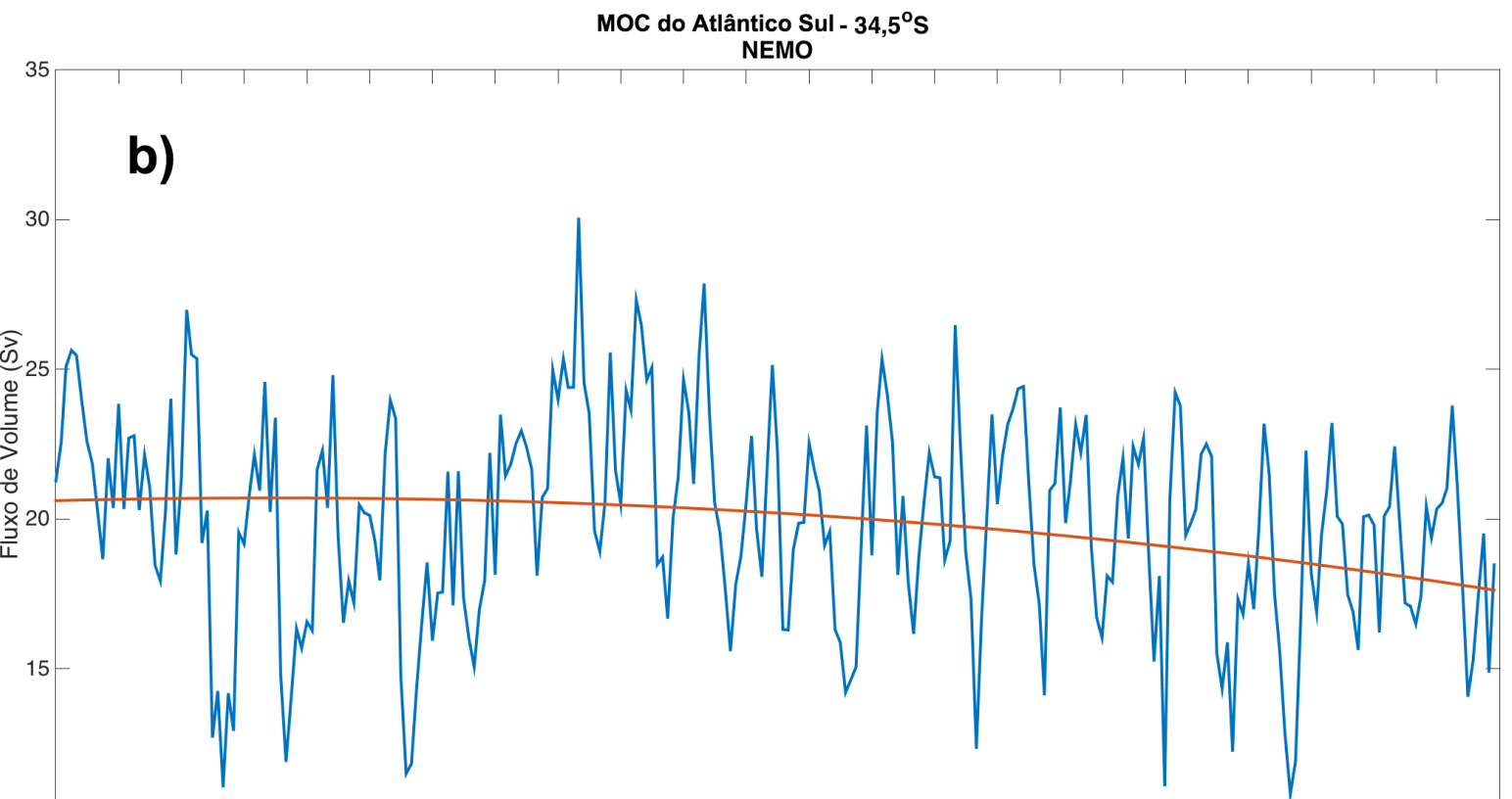

${ }_{1993}^{10} 19941995199619971998199920002001200220032004200520062007200820092010201120122013201420152016$

Figura 26: MOC do Atlântico Sul em 34,5 S para os anos de 1992 a 2015 pela saída do modelo a) ECCO e b) NEMO. A linha vermelha é a tendência interanual. 

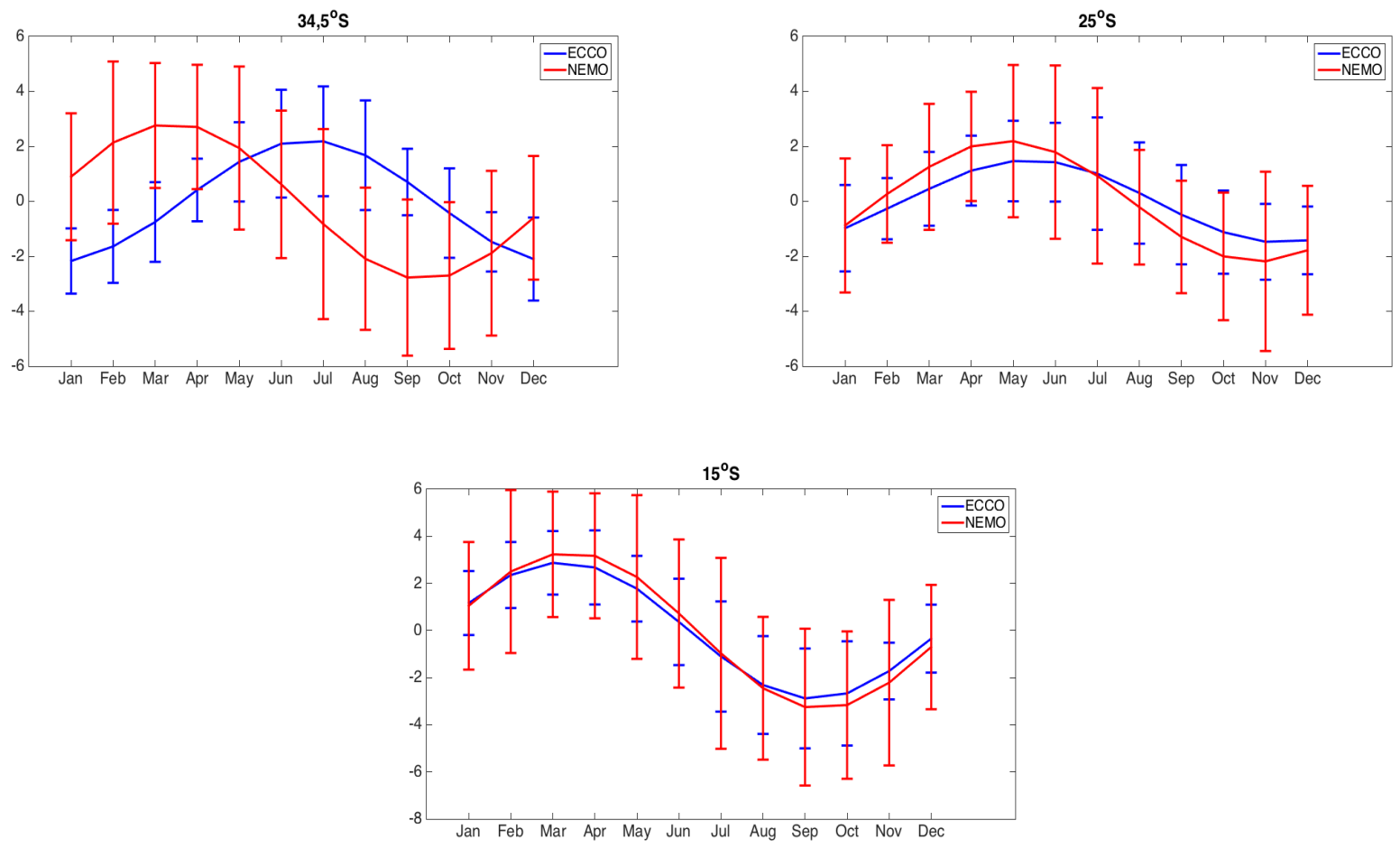

Figura 27: Ciclo anual da anomalia da MOC do Atlântico Sul em $34,5^{\circ} \mathrm{S}, 25^{\circ} \mathrm{S}$ e $15^{\circ} \mathrm{S}$

borda leste, influência da retroflexão do vazamento da Corrente das Agulhas. Devido a dinâmica das duas bordas, o ciclo anual fica defasado ao agrupar ambos os fenômenos que apresentam alta variabilidade interanual (Majumder, Schmid, and Halliwell 2016) conforme visto na Figura 27. A máxima em $34,5^{\circ} \mathrm{S}$ ocorre em Março pelo modelo NEMO e em Julho no modelo ECCO, o mínimo é observado em Setembro e Janeiro, para os modelos ECCO e NEMO, respectivamente. Em $25^{\circ} \mathrm{S}$ os dados são concordantes, com máxima em Maio e mínima em Novembro. O mesmo ocorreu em $15^{\circ} \mathrm{S}$, com ambos os modelos exprimindo o mesmo resultado: uma máxima em Março e uma mínima em Novembro.

\subsection{Aplicação do MEEMD: Clorofila, PAR e nutrientes}

Os algoritmos do Multi-dimensional Ensemble Empirical Mode Decomposition foram aplicados nas séries temporais da concentração de clorofila para cada ponto de grade na área de estudo. A componente de mais baixa frequência que corresponde à escala interanual pode ser entendida como a tendência na evolução espaço-temporal (Figura 28). Nessa figura, a media anual da concentracao de clorofila correspondente a essa componente de baixa frequência é mostrada na forma de distribuição espacial. O padrão que foi observado é que desde 1998, a concentração de clorofila apresenta uma tendência positiva ao sul de $35^{\circ} \mathrm{S}$, tendo uma tendência maior na porção oeste da bacia. Esses valores de alta tendência se distribuem pela porção leste da bacia, até chegar na região equatorial, 
Tabela 3: Tabela contendo os valores da MOC do Atlântico Sul próximo e na latitude de $34,5^{\circ} \mathrm{S}$. $T$ é o transporte de volume e $\sigma$ é o desvio padrão.

\begin{tabular}{|c|c|c|l|c|}
\hline T (Sv) & $\pm \sigma(\mathbf{S v})$ & Série temporal & Latitude & Fonte \\
\hline 18,1 & 2,3 & $2002-2011$ & $35^{\circ} \mathrm{S}$ & Garzoli et al. (2013) \\
\hline 17,9 & 2,1 & $2002-2007$ & $35^{\circ} \mathrm{S}$ & Dong et al. (2009) \\
\hline 19,45 & 3,48 & $1993-2011$ & $34,5^{\circ} \mathrm{S}$ & Dong, Goni, and Bringas $(2015)$ \\
\hline 19,2 & 3,2 & $1979-2000$ & $34,5^{\circ} \mathrm{S}$ & Dong et al. (2011) \\
\hline 18,9 & 3,6 & $1979-2002$ & $34,5^{\circ} \mathrm{S}$ & Dong et al. (2011) \\
\hline 20,66 & 4,13 & $2000-2014$ & $35^{\circ} \mathrm{S}$ & Majumder et al. (2016) \\
\hline 16,67 & 5,57 & $2000-2012$ & $35^{\circ} \mathrm{S}$ & Majumder et al. (2016) \\
\hline 15,49 & 3,08 & $2000-2008$ & $35^{\circ} \mathrm{S}$ & Majumder et al. (2016) \\
\hline 13,58 & 5,37 & $2001-2013$ & $35^{\circ} \mathrm{S}$ & Majumder et al. (2016) \\
\hline 18,46 & 4,17 & $2002-2013$ & $35^{\circ} \mathrm{S}$ & Majumder et al. (2016) \\
\hline 15,55 & 2,3 & $1992-2015$ & $34,5^{\circ} \mathrm{S}$ & Este estudo \\
\hline 19,88 & 3,5 & $1993-2015$ & $34,5^{\circ} \mathrm{S}$ & Este estudo \\
\hline
\end{tabular}

onde há uma inversão de uma tendência negativa para positiva (Figura 28). Pode-se observar que a mancha vermelha abaixo de $35^{\circ} \mathrm{S}$ tem um crescimento maior, principalmente depois de 2006, mas começa a apresentar regiões de tendência negativa após 2014. A região equatorial, por sua vez, apresenta tendência positiva nos primeiros anos, mas decai após 2004. Esse padrão segue até que se começa a transicionar entre as regiões negativas em positivas, de tal forma que a partir de 2012 há uma predominância de aumento na concentração de clorofila. Essa transição entre a região austral e equatorial se dá pela distribuição de anomalias positivas da tendência interanual na porção leste da bacia. Nessa área da bacia é observada uma transição de uma tendência negativa para uma positiva, antes de chegar no Equador.

Uma síntese geral do padrão espacial observado é o aumento da concentração de clorofila vinda ao sul de $35^{\circ} \mathrm{S}$, avançandoo pela porção leste do oceano chegando próximo à região equatorial. Para analisar as regiões no sentido das tendências positivas, três subáreas foram escolhidas ao longo desta trajetória: uma mais ao sul na porção leste (região A), uma em uma região mais central (região B) e uma na região equatorial (região C), as localizações exatas de cada região podem ser encontradas na Tabela 4.

Tabela 4: Regiões escolhidas para análise da clorofila

\begin{tabular}{|c|c|c|}
\hline Região & Latitude & Longitude \\
\hline A & $35^{\circ} \mathrm{S}-25^{\circ} \mathrm{S}$ & $0-10^{\circ} \mathrm{E}$ \\
\hline $\mathrm{B}$ & $25^{\circ} \mathrm{S}-15^{\circ} \mathrm{S}$ & $0-10^{\circ} \mathrm{W}$ \\
\hline $\mathrm{C}$ & $10^{\circ} \mathrm{S}-0$ & $10^{\circ} \mathrm{W}-20^{\circ} \mathrm{W}$ \\
\hline
\end{tabular}

Na Figura 29, temos um esquema contendo a direção da "mancha"de tendência positiva, junto com as regiões $\mathrm{A}, \mathrm{B}$ e $\mathrm{C}$ que foram analisadas. As linhas vermelhas são os transectos que foram calculados o fluxo de volume da MOC no Atlântico Sul (discutido 

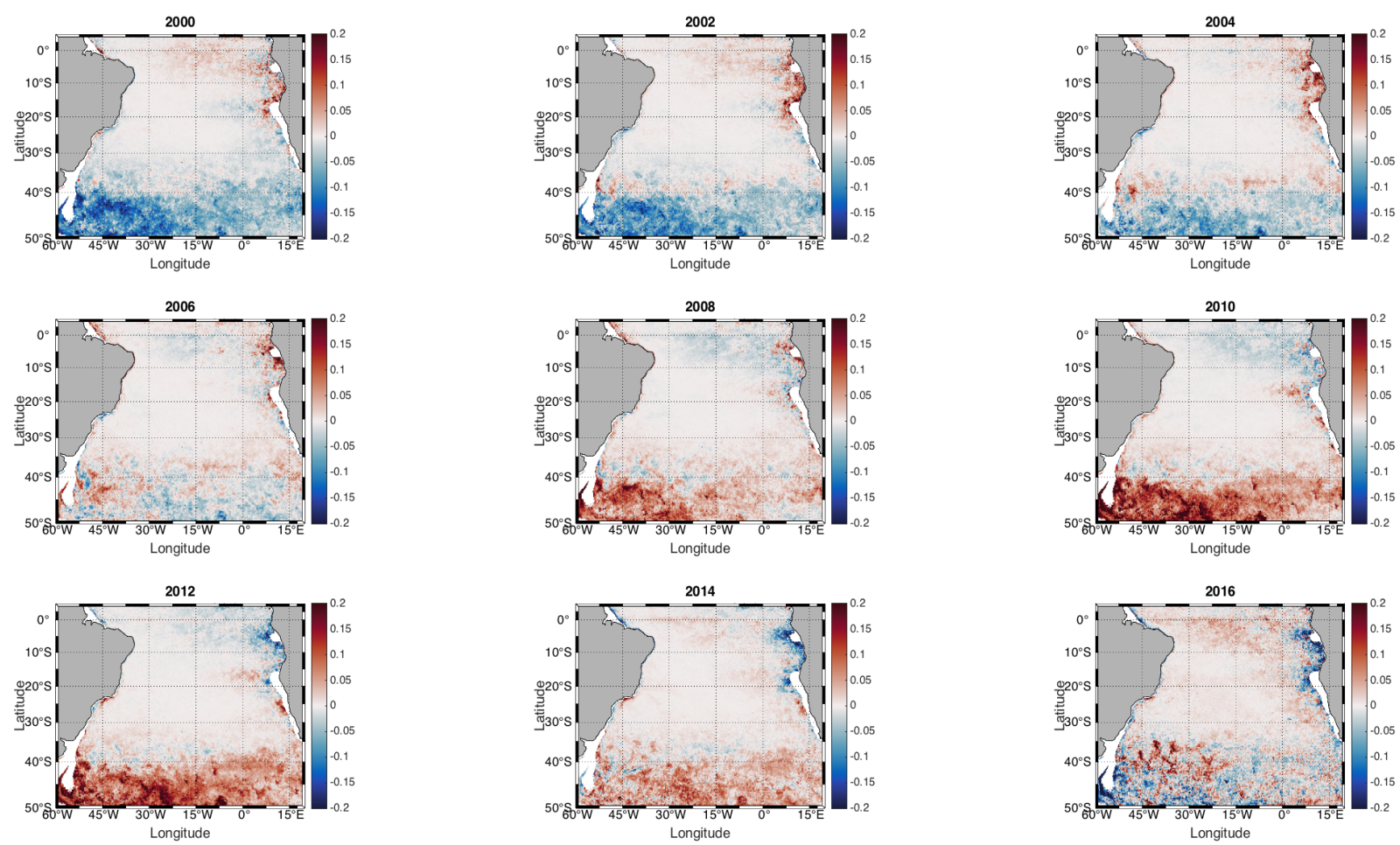

Figura 28: Média anual da componente de mais baixa frequência obtida pela aplicação do método MEEMD na concentração de clorofila $\left(\mathrm{mg} / \mathrm{m}^{3}\right)$. Os valores em branco correspondem a valores com média de concentração de clorofila maior que $0,79 \mathrm{mg} / \mathrm{m}^{3}$

posteriormente nesse estudo).

\subsubsection{Regiões A, B e C}

Os dados de clorofila foram submetidos à análise do MEEMD e suas tendências analisadas dentro das regiões A, B e C. Como duas das principais variáveis abióticas que controlam o crescimento do fitoplâncton são nutrientes e luz, o nitrato integrado (nutriente) e o PAR (luz) também tiveram suas séries temporais analisadas.

A região A (Figuras 30 mostrou um crescimento em escala interanual da concentração de clorofila desde 1998 até um máximo em 2014 com uma leve queda nos anos seguintes. O nitrato integrado, por sua vez, também mostrou um padrão de aumento desde 1998, com uma diminuição na taxa de crescimento desde 2008/2009. O PAR se manteve estável com uma leve oscilação entre os anos de 1998 a 2011, seguido de um decaimento até o final da série. Na região B (Figuras 31) a função da concentração de clorofila para o período é monotônica crescente, o nitrato, por sua vez, apresenta uma curva que cresce desde 1998 com o máximo entre 2010/2011 e a subsequente queda até 2017. O PAR, análogo ao nitrato, aumenta desde 1998 com um pico próximo de 2009 e uma rápida queda até o final da série temporal. Por fim, a região C (Figuras 32) apresenta curvas de clorofila e nitrato integrado de maneira similar, onde a série se mantém estável e cresce monotonicamente até o final do período de estudo. $\mathrm{O}$ ano a partir de quando ocorre 


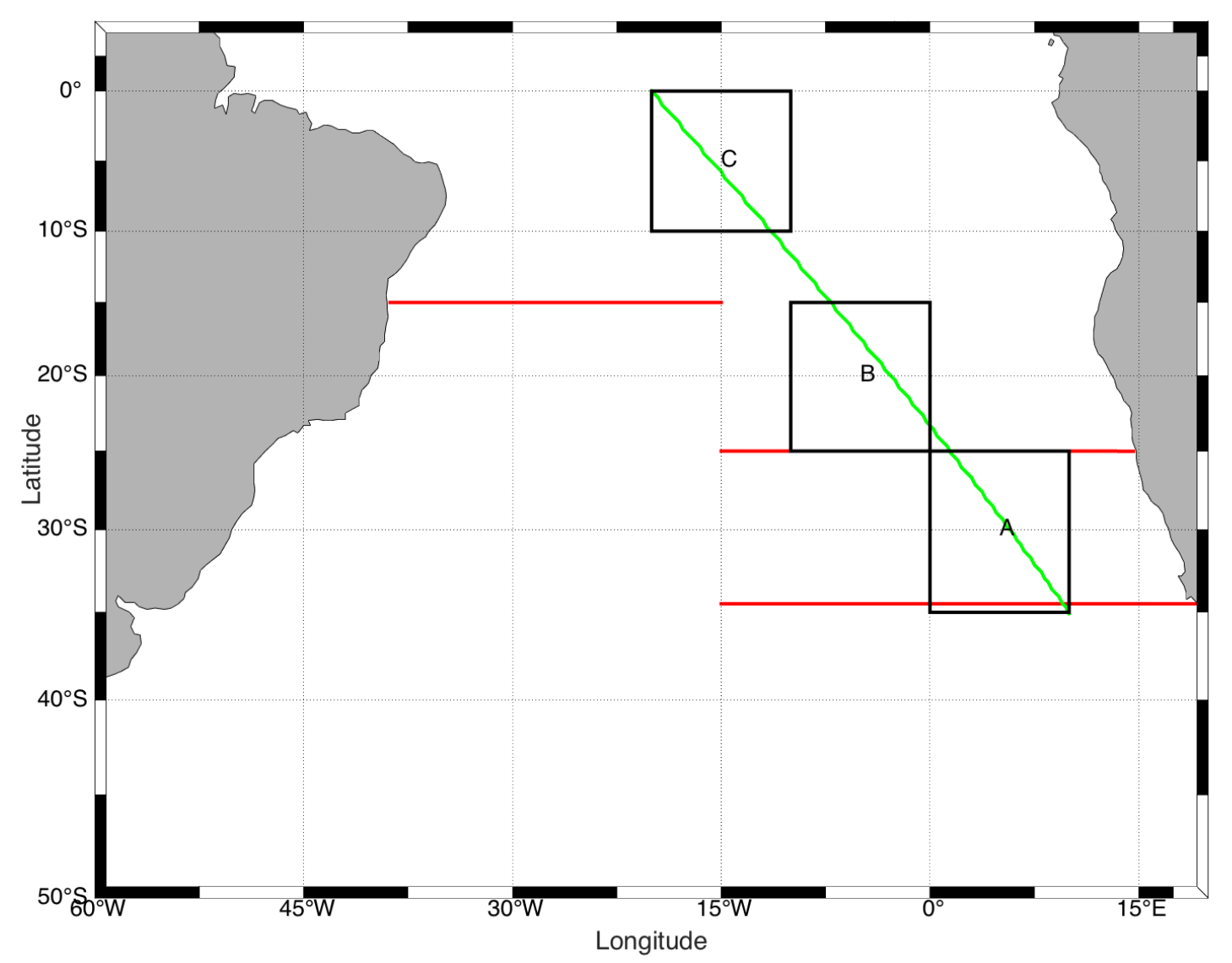

Figura 29: Mapa esquemático contendo as regiões A, B e C (retângulos pretos), a direção da tendência positiva (linha verde) e os transectos utilizados para calcular o fluxo de volume da MOC do Atlântico Sul 

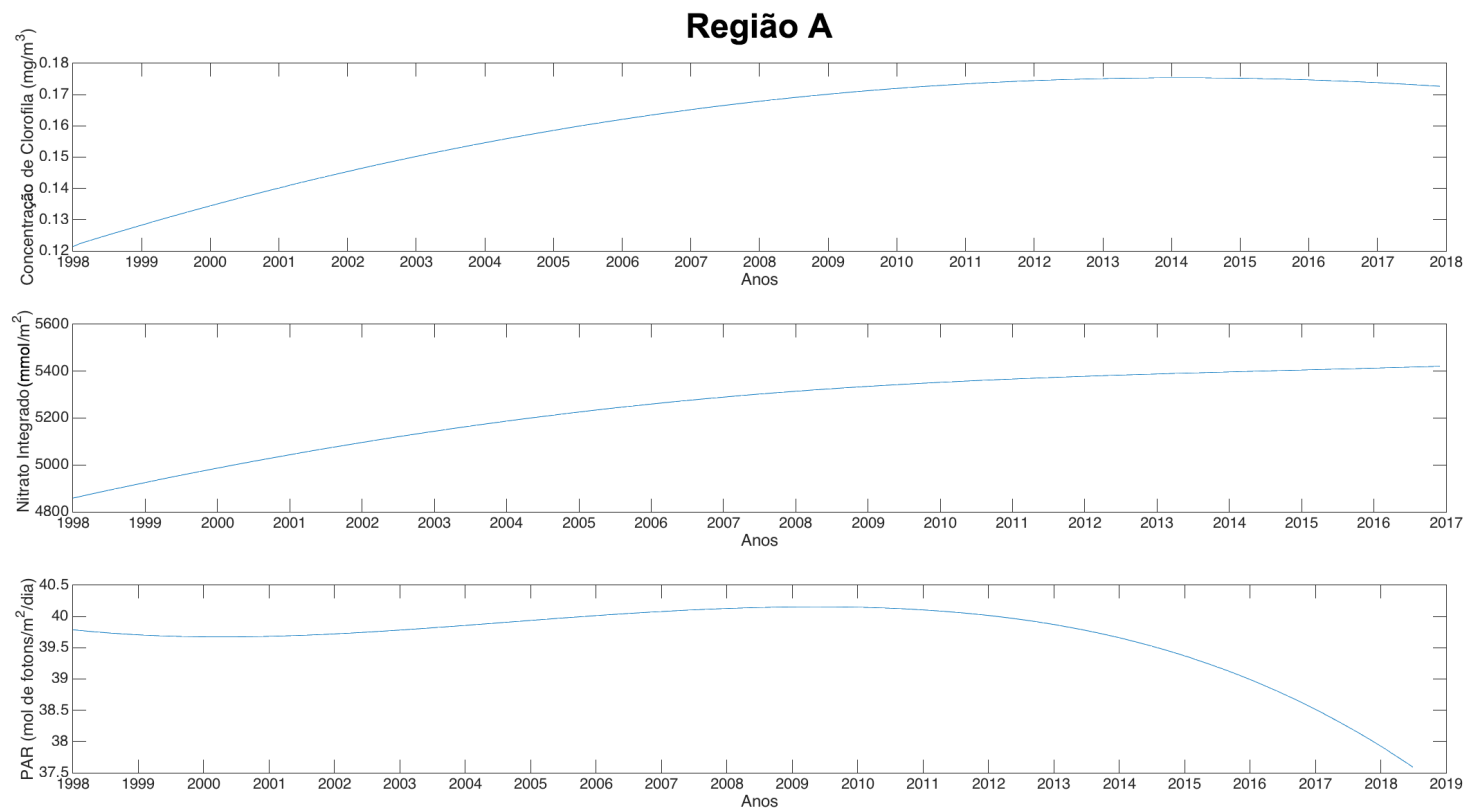

Figura 30: Séries temporais da tendência interanual da concentração de clorofila (painel superior), nitrato integrado (painel do meio) e PAR (painel inferior) da região A

o crescimento foi diferente em cada variável: para a clorofila o crescimento começa após 2006 e, no nitrato integrado, após 2005. O PAR seguiu um padrão de crescimento seguido de decaimento, com um pico central no ano de 2009.

\subsubsection{Nutrientes ou luz?}

Como citado anteriormente, duas das principais variáveis abióticas que controlam o fitoplâncton são luz e nutrientes, sendo aqui representadas pelo PAR e pelo nitrato integrado, respectivamente. Ao aplicar o MEEMD na série temporal da clorofila e observar seu padrão espaço-temporal que nos levou à escolha das regiões $\mathrm{A}, \mathrm{B}$ e C, e analisar os padrões de cada variável. Os padrões observados das curvas do PAR não respondiam ao que era observado na clorofila. Como exemplo podemos citar a região C: a clorofila segue um aumento contínuo a partir de 2006, enquanto que o nitrato integrado acompanha esse mesmo padrão, porém um ano antes, em 2005. O PAR, por sua vez, também segue um aumento antes de 2006, crescendo a partir de 2001, entretanto esse valor decai a partir de 2009/2010. Na região A, a clorofila tem o começo de seu decaimento no final da série com uma queda sutil até o final da mesma, próximo a 2015. O PAR da mesma região começa a decair já em 2010 com uma taxa de decaimento alta comparada com a da clorofila após 2011. Observa-se então que enquanto a clorofila acompanha ao aumento do nitrato, a mesma não segue o padrão do PAR, logo concluímos que os padrões de clorofila em escala interanual nas três localidades são controlados pelos nutrientes e não a luz.

Outro ponto a se levar em conta é a variação espacial do sinal de tendências positivas 

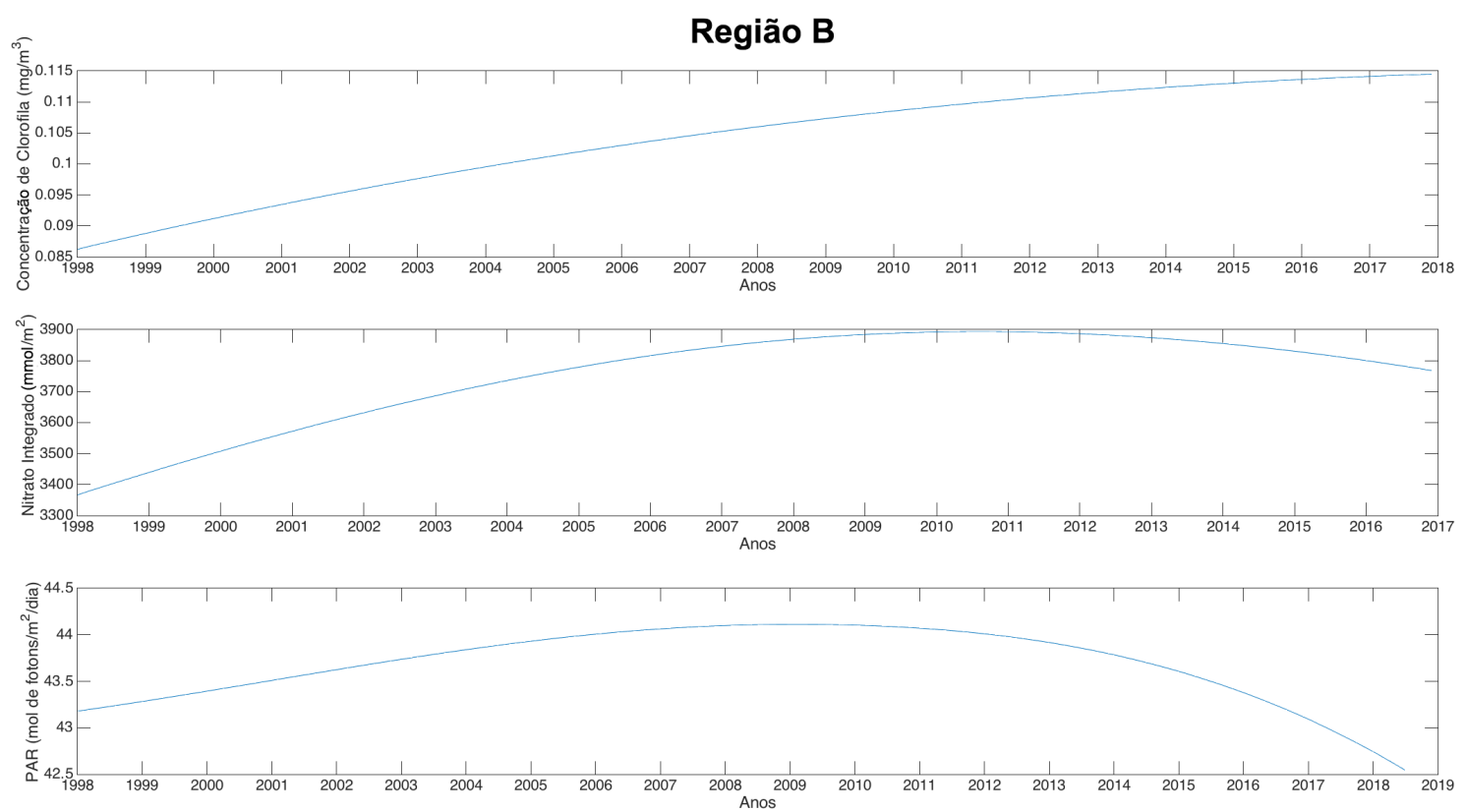

Figura 31: Similar à Figura 30 mas para a região B
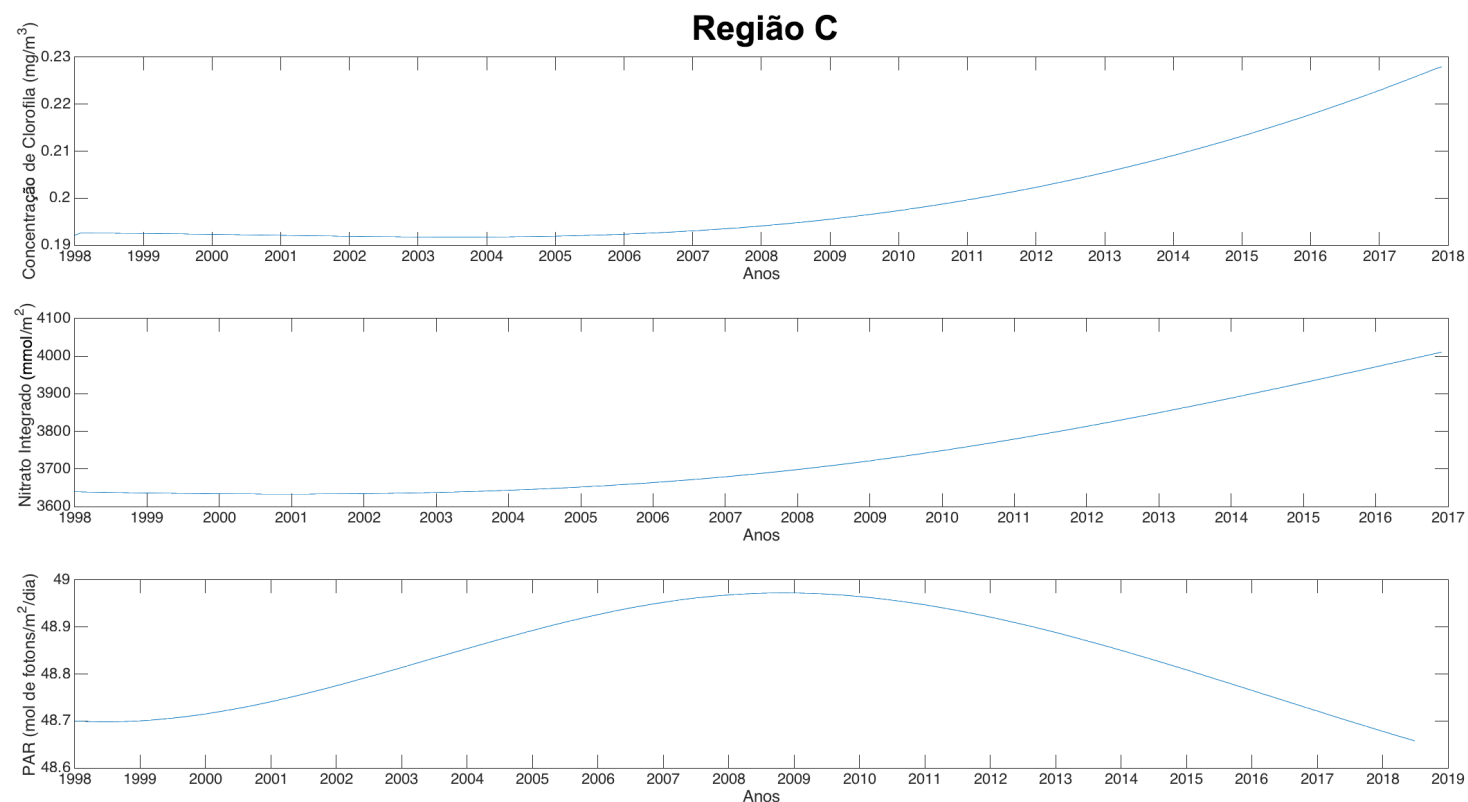

Figura 32: Similar à Figura 30 mas para a região C 
Tabela 5: Variância relativa (em porcentagem) da componente da tendência decacal em relação à variância total do PAR e do Nitrato integrado, por região.

\begin{tabular}{|l|c|c|}
\cline { 2 - 3 } \multicolumn{1}{c|}{} & PAR (mol de fótons $\left./ \mathrm{m}^{2} / \mathrm{dia}\right)$ & Nitrato Integrado $\left(\mathrm{mmol} / \mathrm{m}^{2}\right)$ \\
\hline Região A & 0,04 & 85,5 \\
\hline Região B & 0,11 & 76,0 \\
\hline Região C & 0,12 & 76,3 \\
\hline
\end{tabular}

na concentração de clorofila (Figuras 28), enquanto temos uma variação espacial da região sul, indo pelo leste da bacia sentido ao equador, nos dados de PAR há um máximo em todas as regiões centrado entre 2009/2010 (Figuras 30, 31, e 32). Tal fenômeno não explicaria essa variação espaço-temporal uma vez que o máximo do PAR ocorre de maneira uniforme na bacia como um todo. Pode-se excluir o PAR como variável principal de controle neste cenário, uma vez que na região subtropical e tropical onde se encontram as regiões A,B e C (dentro da província SATL) a luz não é um fator limitante, diferente, por exemplo de regiões polares (Longhurst 2007a; Mitchell et al. 1991).

O PAR também pode ser descartado como variável que controla essa variabilidade através de análise de escala. As Figuras 33 e 34 mostram a série temporal do nitrato integrado e do PAR com suas respectivas tendências interanuais pelo EEMD da região A. Podemos perceber que a tendência do PAR apresenta baixa variabilidade ao longo da série temporal quando comparado com tendência do nitrato integrado. Para determinarmos a contribuição relativa da tendência interanual para a variação total da série temporal, calculamos a variância de cada uma das séries e estimamos a razão entre as mesmas. A contribuição relativa é expressa em porcentagem na Tabela 5. A contribuição da tendência do PAR se mostrou duas ordens de grandeza menor do que quando comparado a variância explicada pela tendência interanual no nitrato integrado, assim o PAR pode ser desprezado através dessa análise de escala.

\subsubsection{Nitrato integrado e concentração de clorofila: Regiões A e B}

O padrão do nitrato integrado com a clorofila foi análogo ao que se observou em relação aos ciclos anuais destas variáveis. Quando em escalas sazonais há um aumento de nitrato integrado, se observa um aumento seguido da clorofila (17) e 20). De maneira similar, um aumento do nitrato integrado em escalas de baixa frequência faz com que se tenha um aumento da clorofila na mesma escala.

Na região A ambas variáveis mostraram uma curva semelhante, com um crescimento contínuo (Figura 30). A clorofila teve uma leve queda no final da série, enquanto o nitrato continua a crescer com uma diminuição na taxa de seu crescimento. O porque desta queda é difícil de explicar pois a influência de outras variáveis não podem ser descartadas do oceano. Como a concentração de nitrato foi integrado na coluna d'água seu valor é representativo de um somatório, desta maneira a diminuição das taxas de crescimento 


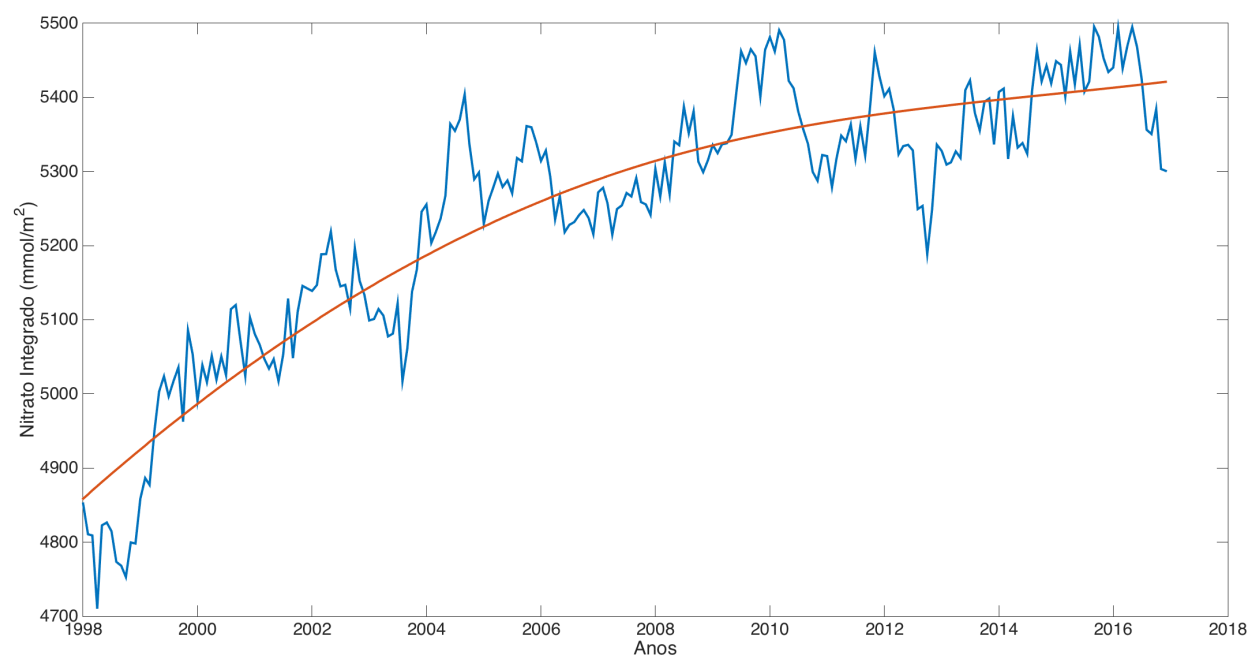

Figura 33: Série temporal do nitrato integrado na região A (azul) com sua tendência interanual (vermelho).

do nitrato integrado observado nos últimos anos pode ser sinal de uma alta utilização de nutrientes na zona fótica sem a mesma taxa de reposição observada em períodos anteriores e que pode ter induzido uma queda na concentração de clorofila em escalas interanuais. Tal hipótese explicaria o máximo da concentração de clorofila nessa escala: a clorofila pode ter continuado a utilizar o nitrato disponível e a medida que este começou a reduzir na zona fótica, a concentração de clorofila diminuiu. Por outro lado, a queda pode também ser influência de alguma variável biótica, um possível grazing por parte dos zooplânctons pode ter alterado a concentração da clorofila na porção final da série temporal, a ponto que o balanço da concentração começou a ser negativo. As curvas, entretanto, seguiram o mesmo padrão de aumento de concentração de clorofila observado em escalas sazonais na região tropical/subtropical; um aumento na concentração de nutrientes leva a um aumento na concentração de clorofila. O que é esperado uma vez que o nitrato é limitante nessa região (Bristow et al. 2017; Longhurst 2007d).

A região B mostra também uma relação de aumento do nitrato integrado levando a um aumento na concentração de clorofila, ambos crescem desde 1998. O nitrato integrado alcança um valor máximo próximo de 2011/2012 enquanto que a clorofila no final da série aparenta se estabilizar principalmente nos dois últimos anos (2016/2017). Sob a hipótese que o nitrato controla o crescimento do fitoplâncton temos que a subsequente queda pós-2011 começa a ter efeito na concentração de clorofila que aparenta a chegar em um possível máximo. É esperado então que se o nitrato integrado continuar com o padrão de queda, nos anos seguintes a concentração de clorofila diminuirá na região B.

Podemos perguntar: Como pode a região B mostrar uma queda no nitrato integrado e o efeito na clorofila, enquanto que na região A a queda na clorofila não aconteceu após o decaimento do nitrato? Isso pode estar provavelmente relacionado ao fato de integrarmos 


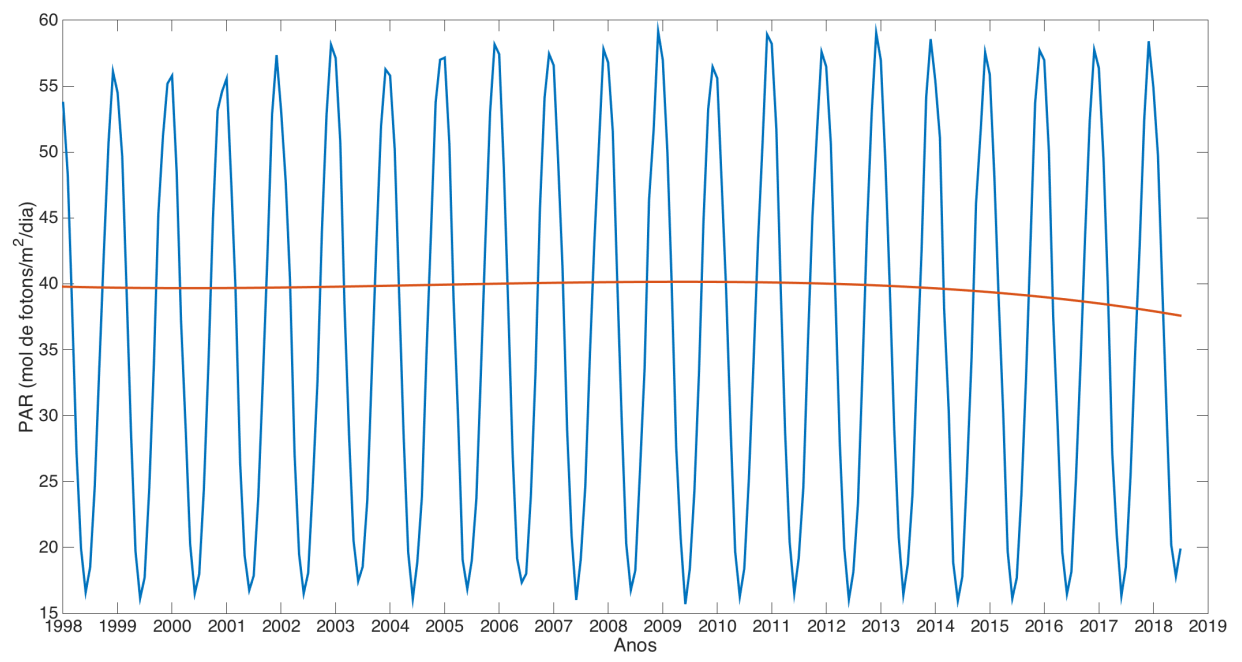

Figura 34: Similar à Figura 33 mas para o PAR.

a concentração de nitrato na coluna d'água gerando algo análogo a um somatório desta concentração. A região A se encontra em uma área com maior concentração de nitrato integrado na média climatológica do que na região B (Figura 21). Assim ao diminuir o nitrato na camada fótica, a região A por receber em níveis intermediários altas concentrações de nitrato oriundas de águas subantárticas fazem com que o nitrato integrado continue aumentando, porém com uma taxa menor uma vez que a concentração como um todo diminuiu devido a influência do fitoplâncton na zona eufótica. Já a região B contempla em seu domínio (mas não só) a extremidade sudeste da área oligotrófica do giro subtropical (Figura 21). Assim uma mudança na concentração de nitrato na zona fótica já tem um efeito maior na média e assim é possível observar a queda.

Como observado na Figura 28 vemos que a distribuição da "mancha" de alta tendência é para noroeste na porção leste da bacia. Sendo assim, enquanto que na região A curva de nitrato tem sua taxa de crescimento modificada próximo aos anos de 2008 a 2009, a queda na região B é observada após 2011, evidenciando uma possível propagação do nitrato. De maneira análoga, com uma mudança em 2008 no nitrato integrado há o começo da queda da concentração de clorofila após 2014, extrapolando para a região B, pode-se esperar então uma possível queda após 2017. Esse padrão é esperado conforme a Figura 31 que aparenta uma estabilização da curva no final da série em 2017.

\subsubsection{Nitrato integrado e concentração de clorofila: Região C}

A região $\mathrm{C}$ também tem as curvas de nitrato integrado e concentração de clorofila correlatas: primeiro há um aumento no nutriente após 2004/2005 e um aumento na concentração de clorofila após 2006/2007. Antes destes anos a curva se mantém estável nos menores valores da série. Como não há nenhum sinal de queda de nitrato integrado não há qualquer 

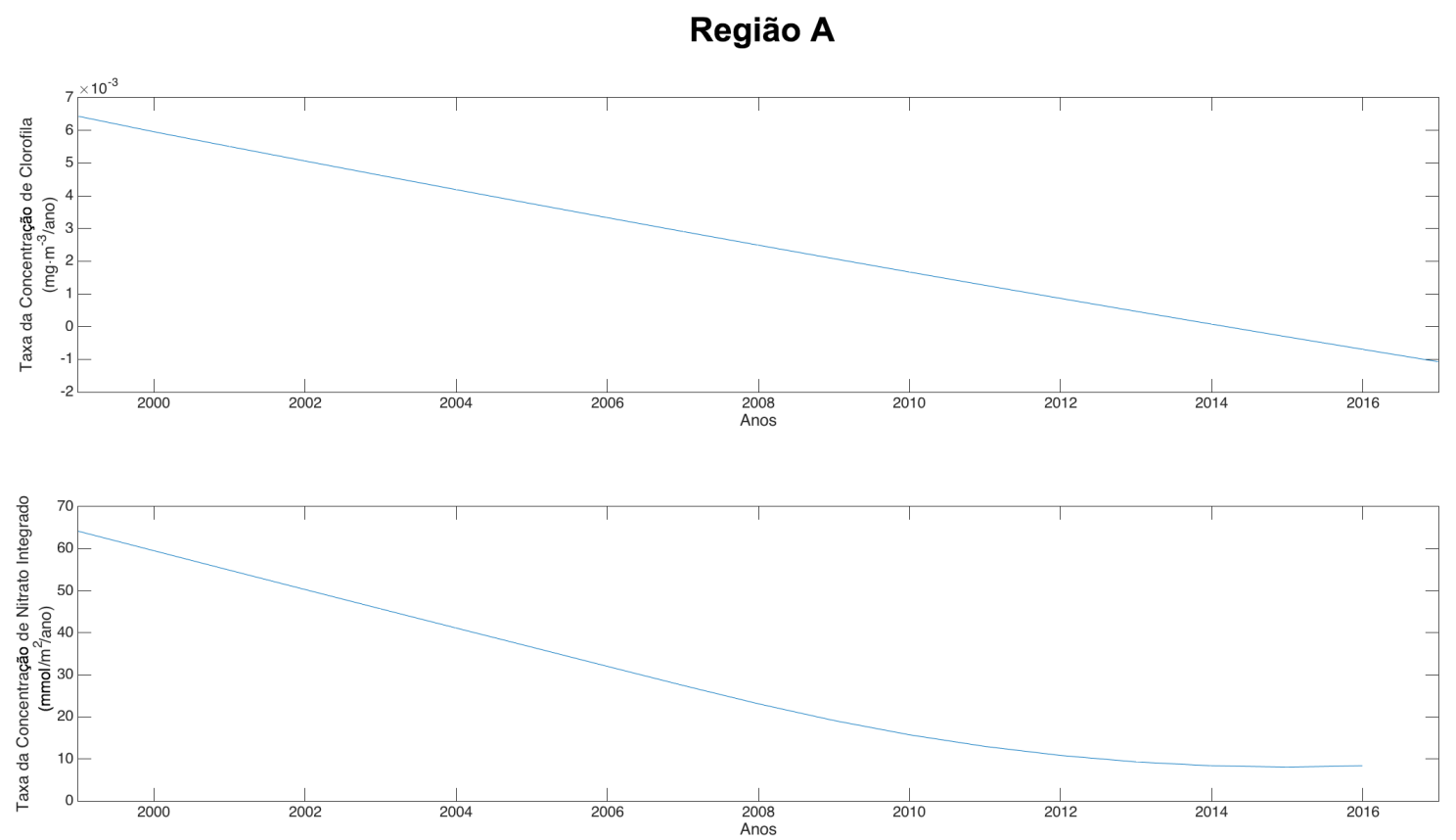

Figura 35: Taxa de variação temporal da tendência interanual da clorofila (painel superior) e do nitrato integrado (painel inferior) para a região A

previsão de queda para a concentração de clorofila.

A região $\mathrm{C}$ tem a peculiaridade de mostrar uma nítida tendência de aumento chegando no sistema, diferente das regiões $\mathrm{A}$ e $\mathrm{B}$, onde há um aumento desde o início da série. Fazendo uma especulação, temos então pela Figura 32 que do início do nitrato integrado começar a aumentar vemos uma defasagem de 2 a 4 anos para o crescimento da clorofila, enquanto pela Figura 30 existe uma defasagem próxima de 7 anos entre a queda do nitrato integrado e a queda da concentração de clorofila. Desta maneira, sendo observada a influência no nitrato integrado na curva de concentração de clorofila podemos colocá-lo como variável controle nesta escala de tendência espaço-temporal.

\subsubsection{Taxa de variação temporal}

Para corroborar o que foi discutido nesta seção as taxas de variação temporal das tendências interanuais de nitrato e clorofila foram calculadas (Figuras 35, 36 e 37). Podemos perceber nestas figuras que as taxas do nitrato integrado e clorofila também apresentam o mesmo padrão e coincidem com os anos de mudança na curva descritos acima. Na região A (Figura 35) a taxa do nitrato integrado após o ano de 2009 tem um decaimento mais sutil se estabilizando próximo de uma taxa de $10 \mathrm{mg} \cdot \mathrm{m}^{-3} /$ ano. A taxa de variação da clorofila acompanha esse decaimento e muda o sinal da sua taxa positiva em 2014. Essa figura evidencia a mudança na curva do nitrato integrado da Figura 30 entre os anos 2008 a 2009. Também mostra que por mais que ocorra uma queda no nitrato pelo seu consumo na zona eufótica, por ser integrado estamos observando um valor de um somatório para 

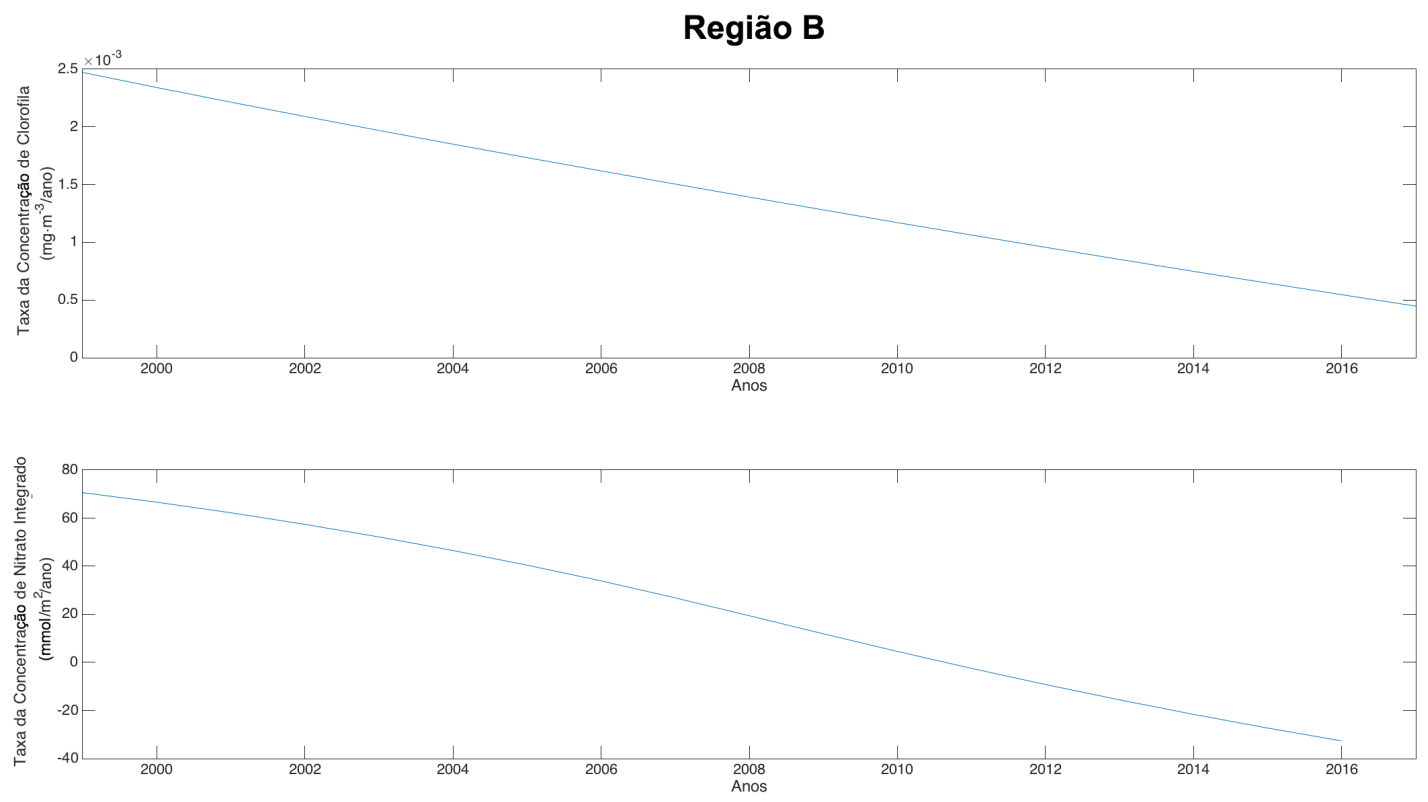

Figura 36: Similar à Figura 35 mas para a região B.
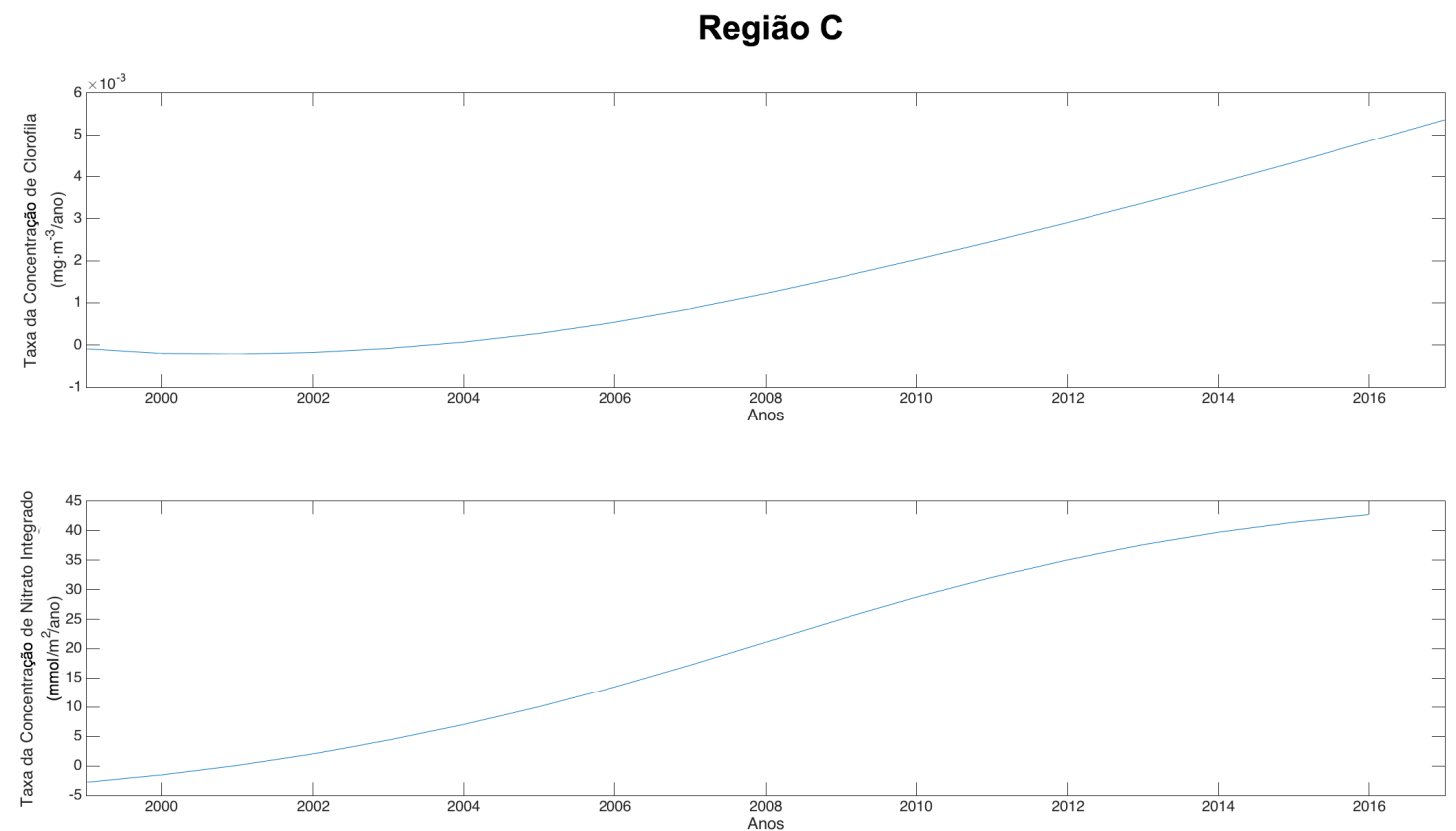

Figura 37: Similar à Figura 35 mas para a região C. 

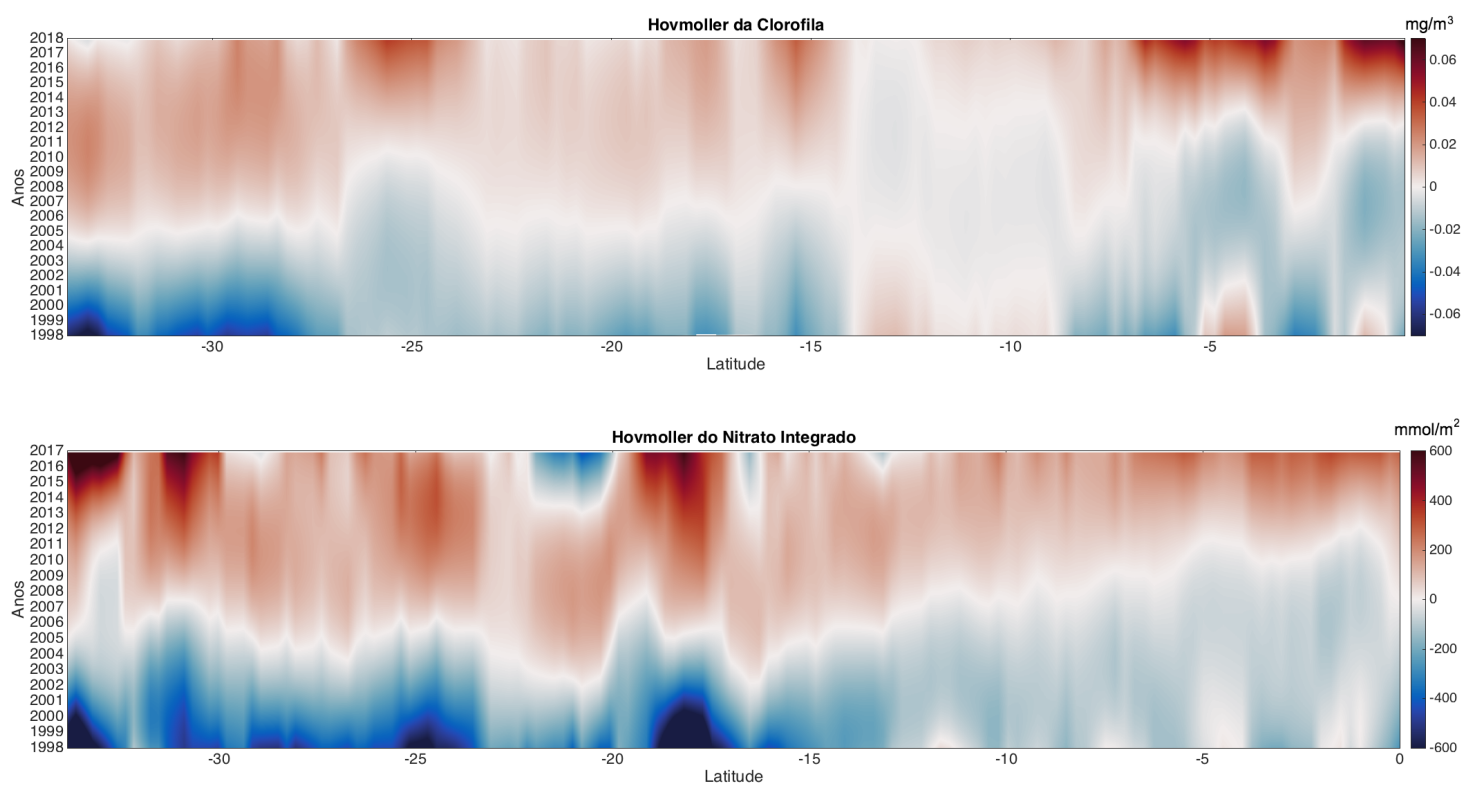

Figura 38: Hovmoller da anomalia da tendência interanual da concentração de clorofila e nitrato integrado. A latitude é referência do transecto verde da Figura 29. Uma média móvel de $1,25^{\circ}$ foi aplicada para remover qualquer ruído presente.

a coluna e não necessariamente este valor fica negativo, uma vez que em camadas mais profundas dentro do limite de integração há uma grande concentração de nitrato.

De maneira análoga, a taxa da tendência da região B (Figura 36) segue o mesmo padrão que da região A (Figura 35), isto é, em ambos o nitrato integrado e a clorofila apresentam uma diminuição de suas taxas. Esse fato mostra que existe mais uma evidência que corrobora que o nitrato é a variável que controla a variação da concentração da clorofila nesta escala. A mudança de sinal da taxa do nitrato integrado na região B ocorre em 2011. Assim, semelhante ao que foi observado entre as Figuras 30 e 31, há uma evidência na propagação do nitrato integrado que teve sua taxa variando em 2009 (Figura 35) e começa a decair em 2011 apenas na região B. Também conseguimos ver que a previsão de queda da clorofila na região B após 2017 é muito provável, uma vez que a taxa está evidenciando uma diminuição ao longo da série temporal.

Por fim, a região C (Figura 37), também é um indício que nitrato é a variável que lidera a variabilidade por mostrar que o aumento na taxa de nitrato integrado leva posteriormente a um aumento na taxa da concentração de clorofila. A clorofila tem uma taxa com pouca variação até 2003, quando apresenta um crescimento até o final da série. O nitrato integrado, apresenta uma taxa monotonicamente crescente, alternando de valor entre 2000 e 2002 . Com a variação das taxas vemos que é consistente o observado nas curvas de tendência interanual da região C (Figura 32) que também mostram uma curva estável no começo da série e um crescimento monotônico. Pelas análise das curvas de tendência interanual foi especulado uma defasagem de 2 a 4 anos. Pelas figuras de taxa da tendência interanual da região C (Figura 37) a taxa do nitrato fica positiva próximo de 
2001 enquanto que a da clorofila se torna positiva após 2003, existindo então uma defasagem de 2 anos. Assim as taxas corroboraram as previsões estimadas entre a relação de tempo entre o aumento (diminuição) do nitrato integrado com o aumento (diminuição) da clorofila. Também pelas taxas foi evidenciado o controle da variável nitrato integrado e de sua propagação.

Para certificar da propagação do nitrato integrado, um diagrama espaço-temporal também conhecido como diagrama de Hovmöller, foi construído para representar a tendência do nitrato integrado. Os Hovmöllers do nitrato integrado e da concentração de clorofila foram delimitado espacialmente pela linha que acompanha a tendência positiva (linha verde) na Figura 29 e ambos se encontram na Figura 38.

Analisando os hovmollers conseguimos ver uma propagação do nitrato saindo de $35^{\circ} \mathrm{S}$ e chegando no Equador. Entretanto, o nitrato integrado não apresenta propagação significativa nas latitudes entre $35^{\circ} \mathrm{S}$ a $20^{\circ} \mathrm{S}$. A explicação é pelo nitrato integrado corresponder a uma média da coluna dentro dos limites de integração. Entre $35^{\circ} \mathrm{S}$ a $20^{\circ} \mathrm{S}$ na porção leste a média do nitrato integrado é alta (Figura 21) recebendo águas com altas concentração de nitrato de origem antártica. Logo, essa região é representativa da variabilidade de nitrato que chega da Água Modal Subantártica. Pela Figura 28 vemos que há uma alteração próximo a região antártica de uma anomalia negativa para positiva no tempo, sinal que há um aumento da clorofila por nitrato. Este fenômeno é observado na porção mais austral do Hovmöller do nitrato integrado que passa por uma mudança de um regime de anomalia negativa para positiva.

O fato do nitrato integrado ser uma média da coluna também explica o porque do Hovmöller do nitrato não coincidir os períodos de anomalia positiva no Hovmöller da anomalia da tendência interanual da concentração de clorofila. Uma anomalia negativa de nitrato integrado não implica que não está chegando nitrato na camada fótica, mas sim que a coluna integrada está abaixo da média da série temporal. Se profundidades em subsuperfície tiverem alta concentração de nitrato, a concentração de nitrato na camada fótica não é significativa na coluna integrada. Além do mais, pelas curvas de tendência (Figuras 30 , 31 e 32) e curvas de taxas destas tendências (Figuras 35, 36 e 37) observamos a resposta na concentração de clorofila, sendo que o Hovmöller da mesma acompanha o padrão de propagação do nitrato integrado. Portanto, a clorofila é relacionada com a propagação do nitrato, mas esta não se propaga. Isto porque a clorofila tem um crescimento local devido ao aporte de nutriente disponível na camada fótica. Isso fica evidente na região próximo de $10^{\circ} \mathrm{S}$ no Hovmöller da clorofila (Figura 38 ), em que há a propagação de anomalia positiva do nitrato integrado mas a clorofila não o acompanha. Esta região é uma região mais estratificada, onde a média da concentração de clorofila (Figura 15) é menor do que as outras do transecto do Hovmöller. Isto leva a crer que há algum mecanismo físico por trás desta propagação. Na próxima seção isto será discutido mais a fundo. Fica digno de nota que pelo Hovmöller da concentração de clorofila, conseguimos rastrear a região de 
transição de tendência negativa para positiva. Próximo a $35^{\circ} \mathrm{S}$ vemos uma transição próximo de 2004 , enquanto que ao norte de $5^{\circ} \mathrm{S}$ essa zona de transição se encontra próximo de 2011. Desta maneira, leva em torno de 7 anos para esse sinal de tendência prositiva na clorofila sair de $35^{\circ} \mathrm{S}$ e chegar próximo ao equador. Castellanos et al. (2017) analisaram perturbações no vazamento das Agulhas, e perceberam que uma perturbação em 1997 saindo próximo de $35^{\circ} \mathrm{S}$ se propagou até $5^{\circ}$ chegando próximo de 2003 , levando 6 anos. Esse valor próximo também é um indício que esse sistema nitrato integrado-concentração de clorofila sofra influência de um transporte de circulação de larga escala.

\subsection{A relação do nitrato integrado com a MOC do Atlântico Sul}

Seguindo Sarmiento et al. (2004) e Palter et al. (2010), a Meridional Overturning Circulation (MOC) tem um papel fundamental em fomentar a concentração de clorofila nas regiões tropicais na faixa latitudinal entre $30^{\circ} \mathrm{N}-30^{\circ} \mathrm{S}$, sendo responsável de $33 \%$ a $75 \%$ da produção tropical global. Este controle ocorre devido a MOC transportar a Água Modal Subantártica (SAMW) rica em nutrientes para norte. Através da interação com as regiões de ressurgências na porção leste das bacias oceânicas, esse nutriente presente na SAMW consegue ser transportado em subsuperfície para a zona fótica (Palter et al. 2010) (ver Introdução). Uma vez em superfície esse nutriente é assimilado pelo fitoplâncton. A medida que esses organismos morrem, ocorre o processo de remineralização e o nutriente fica disponível mais uma vez na coluna d'água em densidades menores e profundidades mais rasas do que a Água Modal Subantártica afunda (Toggweiler 1995; Williams, Roussenov, and Follows 2006). Assim, mesmo após a água modal ter advectado o nutriente, com a remineralização este nutriente continua disponível recirculando no giro subtropical e contribuindo para uma produtividade primária regenerada (Palter et al. 2010). Isto foi observado analisando a tendência oriunda da aplicação do MEEMD no centro do giro subtropical. Por ser a região com maior estratificação do Atlântico Sul, apresenta uma barreira física para os nutrientes presentes na SAMW chegarem na zona eufótica. Entretanto, ao observarmos os sinais de aumento de tendência na porção leste (Figura 28) depreendemos um aumento na concentração de clorofila na região do giro subtropical (Figura 39 . Logo, isto confirma uma possível prova da recirculação do nitrato após a remineralização, em concordância com Toggweiler and Samuels (1995), Williams, Roussenov, and Follows (2006) e Palter et al. (2010).

Baseado nas análises apresentadas e tendo em vista que os resultados concordam com estudos pretéritos já mencionados, a nossa hipótese é que em escalas interanuais a MOC é responsável pelo transporte meridional do nitrato no Atlântico Sul e por conseguinte, da concentração de clorofila. Para testarmos essa hipótese foi calculado a contribuição do transporte de volume da MOC na porção leste da bacia do Atlântico Sul (ver Material e Métodos) assumindo que as regiões de ressurgências mais persistentes alimentam o fluxo 

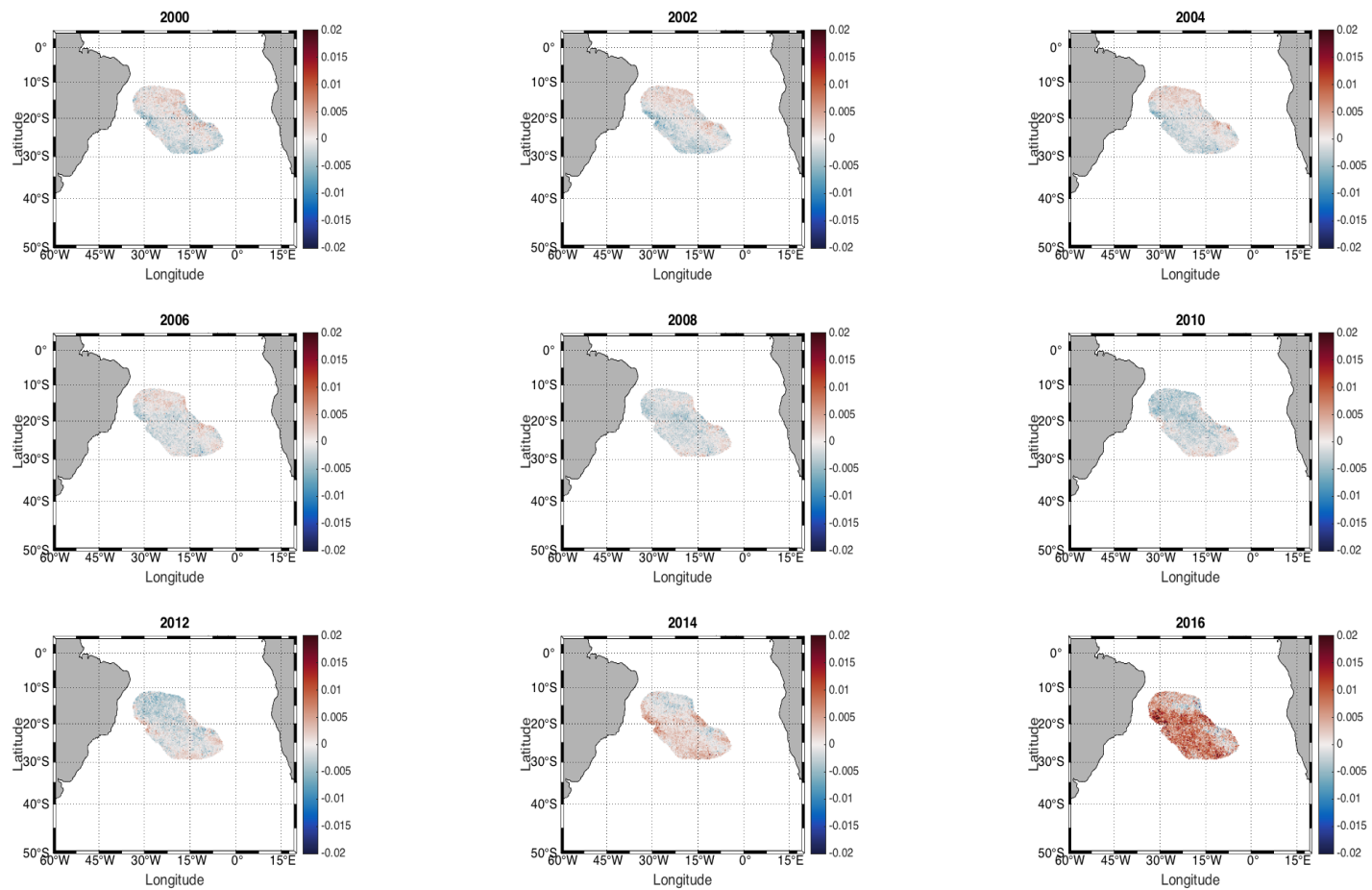

Figura 39: MEEMD da clorofila aplicado a região do giro subtropical do Atlântico Sul. As regiões em branco são valores de clorofila maior que $0,05 \mathrm{mg} / \mathrm{m}^{3}$

\section{ECCO}
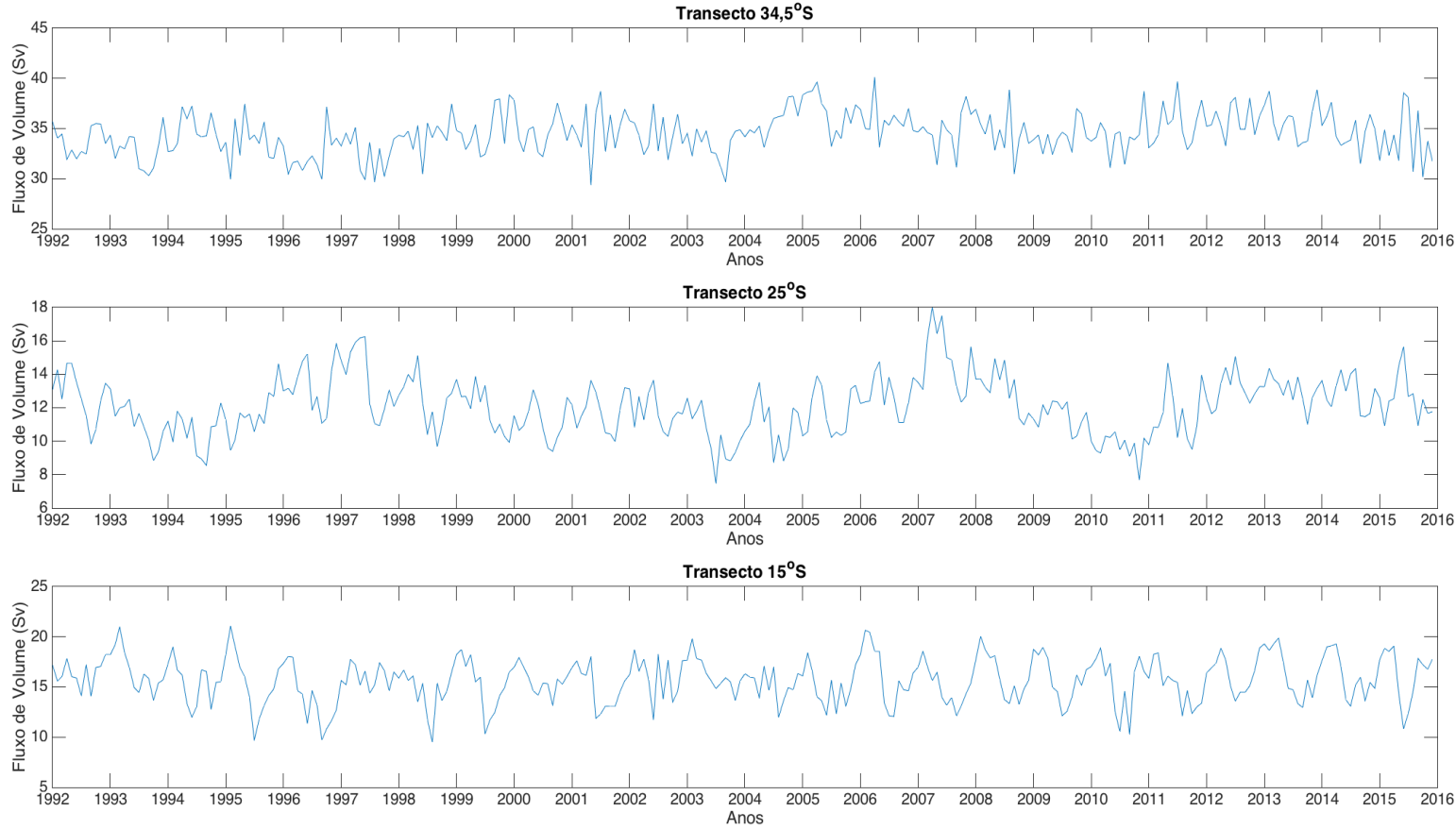

Figura 40: Série temporal da MOC do Atlântico Sul nas respectivas latitudes entre os anos de 1993 a 2015. Dados são do modelo ECCO. 


\section{NEMO}
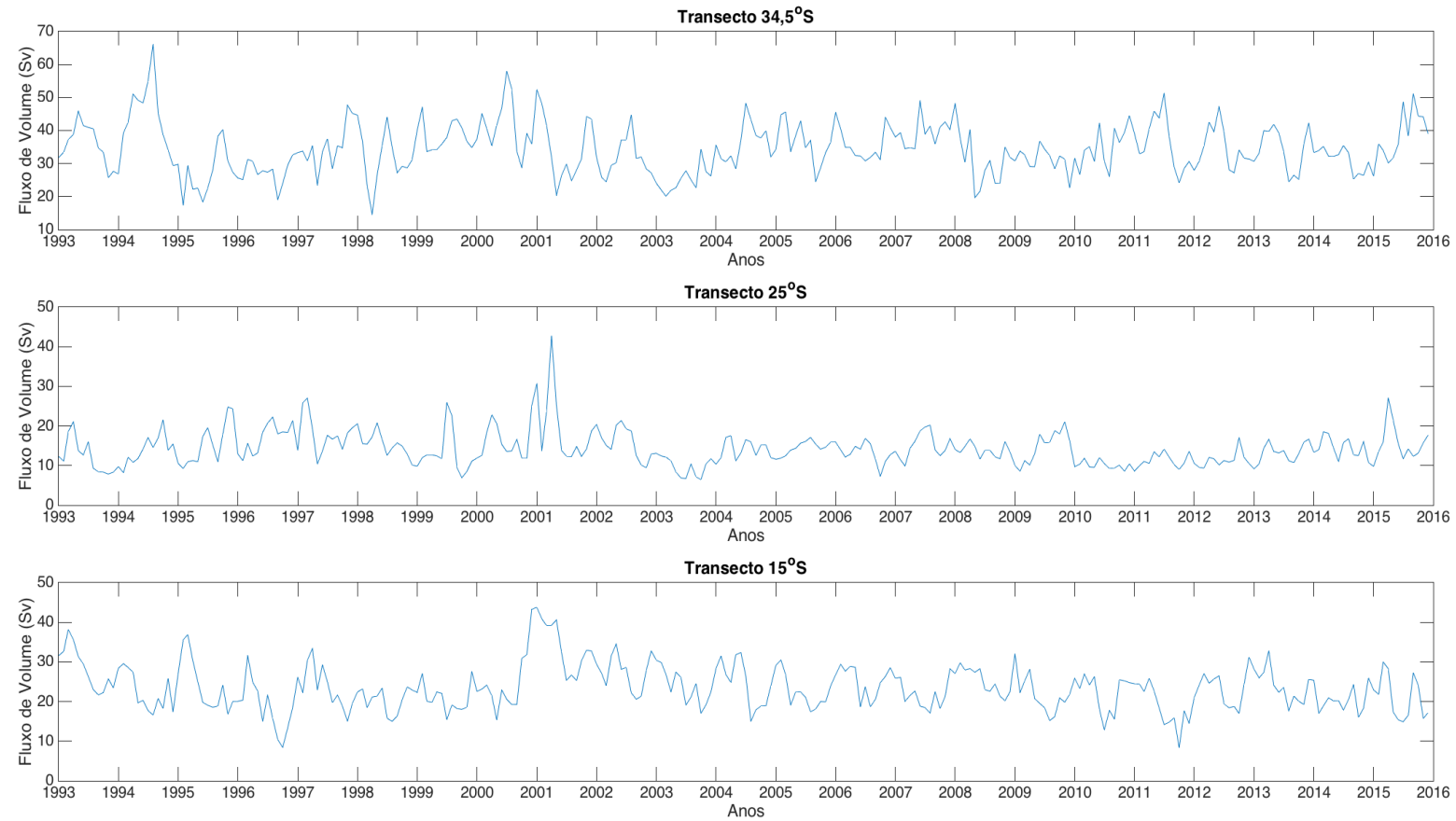

Figura 41: Série temporal da MOC do Atlântico Sul nas respectivas latitudes entre os anos de 1992 a 2015. Dados são do modelo NEMO.

vertical dos nutrientes na SAMW para camadas mais rasas (Palter et al. 2010). Para poder comparar com o que foi observado nas regiões "A-B-C" foi calculado o fluxo de volume da MOC no Atlântico Sul em latitudes próximas às três regiões. As latitudes escolhidas foram:

- $34,5^{\circ} \mathrm{S}$ (associada à região $\left.\mathrm{A}\right)$

- $25^{\circ} \mathrm{S}$ (associada à região $\left.\mathrm{B}\right)$

- $15^{\circ} \mathrm{S}$ (associada à região $\mathrm{C}$ )

$\mathrm{O}$ transecto em $15^{\circ} \mathrm{S}$ foi calculado na porção oeste da bacia, isto porque a Corrente de Benguela cruza da região leste para oeste em sua porção mais ao norte. Todos os transectos se encontram a sul das regiões A-B-C para quantificar o fluxo de volume da MOC que é transportado nestas regiões. Os resultados obtidos do fluxo de volume da MOC do Atlântico Sul dos dois modelos oceânicos (ECCO e NEMO) podem ser vistos nas Figuras 42 a 44.

\subsubsection{Relação das regiões $A, B$ e $C$ com os transectos}

A série temporal dos transectos por modelo pode ser observada nas Figuras 40 e 41 e as suas médias e desvios padrão na Tabela 6. As médias do transporte de volume da MOC na porção leste e oeste foram semelhantes entre os modelos dentro do intervalo 
Transecto $34,5^{\circ} \mathrm{S}$
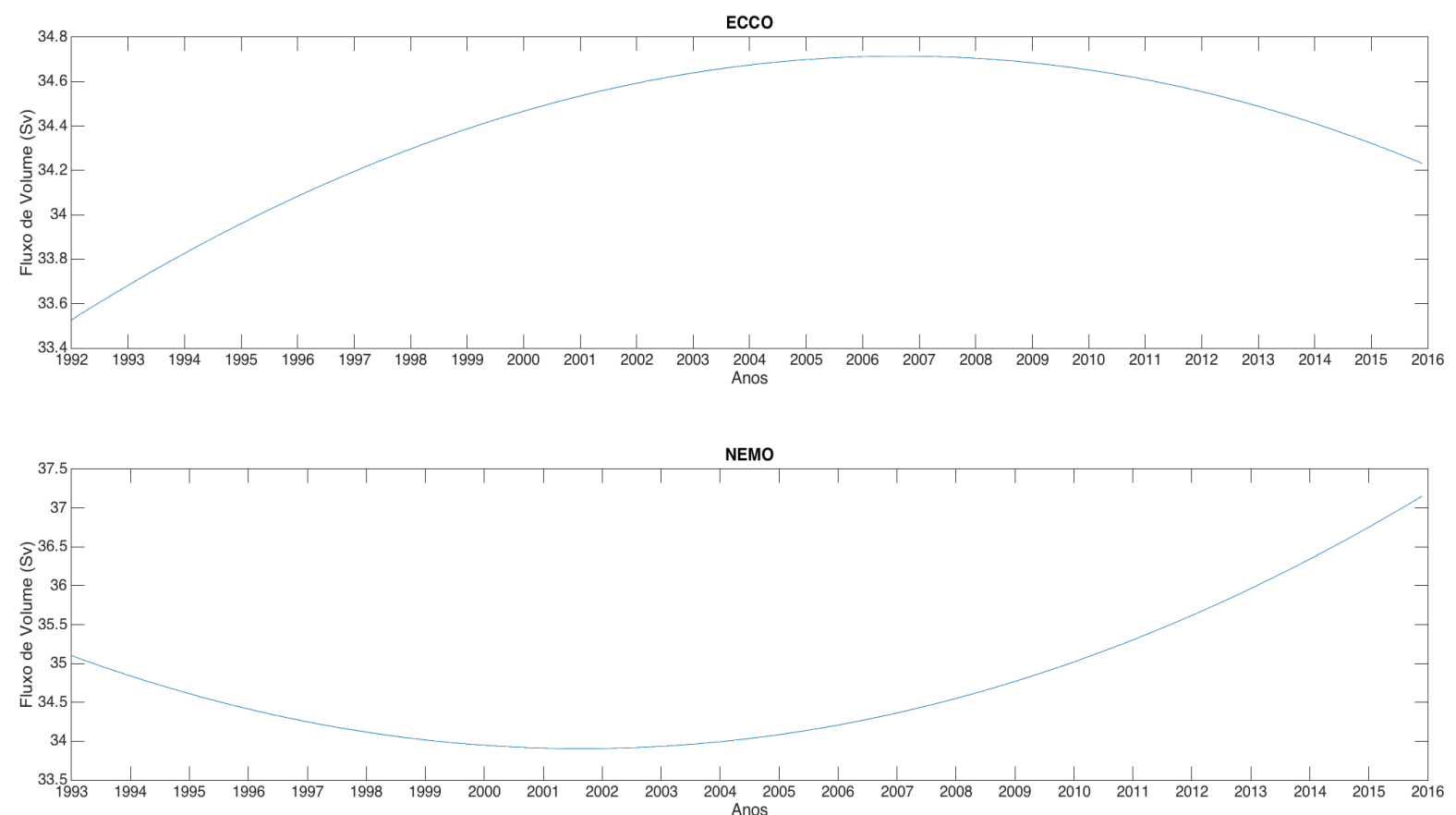

Figura 42: Série temporal da tendência interanual do transporte de volume ( $\mathrm{Sv}$ ) da MOC do Atlântico Sul em $34,5^{\circ} \mathrm{S}$ proveniente de saídas dos modelos ECCO (painel superior) e NEMO (painel inferior) na porção leste da bacia.

\section{Transecto $25^{\circ} \mathrm{S}$}
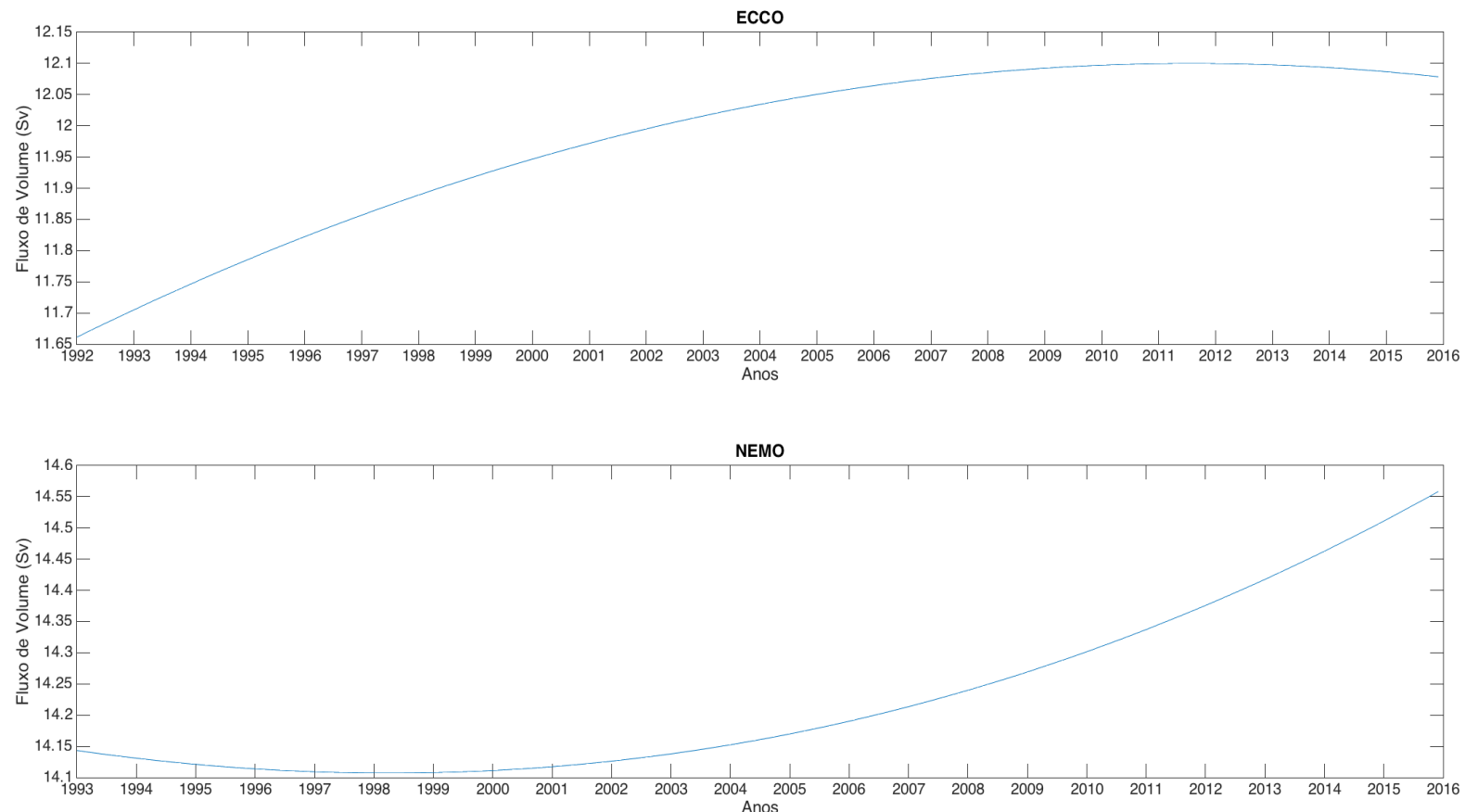

Figura 43: Série temporal da tendência interanual do transporte de volume ( $\mathrm{Sv}$ ) da MOC do Atlântico Sul em $25^{\circ} \mathrm{S}$ proveniente de saídas dos modelos ECCO (painel superior) e NEMO (painel inferior) na porção leste da bacia. 


\section{Transecto $15^{\circ} \mathrm{S}$}
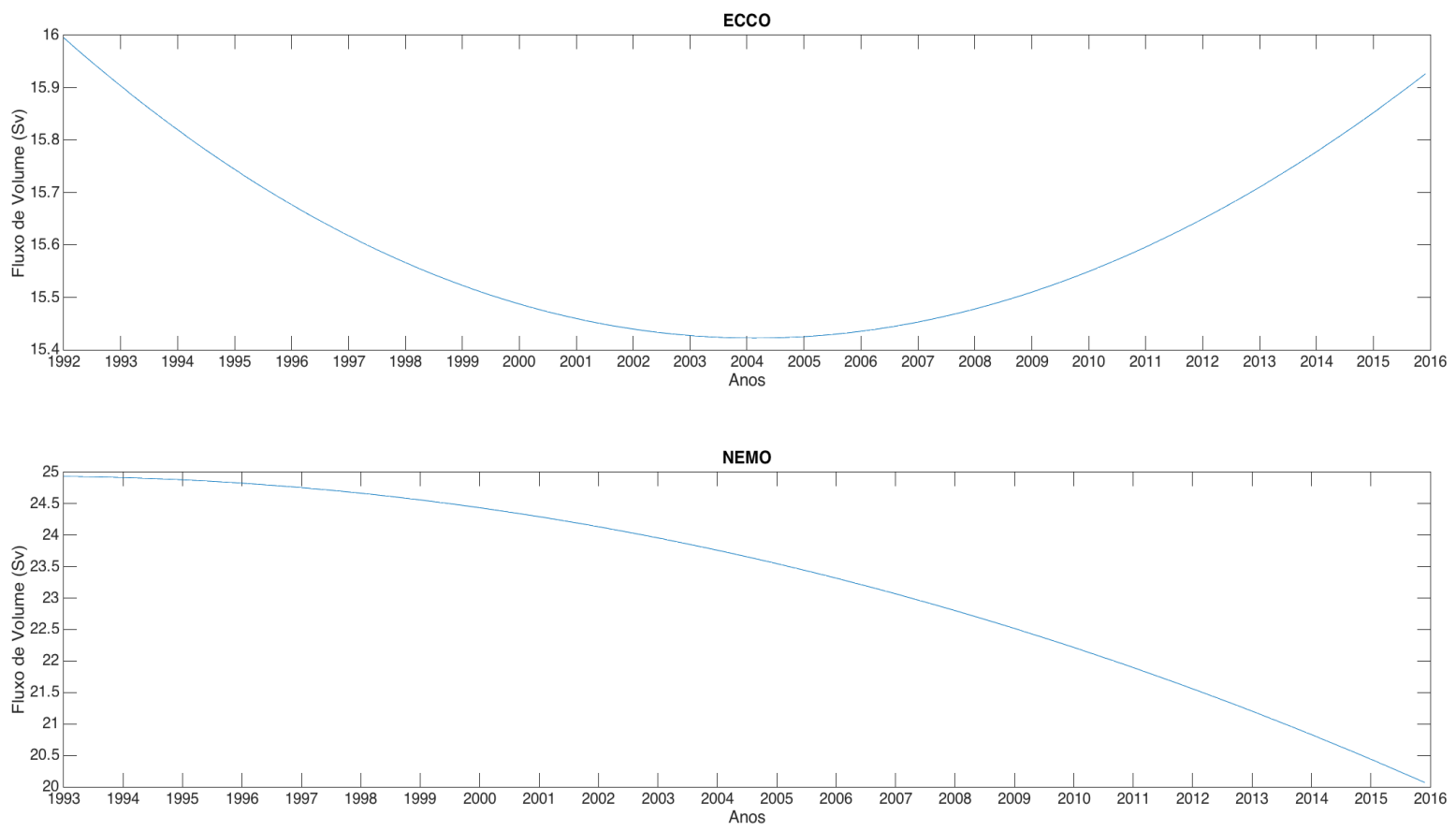

Figura 44: Série temporal da tendência interanual do transporte de volume (Sv) da MOC do Atlântico Sul em $15^{\circ} \mathrm{S}$ proveniente de saídas dos modelos ECCO (painel superior) e NEMO (painel inferior) na porção oeste da bacia.

de erro de cada medida. O desvio padrão do modelo NEMO foi maior que o ECCO e apresentou médias levemente maiores. A diferença máxima entre médias foi de 7,9 Sv no transecto na porção oeste localizado na latitude de $15^{\circ} \mathrm{S}$. As tendências interanuais por transecto se encontram na Figura 29. Dentro de cada modelo, as curvas da tendência interanual do transecto na porção leste $\left(34,5^{\circ} \mathrm{S}\right.$ e $\left.25^{\circ} \mathrm{S}\right)$ foram concordantes em seu padrão e diferentes do padrão desta curva na porção leste. Os modelos apresentaram padrão de curva de tendência diferentes e discordantes entre si. Na porção leste, o ECCO mostrou curvas de tendência interanual crescentes que aparentam a ter uma diminuição na taxa de crescimento, chegando a reverter em $34,5^{\circ} \mathrm{S}$. O NEMO, em sua porção leste teve curvas de tendência crescentes com um mínimo na metade da série temporal. Na porção oeste, a tendência interanual proveniente da análise do EEMD também não foi concordante entre modelos nas séries temporais da MOC do Atlântico Sul. A tendência da série temporal do ECCO apresenta na porção oeste uma curva decrescente no início da série temporal, mas que inverte sua taxa de crescimento ficando positiva enquanto a tendência da série temporal do modelo NEMO é monotonicamente decrescente. 
Tabela 6: Tabela com as médias e desvios padrões da MOC do Atlântico Sul dos modelos ECCO e NEMO

\begin{tabular}{|c|c|c|c|}
\cline { 2 - 4 } \multicolumn{1}{c|}{} & Latitude & Média (Sv) & Desvio Padrão (Sv) \\
\hline \multirow{3}{*}{ ECCO } & $15^{\circ} \mathrm{S}$ & 15,6 & 2,2 \\
\cline { 2 - 4 } & $25^{\circ} \mathrm{S}$ & 12,1 & 1,7 \\
\cline { 2 - 4 } & $34,5^{\circ} \mathrm{S}$ & 34,5 & 2,1 \\
\hline \multirow{3}{*}{ NEMO } & $15^{\circ} \mathrm{S}$ & 23,5 & 5,8 \\
\cline { 2 - 4 } & $25^{\circ} \mathrm{S}$ & 14,2 & 4,5 \\
\cline { 2 - 4 } & $34,5^{\circ} \mathrm{S}$ & 34,4 & 7,8 \\
\hline
\end{tabular}

Em relação ao padrão das tendências interanuais da MOC, podemos citar que::

- Na tendência da série temporal do modelo ECCO houve um aumento da MOC do Atlântico Sul na porção leste no período investigado. Em $34,5^{\circ} \mathrm{S}$ foi obtido um valor máximo de $34,6 \mathrm{~Sv}$ em 2007 e em $25^{\circ} \mathrm{S}$, o máximo foi próximo de $12,1 \mathrm{~Sv}$ em 2012.

- A tendência da porção oeste em $15^{\circ} \mathrm{S}$ da série do modelo ECCO apresenta um mínimo em 2004 de 15,4 Sv seguido de um aumento monotônico até o final da série temporal.

- O modelo NEMO, por sua vez, apresentou uma tendência interanual na porção leste com uma curva que tem uma queda no início da série e um aumento monotônico subsequente. Na latitude de $34,5^{\circ} \mathrm{S}$ o mínimo observado é em 2002 com 34 Sv, enquanto que na latitude de $25^{\circ} \mathrm{S}$ essa queda foi mais sutil, com uma variação de 0,05 Sv, alcançando um mínimo de 14,1 Sv entre 1998/1999.

- A tendência interanual da série temporal da porção oeste da MOC do Atlântico Sul do modelo NEMO mostra um decaimento desde o começo da série oscilando de 25 Sv em 1993 para 20 Sv em 2016.

Podemos perceber que por mais que os valores da MOC sejam concordantes dentro da margem de erro, as tendências são discordantes. Cada modelo mostrou um resultado oposto no transecto análogo. Desta maneira, considerando esses resultados dois cenários podem ser investigados. O primeiro é o do modelo ECCO onde observa-se um aumento do transporte da MOC seguido de uma queda nos últimos anos na porção leste e o segundo cenário do modelo NEMO que apresenta um mínimo no começo da série temporal e um aumento da MOC do Atlântico Sul nos últimos anos na mesma porção da bacia. Qual exprime os "verdadeiros" resultados é difícil de analisar, pois as variáveis envolvidas podem ser múltiplas além de levar em conta artifícios matemáticos que os próprios modelos utilizam para tentar resolver as equações. O que este estudo apresenta é uma análise dos resultados entre nitrato e clorofila das regiões A-B-C e sua relação com o transporte da MOC nos transectos respectivos. As taxas das curvas de tendência interanual da MOC do 
Transecto $15^{\circ} \mathrm{S}$
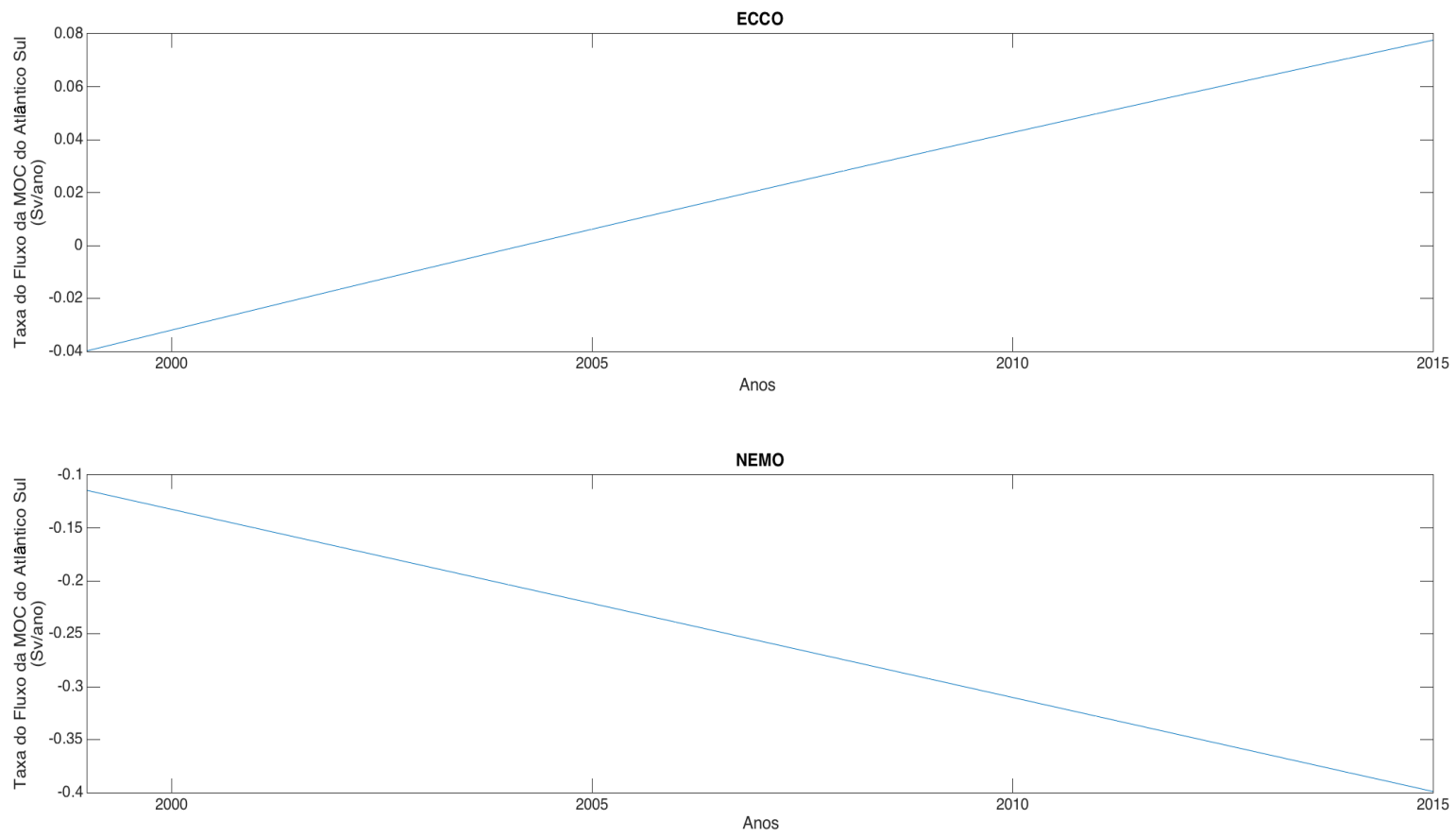

Figura 45: Taxa da tendência interanual do fluxo da MOC do Atlântico Sul no transecto de $15^{\circ} \mathrm{S}$.

Atlântico Sul foram calculadas para auxiliar nesta análise e se encontram nas Figuras 45, $46 \mathrm{e} 47$.

No cenário 1, o cenário representado pelo modelo ECCO, temos uma concordância entre a variabilidade da concentração de clorofila e nitrato integrado em escala interanual com o que foi observado na variabilidade do transporte da MOC nos transectos. Na região A vemos uma mudança na curva de tendência próximo de 2008 e 2009 (Figura 30) e com uma taxa de variação do nitrato integrado sendo alterada após 2009 (Figura 35). Na Figura 47 vemos que no modelo ECCO a taxa da MOC muda de sinal próximo de 2007/2008. Também podemos observar que nesses anos o fluxo de volume da MOC do Atlântico Sul atinge seu máximo. Na região $\mathrm{B}$, foi observado algo análogo à região $\mathrm{A}$. $\mathrm{O}$ ano em que a taxa do nitrato integrado fica negativa (Figura 36 coincide com o ano em que a curva decrescente do transporte de volume da MOC em $25^{\circ} \mathrm{S}$ passa pelo zero (Figura 46). Isso leva a crer que a queda da tendência interanual observada após 2011 na MOC do Atlântico Sul em $25^{\circ} \mathrm{S}$ (Figura 43) levou a uma queda na tendência do nitrato integrado na região $\mathrm{B}$ (Figura 31). A região $\mathrm{C}$ também apresenta concordância nos dados com o transecto em $15^{\circ}$ S. Após o mínimo de 2004 no fluxo de volume da MOC do Atlântico Sul (Figura 44), vemos um crescimento monotônico da tendência interanual, semelhante ao padrão da tendência interanual do nitrato integrado, que aumenta após 2004 (Figura 32). 
Transecto $25^{\circ} \mathrm{S}$
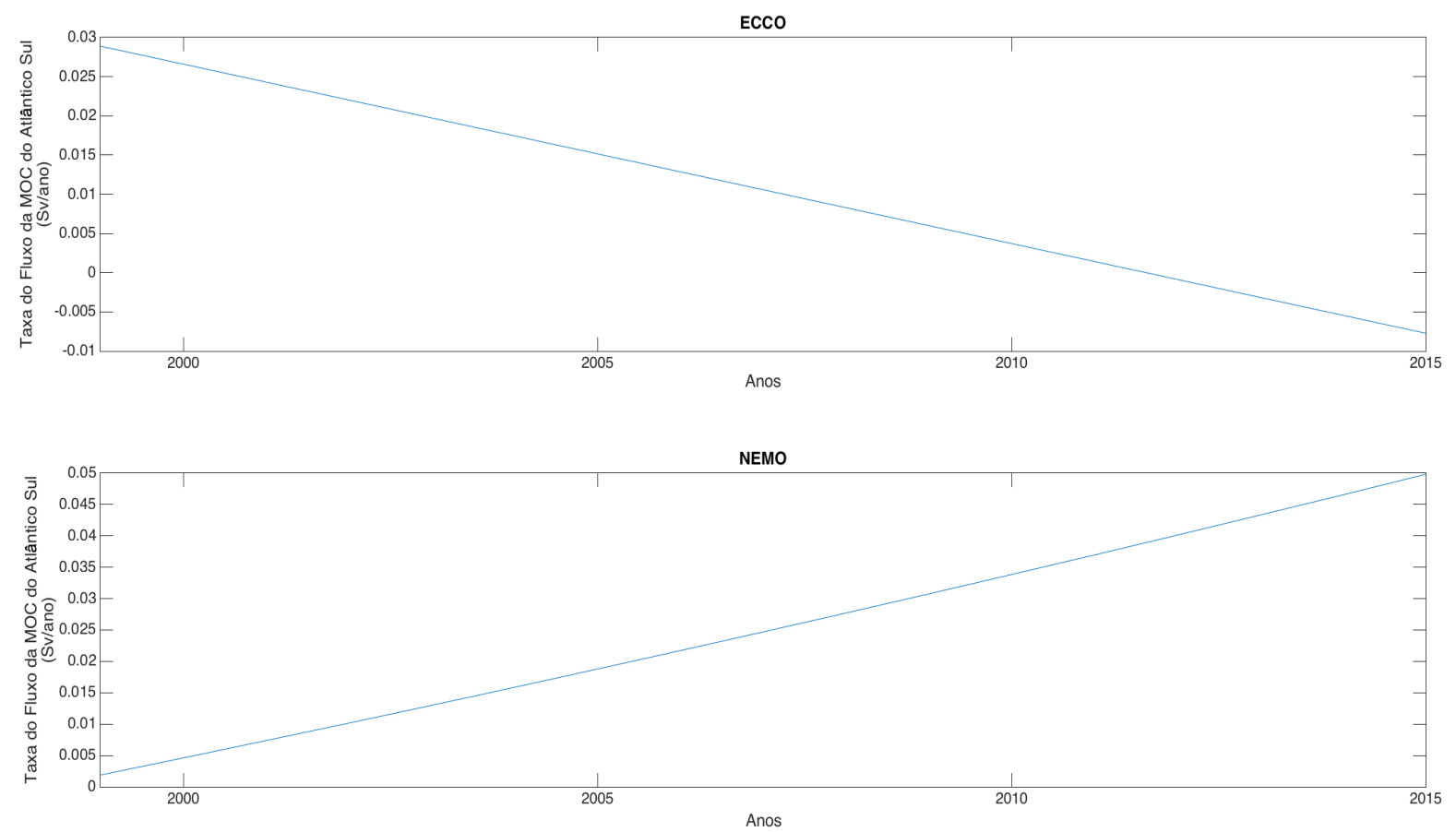

Figura 46: Taxa da tendência interanual do fluxo da MOC do Atlântico Sul no transecto de $25^{\circ} \mathrm{S}$.

Transecto $34,5^{\circ} \mathrm{S}$

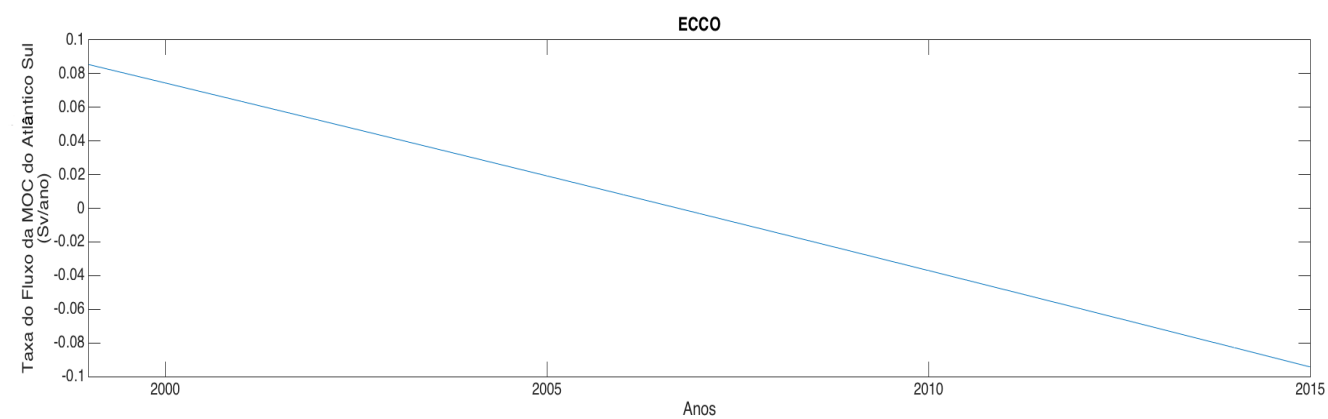

NEMO

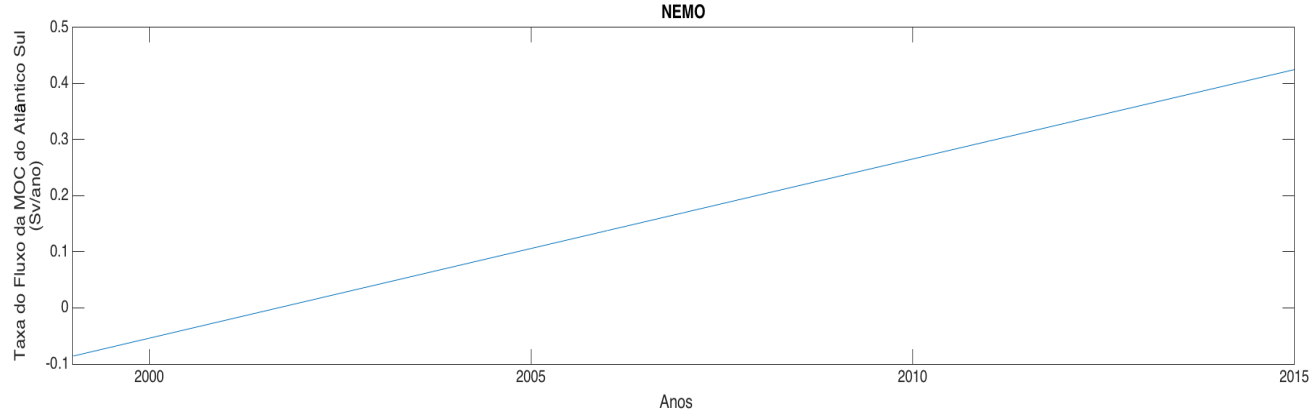

Figura 47: Taxa da tendência interanual do fluxo da MOC do Atlântico Sul no transecto de $34,5^{\circ} \mathrm{S}$. 
Ambas as taxas das tendências interanuais do fluxo de volume da MOC e nitrato integrado apresentam um crescimento monotônico com transição de uma taxa negativa para positiva (Figuras $37 \mathrm{e} 45$ ).

Fica digno de nota que o fluxo de volume da MOC do Atlântico Sul na porção oeste em $15^{\circ} \mathrm{S}$ do modelo ECCO vem decaindo desde 1992 (Figura 44), assim em 1998 (quando começa a série temporal do nitrato integrado e clorofila) a queda é contínua. Isso indica que o transporte de nitrato chegando na zona fótica vem diminuindo desde 1992 e talvez tenha alcançado um nível mínimo, explicando o porque de sua taxa começa em valores negativos. A medida que o fluxo de volume da MOC do Atlântico Sul na porção oeste começa aumentar em 2004 vemos um subsequente aumento do nitrato integrado, e posteriormente, da concentração de clorofila. Todos esses valores e padrões descritos mostram que o cenário 1 é um cenário onde tem uma relação direta e proporcional entre nitrato integrado e fluxo de volume da MOC. Desta maneira, no cenário 1, a tendência temporal positiva ou negativa da clorofila no Atlântico Sul é uma resposta ao tanto de nitrato que consegue chegar na zona eufótica modulado pelo fluxo de volume da MOC do Atlântico Sul na porção oeste ou leste da bacia.

No cenário 2, representado pelo modelo NEMO, apresenta uma relação inversa entre as variações interanuais do transporte de volume da MOC no Atlântico Sul e nitrato integrado. As taxas de variação da tendência interanual entre essas variáveis é oposta. $\mathrm{Na}$ curva de tendência interanual do transecto em $34,5^{\circ} \mathrm{S}$ há uma leve queda desde 1998 seguido de um aumento contínuo. Esse padrão explicaria o crescimento de nitrato integrado até 2008 em sua curva de tendência (Figura 30), que também está aumentando no mesmo período. Entretanto, não explicaria o porque do nitrato integrado ter um baixo crescimento no final da série temporal, ou ainda ter uma taxa negativa (Figura 35). Isso é igualmente observado comparando as curvas de tendência da região B. O nitrato integrado tem um crescimento até 2011 (Figura 31), logo a tendência da MOC (Figura 43) é concordante, uma vez que essa cresce desde 1998. A queda após 2011 no nitrato integrado, por sua vez, apresenta uma relação inversa com o fluxo de volume da MOC do Atlântico Sul. $\mathrm{O}$ nitrato integrado da região $\mathrm{C}$, apresenta uma relação inversa com o fluxo de volume da MOC do Atlântico Sul em todo o seu domínio temporal. As taxas e as curvas de tendência interanual, são opostas entre si. A taxa da curva observada no transecto em $15^{\circ} \mathrm{S}$ (Figura 45) é negativa desde o começo de 1998, mostrando uma MOC decrescente.

Desta forma, por mais que exista uma concordância em um período entre o fluxo de volume da MOC com o nitrato integrado nas regiões A e B, a relação do fluxo de volume da MOC com a região $\mathrm{C}$ é inverso em toda série temporal. Na tendência interanual do fluxo de volume da MOC no transecto em $15^{\circ} \mathrm{S}$ (Figura 44), vemos uma queda desde 1993. Assim, é possível que o transporte da MOC exerça certa influência até um certo limite e depois tenha uma relação inversa, como foi observado na região A e B e seus transectos análogos. Sob esta especulação, a queda observada no transecto em $15^{\circ} \mathrm{S}$ teria 
levado a uma queda do nitrato integrado. Logo, desde 1993 a região C experimentaria valores mínimos de nitrato (e, consequentemente de clorofila), que pode ser observado na curva de tendência da região C (Figura 32): no início da série, os dados apresentam baixa oscilação próximo de um valor mínimo. Com a contínua queda do fluxo de volume MOC em $15^{\circ} \mathrm{S}$, se estabeleceria uma relação inversa e o nitrato integrado começaria a apresentar taxas positivas. Isso mostra que o fluxo de volume da MOC não é o único mecanismo responsável pelo controle do nitrato integrado, e consequentemente, da concentração de clorofila em escalas de baixa frequência. Isso leva a crer que possa existir a interação de uma ou mais variáveis no controle das mesmas.

Definir quais cenários são a representação da realidade é difícil de se afirmar, principalmente pela falta de medidas e de análise de outras variáveis. Entretanto, pode-se fazer uma análise lógica-dedutiva e, assim, emitir um parecer provável, que será feito a seguir.

No cenário 2, temos que o transporte pela MOC do Atlântico Sul não é o único fator que influencia o nitrato integrado e que a relação com o fluxo de volume da MOC é proporcional até um limite, onde sua relação começa a ser inversa. Sob esta ótica, um aumento (ou diminuição) contínua interfira em outra(s) variável (variáveis) que alterem a concentração de concentração de clorofila e nitrato integrado. Sabe-se que o efeito da advecção pode afetar a clorofila e a estratificação da coluna d'água pelo transporte de calor, sal e nutrientes (Dave and Lozier 2015), sendo observado em escalas interanuais (Dave and Lozier 2013). Assim a mudança no fluxo de volume na porção leste ou oeste da MOC do Atlântico Sul teria o potencial de alterar a estratificação. Há uma correlação positiva entre o transporte da MOC do Atlântico Sul com o transporte meridional de calor (Dong et al. 2009; Dong, Goni, and Bringas 2015; Majumder, Schmid, and Halliwell 2016). Desta maneira, um possível aumento (diminuição) nas porções leste e oeste poderiam advectar mais calor causando uma possível alteração na densidade da coluna d'água. A estratificação tem uma relação inversa com a clorofila na região tropical/subtropical (Longhurst 2007d), pois apresenta uma barreira física entre águas da termoclina ricas em nutrientes com águas pobres em nutrientes na camada de mistura. Isto seria possível de explicar a relação inversa observada na região $\mathrm{C}$, uma queda no fluxo de volume da MOC, levaria a um menor transporte de calor, que por sua vez, poderia deixar a água menos estratificada, e mais suscetível a entrada vertical de nitrato para a zona fótica. Um estudo mais a fundo do transporte de calor e sal da MOC do Atlântico Sul é necessário para confirmar tal especulação, entretanto essa análise está além deste estudo. Outro possível impacto é pela parte biótica, Olonscheck et al. (2013) mostraram por modelo que um aquecimento global por uma emissão de $\mathrm{CO}_{2}$ levaria a uma queda da produtividade primária por um aquecimento geral do oceano e uma aceleração no metabolismo do zooplâncton, afetando assim o grazing realizado por este. Logo, com um cenário onde há um maior (menor) transporte de calor não só diminuiria (aumentaria) o nitrato integrado pela estratificação, como aumentaria (diminuiria) o grazing realizado pelo zooplâncton. Isto reforçaria a ideia do que 
foi observado na região A-B-C, porém para fazer tal afirmação também seria necessário uma análise meticulosa da parte biótica que, assim como um estudo de fluxo de calor da MOC, está além deste estudo.

No cenário 1, temos que o transporte de nitrato integrado é modulado pelo fluxo de volume da MOC do Atlântico Sul localmente (na porção oeste e leste), e desta maneira, controla a produtividade primária, expressa neste estudo pela concentração de clorofila. Este cenário é o que conseguiu apresentar uma explicação direta pelo controle da clorofila e explicar o porque da distribuição espacial de anomalias positivas da tendência interanual na Figura 28, Esse padrão corrobora o mecanismo descrito por Palter et al. (2010) estando de acordo espacial e temporalmente. Ou seja, em escadal interanual, os nutrientes que afundam na água que forma a Água Modal Subantártica (SAMW) alimenta a produtividade entre $30^{\circ} \mathrm{S}$ e $30^{\circ} \mathrm{N}$ através da porção leste da bacia onde há as grandes ressurgências e a recirculação dos nutrientes que foram remineralizados. Isto ocorre pois o Oceano Austral é uma das maiores regiões High Nutrient Low Chlorophyll (HNLC), os nutrientes que afloram desde altas profundezas pela ressurgência antártica não são totalmente utilizados por serem limitados por ferro e luz (de Baar et al. 1990; Martin, Gordon, and Fitzwater 1990; Mitchell et al. 1991; Nelson and Smith Jr 1991). Esta água quando chega na superfície, rica em nutrientes, é transportada para norte por transporte de Ekman até a região da frente polar e frente subantárticia, onde afundam dando origem a SAMW e a Água Intermediária Antártica (AIA).

Dada a importância do oceano Austral diversos estudos tem estudado a biogeoquímica da SAMW e a AIA sob efeito de forçantes físicas (Iida, Odate, and Fukuchi 2013; Pardo et al. 2017; Panassa et al. 2018; Ayers and Strutton 2013). Ayers and Strutton (2013) mostraram que no setor do Pacífico do oceano Austral um aumento na ressurgência antártica e na MOC implicaria uma maior concentração de nutrientes na SAMW. Panassa et al. (2018) analisaram diversas variáveis biogeoquímicas (incluindo o nitrato) e físicas da AIA em escalas interanuais no oceano Austral dentro do setor do Atlântico Sul na longitude de $0^{\circ}$. Esses autores acharam um aumento nos nutrientes, carbono inorgânico dissolvido e utilização aparente de oxigênio (AOU) e uma queda na temperatura e salinidade. Concluiram que o padrão observado destas variáveis poderiam ocorrer sob duas hipóteses:

1. A primeira delas seria o quadro de uma forte remineralização e uma diminuição na produtividade primária. Tal hipótese, entretanto, só faz sentido após 2011, pois foi observado uma queda na produtividade primária na região (Kahru, Lee, and Mitchell 2017). Entretanto, esse cenário não explica a mudança nas variáveis físicas, então não pode ser a única explicação.

2. O segundo quadro proposto implica em um aumento da MOC devido à ação dos ventos de oeste, resultando em um aumento na ressurgência, transporte para norte e 
aumento na taxa de subducção. Tal hipótese explicaria não só o padrão observado das variáveis biogeoquímicas como das variáveis físicas. Essa hipótese também parece corroborar outros achados na literatura com relação ao nutrientes e a temperatura na mesma região (Pardo et al. 2017; Tanhua et al. 2017; Hoppema et al. 2015).

A tendência da concentração de clorofila menos a sua média (anomalia) e a taxa de variação temporal da mesma próximo a região de estudo de Panassa et al. (2018) foi calculada e se encontra na Figura 48. De fato, vemos uma queda na taxa da anomalia da tendência da concentração de clorofila após 2011, em concordância com o que foi visto na literatura (Kahru, Lee, and Mitchell 2017), com uma queda contínua desde 2006 (Figura 48). Entretanto, vemos que até 2014 a tendência foi crescente e com taxas de variação temporal positivas. Assim, a queda da concentração da clorofila não explicaria o aumento das variáveis biogeoquímicas antes de 2011, refutando a hipótese 1 do estudo de Panassa et al. (2018). A segunda hipótese, por sua vez, explica todas as variáveis do estudo de Panassa et al. (2018) e está de acordo com observado em outras regiões do oceano austral (Ayers and Strutton 2013, Pardo et al. 2017).

Uma aceleração da MOC pode implicar num aumento no transporte de nutrientes na SAMW/AIA. Isso também é condizente com o cenário do modelo ECCO, que implica que é o fluxo de volume na porção oeste ou leste da MOC do Atlântico Sul que modula a tendência interanual da concentração de clorofila no Atlântico Sul. Os dados do ECCO também mostraram uma tendência de aceleração da MOC do Atlântico Sul pelo seu fluxo de volume desde 2002 (Figura 49) estando assim de acordo com o que foi observado na literatura (Ayers and Strutton 2013; Panassa et al. 2018; Pardo et al. 2017), diferente do modelo NEMO (Figura 50) que mostra uma queda no fluxo de volume da MOC do Atlântico Sul desde o início da série.

Como síntese podemos dizer que foi observado dois cenários distintos:

- O primeiro destes é representado pela tendência interanual da MOC proveniente da série temporal do fluxo de volume do modelo ECCO, o cenário 1. O cenário 1 mostra uma relação direta entre o fluxo de volume na porção oeste ou leste da MOC do Atlântico Sul, nitrato integrado e concentração de clorofila. O cenário 1 é concordante com o que é descrito na literatura, estando de acordo com Palter et al. (2010). Também está de acordo com achados na literatura como Panassa et al. (2018, Ayers and Strutton (2013) e os estudos que estão de acordo com estes como (Pardo et al. 2017; Tanhua et al. 2017; Hoppema et al. 2015).

- O cenário 2 é representado pela tendência interanual da MOC proveniente da série temporal do fluxo de volume do modelo NEMO. O cenário 2 mostra que há uma relação entre o fluxo de volume da MOC do Atlântico Sul e nitrato integrado até algum possível limite. Passado esse limite a relação é inversa pela influência de 

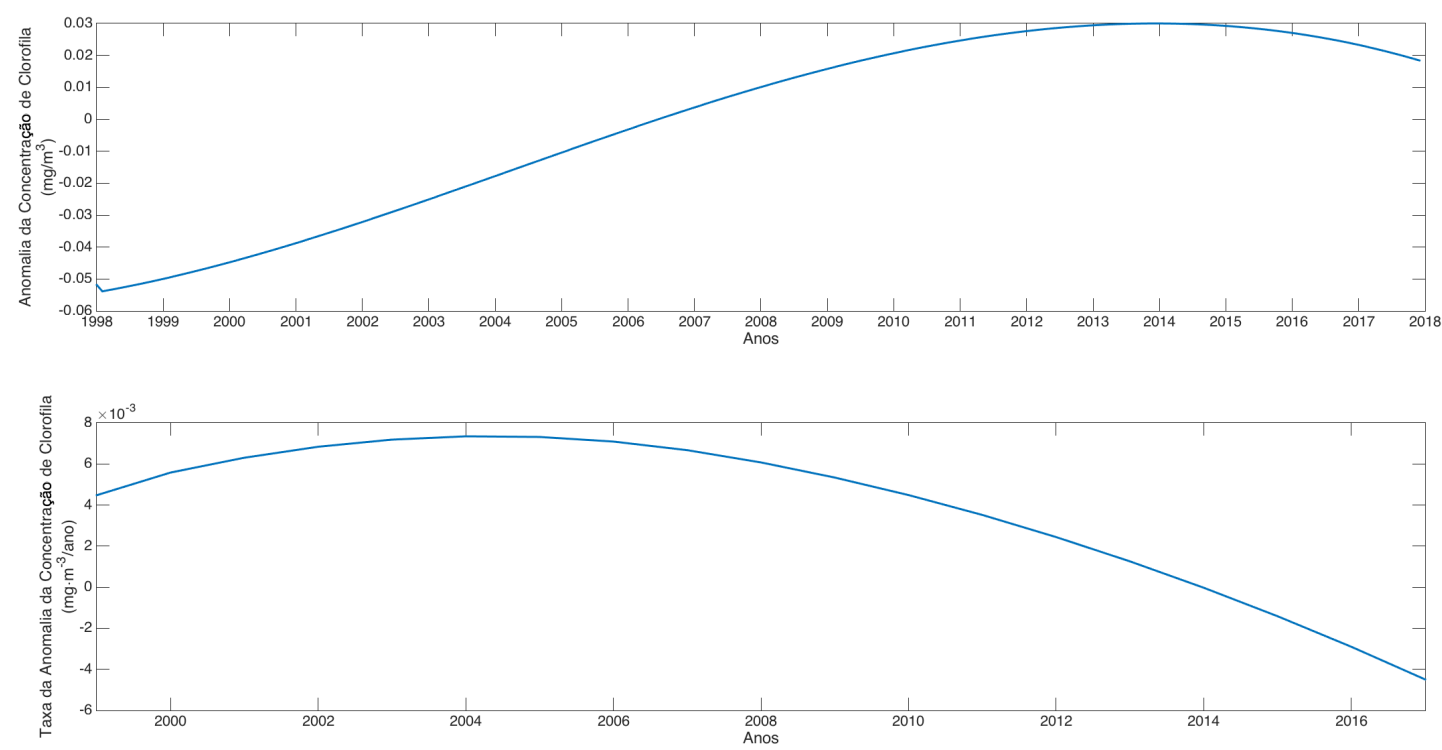

Figura 48: Média da anomalia da tendência interanual da concentração da clorofila (painel superior) e a sua taxa (painel inferior) próximo à região de estudo de Panassa et al. (2018). A região utilizada foi entre $1^{\circ} \mathrm{W}$ e $1^{\circ} \mathrm{E}$ e $45^{\circ} \mathrm{S}$ a $50^{\circ} \mathrm{S}$

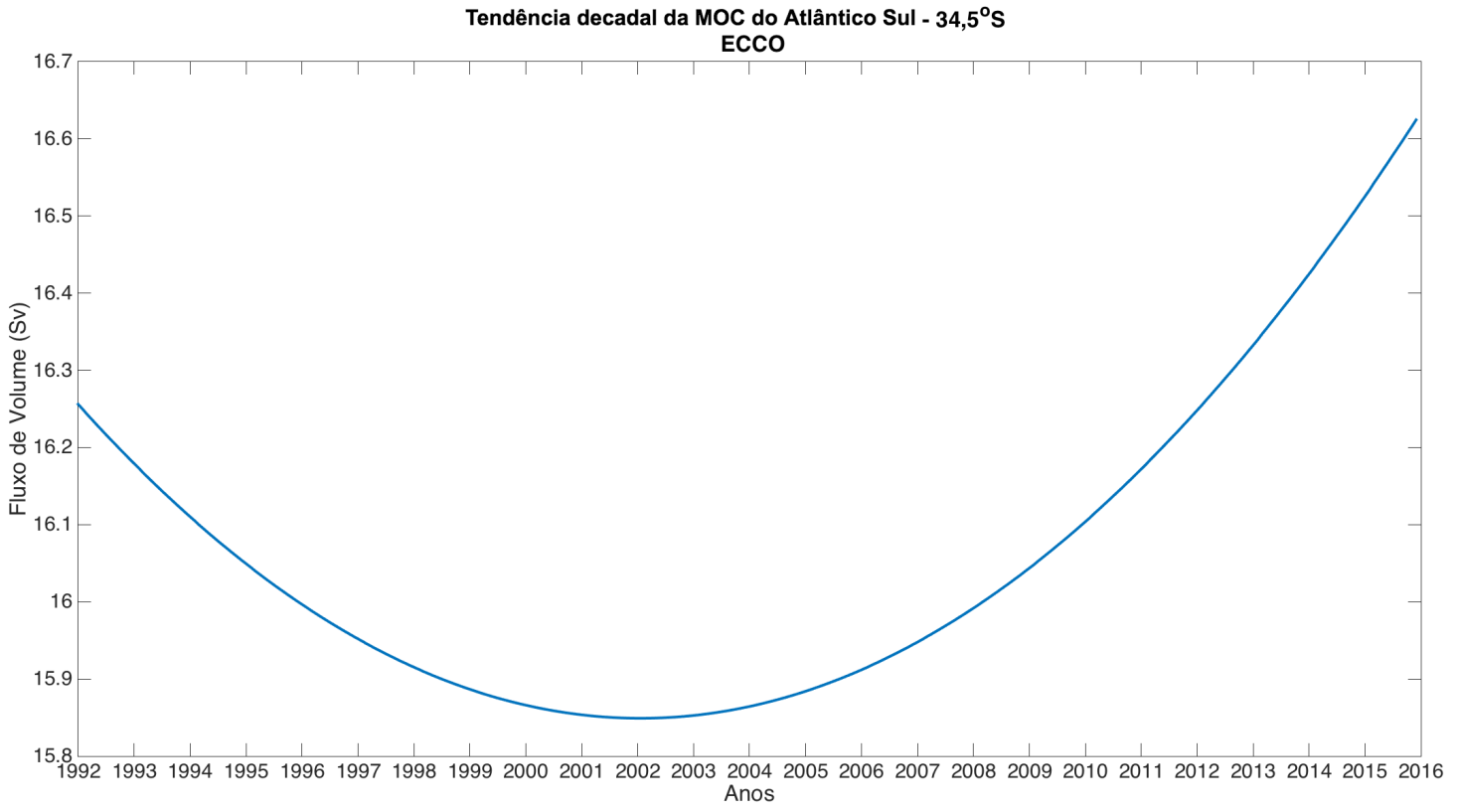

Figura 49: Tendência temporal da MOC do Atlântico Sul em $34,5^{\circ} \mathrm{S}$ pelo modelo ECCO 


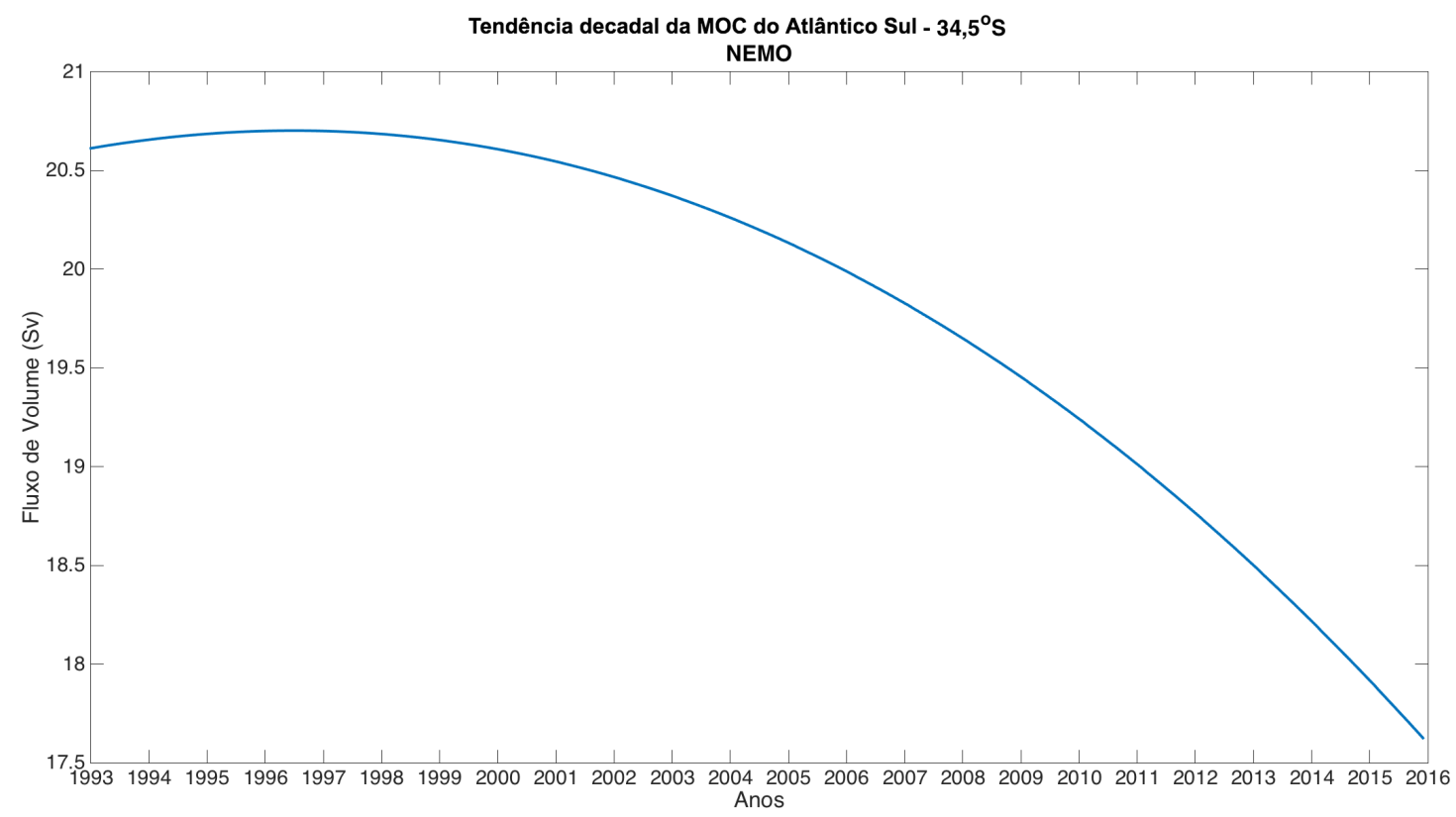

Figura 50: Tendência temporal da MOC do Atlântico Sul em $34,5^{\circ} \mathrm{S}$ pelo modelo NEMO

outras variáveis. Como possíveis variáveis que possam controlar podemos citar fluxo de calor e o grazing do zooplâncton. Estas variáveis tem uma relação inversa com o nitrato integrado (fluxo de calor) e a concentração de clorofila (fluxo de calor e grazing). Entretanto, é preciso um estudo mais meticuloso destas variáveis para entender se estas estão de fato afetando este sistema. O modelo NEMO, por sua vez, não é concordante com o estudo de Panassa et al. (2018) e Ayers and Strutton (2013) que afirmam uma aceleração da MOC nos últimos anos (Figura 50).

Analisando assim os dois cenários observa-se que no cenário 2 há uma relação indireta do sistema MOC-nitrato integrado-clorofila e há a necessidade de mais variáveis para uma possível explicação. Já no cenário 1 há uma relação mais direta e simples no sitema MOCnitrato integrado-clorofila. Por falta de uma análise no fluxo de calor e sal, estratificação e comportamento do zooplâncton deixa o cenário 2 inconclusivo e não condizente com estudos da literatura. O cenário 1 conseguiu uma explicação plausível como também foi fundamentado com o que foi observado na literatura. Portanto, é a explicação mais plausível a partir dos dados utilizados neste estudo. Desta maneira, este estudo afirma que há necessidade de analisar outras variáveis para poder tirar alguma conclusão mas que na presente conjuntura o cenário 1 é o mais possível/plausível.

\section{4 Índices Climáticos}

Seja qual cenário representar melhor a realidade, em ambos a MOC exerce papel fundamental no controle de nitrato e produtividade primária. Como parte final da análise foi realizado uma correlação cruzada de dois índices climáticos com a MOC do Atlântico 
Tabela 7: Tabela com os períodos de cada componente (IMF) dos índices climáticos e da MOC do Atlântico Sul por cada modelo. Os períodos estão em anos.

\begin{tabular}{|c|c|c|c|c|c|c|c|c|}
\cline { 2 - 9 } \multicolumn{1}{c|}{} & C1 & C2 & C3 & C4 & C5 & C6 & C7 & C8 \\
\hline AAO & 0,4 & 1,1 & 3,4 & 10,6 & 28,5 & 102,4 & 224 & - \\
\hline NIÑO & 0,4 & 1,0 & 2,7 & 7,9 & 32,9 & 53,40 & 434 & 1244 \\
\hline ECCO & 0,4 & 1,2 & 2,8 & 12,3 & 30,0 & 76,80 & 110 & -- \\
\hline NEMO & 0,3 & 1,2 & 2,8 & 6,2 & 32,2 & 58,20 & 265 & -- \\
\hline
\end{tabular}

Sul: a Oscilação Antártica (AAO) e o El Niño Oscilação Sul (ENSO). A correlação dos índices foi feita com o transporte de volume da MOC do Atlântico Sul na latitude de $34,5^{\circ} \mathrm{S}$.

Para realizar a correlação do transporte da MOC do Atlântico Sul com os índices da AAO e ENSO, ambos foram submetidos a decomposição do EEMD, ou seja, o mesmo tratamento dado ao transporte da MOC. A partir da série temporal dos índices, a aplicação do EEMD permitiu a decomposição em diferentes escalas de tempo intrínsicas ao movimento (IMF) e ao resíduo final, a tendência. Um teste de significância (ver Apêndice) foi utilizado para saber quais IMF's são estatisticamente significantes (Figura 51). Dentre os IMF's que passaram o teste de significância foram escolhidos aqueles com períodos em escalas maiores que um ano. As componentes de cada índice climático e seus períodos podem ser vistos na Tabela 7. Por fim, as correlações cruzadas foram feitas com os IMF's estatisticamente significantes de escala interanual entre a os índices climáticos (El Niño e AAO) com a MOC do Atlântico Sul (ECCO e NEMO).

A relação da AAO com a MOC do Atlântico Sul ocorre devido a influência dos ventos de oeste. Nas últimas décadas a AAO vem mostrando tendências positivas com influências no ambiente antártico (Thompson et al. 2011; Marshall 2003). Como consequência dessas mudanças vemos uma intensificação e um deslocamento para sul dos ventos de oeste e enfraquecimento desses ventos na porção norte de seu domínio fazendo com que ocorra anomalias no rotacional da tensão do cisalhamento dos ventos de oeste (anomalias positivas para sul e negativas para norte) (Hall and Visbeck 2002; Saenko, Fyfe, and England 2005). Estas anomalias do rotacional da tensão de cisalhamento causam convergências e divergências na coluna d'água. Por continuidade, essas anomalias resultam em uma maior ressurgência antártica para sul e uma maior subducção para norte, e por sua vez, em uma aceleração do ramo superior austral da MOC (Saenko, Fyfe, and England 2005). Isto causa o aumento da concentração de nutrientes trazidos pela ressurgência e, como resultado da convergência, há maior subducção da Água Modal Subantártica (SAMW) e Água Intermediária Antártica (AIA) com mais nutrientes sendo transportados pela MOC. (Ayers and Strutton 2013; Panassa et al. 2018).

O El Niño Oscilação Sul tem um efeito mais indireto na circulação do Atlântico Sul. Podemos citar sua influência no Dipolo do Atlântico Sul (DAS). O DAS ocorre quando 
há uma alteração no sistema de alta pressão conhecido como Alta subtropical do Atlântico Sul. Um deslocamento deste sistema para sul e intensificação do mesmo gera uma fase positiva ao passo que, o oposto, uma fase negativa. Como consequência há uma alteração da intensidade dos ventos dentro do domínio do dipolo (Fauchereau et al. 2003; Rodrigues, Campos, and Haarsma 2015). Essa alteração influencia os ventos de oeste que são de extrema importância para a ressurgência antártica e na formação da AIA/SAMW; com uma fase positiva da DAS temos o seu enfraquecimento, enquanto que para uma fase negativa, sua intensificação. Rodrigues, Campos, and Haarsma (2015) mostraram que através do modo climático Pacífico-América do Sul (PSA) isto é, trem de ondas de Rossby atmosféricas que se propagam do Pacífico até a América do Sul devido a perturbações no Pacífico, o ENSO tem a capacidade de alterar a alta subtropical, que modula as fases do DAS e que, por sua vez, alteram os de oeste.

Uma relação do ENSO no vazamento das Agulhas também é possível. O vazamento das Agulhas é a conexão das águas quentes e salinas do Índico com o Atlântico Sul, onde alimenta o ramo superior da MOC do Atlântico Sul (Beal et al. 2011). Assim, uma mudança no seu transporte pode significar uma mudança no transporte do ramo superior que é o responsável por transportar a SAMW/AIA para norte, como visto em Biastoch and Böning (2013). Esses autores calcularam que um vazamento das Agulhas mais forte levaria a um aumento de $48 \%$ no transporte da Água Modal Subantártica e 45\% na água Intermediária Antártica afetando, portanto, o mecanismo descrito por Palter et al. (2011). Sua importância se deve também pelo vazamento das Agulhas ter a capacidade de alterar a MOC em diversas escalas de tempo Biastoch, Böning, and Lutjeharms (2008, Beal et al. (2011, Weijer et al. (2002). O transporte de águas mais quentes e salinas, o vazamento das Agulhas pode alterar as propriedades termohalinas do Atlântico Sul e afetar a MOC como um todo na escala de centenas de anos (Beal et al. 2011; Biastoch and Böning 2013). Estudos tem mostrado que uma alteração nos ventos de oeste tem o potencial de afetar significativamente o vazamento das Agulhas (Beal et al. 2011; Biastoch and Böning 2013). O ENSO consegue causar anomalias no padrão de circulação de ventos (como observado na sua influência no DAS), além de se ter evidências de uma forte influência do ENSO na Corrente das Agulhas, mostrando que através de um modo tropical do PacíficoÍndico, o ENSO é responsável por uma variância interanual de 11,5\% na Corrente das Agulhas (Elipot and Beal 2018).

Dentre as componentes significativas dos IMF's da série temporal da AAO podemos utilizar as componentes $\mathrm{C} 3$ e C4; do El-Niño, C3, C4, C6, C7 e C8; do modelo ECCO, C3, C4 e C7; e do modelo NEMO, C3, C5, C6 e C7. Das componentes em comum entre os IMF's significantes da MOC do Atlântico Sul com os índices climáticos, conseguiu uma correlação cruzada entre:

- $\mathrm{MOC} \times \mathrm{AAO}$ - componentes $\mathrm{C} 3$ e C4 (esta última só do modelo ECCO); 


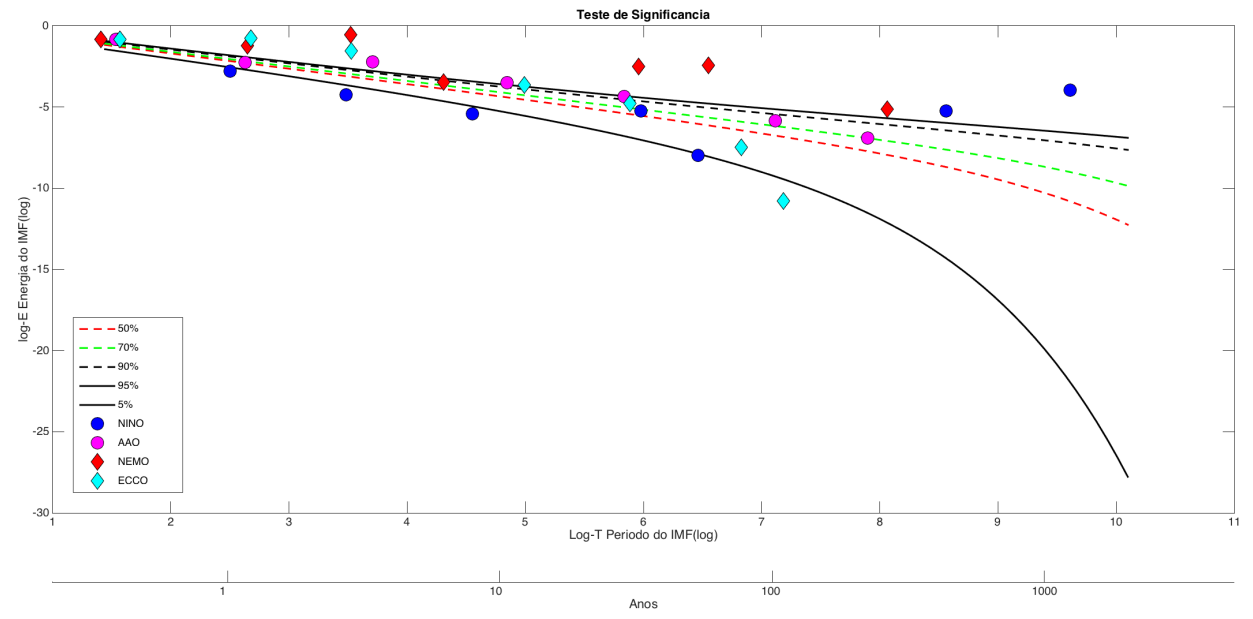

Figura 51: Teste de significância para os IMF's da MOC do Atlântico Sul (ECCO e NEMO) e dos índices climáticos. As linhas escuras contínuas se referem a um intervalo de confiança de $5 \%$ e $95 \%$. As linhas tracejadas verdes, vermelhas e pretas se referem a intervalos de confiança de 70\%,50\% e 90\%, respectivamente. Os losangos azul e vermelho são IMF's da MOC do Atlântico Sul (ECCO e NEMO) e os círculos azul e magenta do El-Niño e AAO, respectivamente

- $\mathrm{MOC} \times \mathrm{ENSO}$ - as componentes C3, C4 (só do modelo ECCO), C6 (só do modelo NEMO) e C7.

Só foram aceitas correlações com um intervalo de confiança acima de 95\%. A componente C7 não foi utilizada por ser uma curva de baixa frequência suavizada, portanto apresenta baixo grau de liberdade. Os resultados podem ser vistos na Tabela 8 .

Nas correlações apenas aquelas envolvendo a AAO apresentaram valores dentro de um intervalo de confiança de $95 \%$, e dentre estas apenas duas componentes se destacaram por apresentar valores maior que 0,3: as componentes C3 e C4. Destas duas componentes foi observada correlações relativamente baixas mas consistentes na defasagem entre os sinais. A correlação mais alta foi de 0,49 com um atraso de um pouco mais de 5 anos,

Tabela 8: Resultado das correlações entre os índices climáticos e a MOC do Atlântico Sul em cada IMF. Os resultados em branco foram aqueles que não conseguiram um intervalo de confiança de $95 \%$. A defasagem é expressa em meses.

\begin{tabular}{|c|l|c|c|}
\hline Componente & Correlação & Resultado & Defasagem \\
\hline \multirow{4}{*}{ C3 } & AAO $\times$ ECCO & 0,37 & 64 \\
\cline { 2 - 4 } & AAO $\times$ NEMO & $-0,33$ & 66 \\
\cline { 2 - 4 } & NINO $\times$ ECCO & - & -- \\
\cline { 2 - 4 } & NINO $\times$ NEMO & - & -- \\
\hline \multirow{2}{*}{ C4 } & AAO $\times$ ECCO & 0,49 & 65 \\
\cline { 2 - 4 } & NIÑO $\times$ ECCO & - & -- \\
\hline \multirow{2}{*}{ C6 } & NIÑO $\times$ NEMO & - & - \\
\hline
\end{tabular}


isto é, oscilações na escala de décadas da AAO perturbaria a MOC do Atlântico Sul cinco anos depois. Fica digno de nota, que utilizando um intervalo de confiança de $90 \%$ para os IMF's a componente C5 do AAO seria considerada significativa. Aplicando a correlação cruzada com a C5 do NEMO, que apresenta uma significância estatística acima do intervalo de $95 \%$, consegue-se uma correlação alta de $-0,75$, com uma defasagem de 59 meses. Tal resultado pode mostrar que existe uma forte correlação da MOC do Atlântico Sul com a AAO em escalas interanuais expresso pelas componentes C4 e C5 (entre aproximadamente 10 a 30 anos). Entretanto, é necessário outras séries temporais do transporte de volume da MOC do Atlântico Sul para chegar a qualquer dedução se esse índice climático é correlacionado positivamente ou negativamente, dado cada componente (C3 e C4) mostraram sinais opostos em suas correlações.

Há na literatura a relação da AAO com a MOC nesta escala. Wei, Lohmann, and Dima (2012) realizaram um estudo em que analisaram a relação da AAO nos principais modos de variabilidade da MOC pelo uso de modelos computacionais. Nesta análise perceberam que um cenário de AAO positivo (deslocamento para sul e intensificação dos ventos de oeste) na circulação do oceano austral causaria um impacto no transporte de volume da massa d'água Água Profunda do Atlântico Norte (APAN) na escala de uma década e que esta anomalia se propagaria para o Atlântico Norte na escala de centenas de anos. A saída de mais modelos e/ou uma série temporal da MOC do Atlântico Sul por dados in situ poderiam auxiliar a entender melhor este problema e qual o resultado que esta forçante atmosférica pode ter na MOC.

Por parte do El Niño, nenhuma correlação foi determinada com um intervalo de confiança de 95\%, deduzindo por estes resultados que a influência do El Niño é pequena nas escalas interanuais ou nula. Semelhante ao que foi pensado para a AAO, mais saídas de modelos ou dados in situ da MOC do Atlântico Sul poderiam consolidar tal afirmação. 


\section{Conclusão}

O fitoplâncton tem papel fundamental no ecossistema marinho e global, sendo não só a base da cadeia alimentar como também responsável por grande parte do oxigênio que respiramos. Seu impacto pode ser visto em diversos ciclos biogeoquímicos, dentre eles, o do carbono que tem o potencial de impactar o clima terrestre. Estes organismos dependem fortemente do movimento das águas para sua sobrevivência, assim podem ser considerados traçadores ativos para diversos fenômenos físicos. Dentre eles, podemos citar as correntes, uma vez que estas podem transportar nutrientes como também remover/colocar o fitoplâncton na zona fótica. Em diversas escalas temporais, o fitoplâncton pode sofrer impactos sendo modificado por advecção de calor, sal e nutrientes (Dave and Lozier 2015). Em termos de advecção horizontal, podemos mencionar a Circulação de Revolvimento Meridional (MOC), uma vez que esta afeta o transporte de calor e sal, altera a distribuição de massas d'água, tem controle na estratificação e está envolvida no transporte e regulagem de diversos traçadores químicos e nutrientes (Kuhlbrodt et al. 2007). Há na literatura diversos estudos relacionando a MOC com a clorofila, um proxy para estimar a produtividade primária (Schmittner 2005; Sarmiento et al. 2004; Palter et al. 2010; Zhang et al. 2018; Sanchez-Franks and Zhang 2015).

Este estudo teve como objetivo estudar a influência da MOC do Atlântico Sul na distribuição da concentração de clorofila do Atlântico Sul, em escalas interanuais, uma escala de baixa frequência. Em especial, este estudo teve o intuito de analisar como a tendência da concentração de clorofila variou entre 1998 a 2017 e como a tendência da MOC do Atlântico Sul explicaria tal variação através do transporte de nutrientes ao longo da bacia e sendo modulado pelas ressurgências de borda leste (Palter et al. 2010). Para isto foi utilizado um método de decomposição chamado Multi-Dimensional Ensemble Empirical Mode Decomposition (MEEMD). O MEEMD não se utiliza de uma fórmula matemática à priori como outros métodos de decomposição como Fourier ou ondaleta, levando em conta as variações locais ao longo da série temporal. Tal característica garante que este método possa ser utilizado para representar melhor as variações em séries temporais com tendência não lineares e não estacionárias. (Huang et al. 1998; Wu, Huang, and Chen 2009). A vantagem em se utilizar esse método é que as funções ajustadas em uma parte da série temporal não se alteraram com adição de novos dados, uma vez que a subsequente evolução de um sistema físico não pode alterar acontecimentos pretéritos (Ji et al. 2014). Como resultado o MEEMD apresenta várias componentes ortogonais oscilatórias (conhecidas como Intrinsic Mode Functions (IMF) e um resíduo sem componentes oscilatórias análogo a uma tendência (Huang et al. 1998; Wu et al. 2007). Esta poderosa ferramenta matemática possibilita a análise de séries temporais determinando as tendências no tempo e no espaço.

Os dados de concentração de clorofila utilizados nestes estudo foram obtidos do Glob- 
Colour, um produto que combina dados de clorofila proveniente de diferentes plataformas de satélites para compor uma base de dados com maior resolução espacial e temporal. O transporte de volume da MOC no Atlântico Sul foi estimado através de saídas dos campos de velocidade de dois modelos oceânicos: ECCO e NEMO. O Estimating the Circulation and Climate of the Ocean (ECCO) assimila medidas de diversas plataformas observacionais e fornece estimativas de diversas variáveis físicas/oceanográficas. O modelo de reanálise MERCATOR (sendo descrito neste estudo como NEMO) utiliza de diversos dados (sejam eles observacionais ou de modelo) para construir uma série contínua e gradeada de variáveis oceânicas.

Dois fatores que podem influenciar na variabilidade do fitoplâncton foram utilizados para a análise. O primeiro foi o nutriente, representado pelo nitrato integrado na coluna d'água até uma profundidade média da Água Modal Subantártica (SAMW). Nossa hipótese é que o nutriente integrado teria variações em escalas interanuais relacionadas com o transporte de volume da MOC do Atlântico Sul e pelo mecanismo associado às ressurgências do lado leste da bacia, citado por Palter et al. (2010). A outra variável seria a radiação fotossinteticamente ativa (PAR), que expressa a quantidade de luz necessária para a realização da fotossíntese. Esta variável não teria uma relação com a MOC mas sim, muito provavelmente, com a forçante solar ou turbidez da coluna d'água. Desta maneira, ambas variáveis poderiam influenciar o fitoplâncton, porém representando mecanismos diferentes. Os dados de nitrato são provenientes da saída de uma reanálise de um modelo biogeoquímico do tipo hindcast (sem assimilação de dados) sendo denominado neste estudo como PISCES. O PAR, semelhante a clorofila, foi obtido do produto conhecido como Globcolour que integra dados de diversos satélites.

Através da decomposição MEEMD, os padrões espaço-temporais da tendência em escala interanual da clorofila puderam ser analisadas. Nessa escala, a clorofila apresentou um padrão com aumento na região mais austral da área de estudo e esse padrão se distribuiu ao longo da série temporal para norte na porção leste da bacia sendo traçada até a região equatorial. Para analisar melhor este padrão foram selecionadas três regiões (denominadas A, B e C) que contemplam o sentido da propagação do sinal. Em cada região foi analisada a tendência da clorofila, do PAR e do nitrato integrado. O transporte de volume da MOC foi calculado em seções imediatamente ao sul de cada região selecionada. Desta forma, seu cálculo ocorreu tanto na porção leste quanto na oeste, dependendo da localização das regiões A, B e C. Foi observado que o padrão das curvas de tendência interanual da clorofila e nitrato integrado foram análogos ao que se observa em escalas sazonais em regiões tropicais/subtropicais: um aumento (diminuição) na concentração de nutriente leva a um aumento (diminuição) na concentração de clorofila. Concluímos que o PAR não influencia na variabilidade da clorofila nessa escala a partir de uma análise de escala quando comparado com o nitrato integrado e portanto a área de estudo não é limitada por luz. Desta maneira, uma vez verificada que a concentração de nitrato influencia 
as variações da clorofila nessa escala, numa próxima análise procuramos verificar a influencia da MOC nessa variabilidade. Para tanto, foram utilizadas as saídas dos modelos ECCO e NEMO para a estimativa das séries temporais de transporte de volume da MOC nas latitudes de $34.5^{\circ} \mathrm{S}, 25^{\circ} \mathrm{S}$ e $15^{\circ} \mathrm{S}$. Após a aplicação dos algoritmos de decomposição, analisamos as tendências interanuais. Os modelos discordaram entre si com relação as suas tendências, criando assim dois possíveis cenários para explicar o que foi observado na clorofila.

\section{Modelo ECCO}

As curvas da tendência interanual do transporte de volume estimando através de saídas do modelo ECCO acompanhavam as curvas de nitrato integrado, isto é, um aumento (diminuição) na MOC do Atlântico Sul local (porção leste/oeste) levaria a um aumento (diminuição) do nitrato integrado. Desta maneira, o padrão espaçotemporal da clorofila seria explicado pelo transporte de nutrientes pela MOC, estando de acordo com diversos estudos na literatura sobre este mecanismo e padrão da MOC no transporte de nutrientes (Sarmiento et al. 2004; Palter et al. 2010; $\mathrm{Pa}-$ nassa et al. 2018; Ayers and Strutton 2013).

\section{Modelo NEMO}

Os resultados envolvendo saídas do modelo NEMO por sua vez não explicariam diretamente a tendência do nitrato integrado, uma vez que as variações do transporte de volume da MOC do Atlântico Sul não implicariam no mesmo efeito diretamente. Assim deve haver outras forçantes/variáveis envolvidas sob este cenário. Neste estudo especulamos duas possíveis explicações para as variações observadas. A primeira destas é que há uma relação direta entre o transporte de volume da MOC do Atlântico Sul com o transporte de calor (Dong et al. 2009; Dong, Goni, and Bringas 2015: Majumder, Schmid, and Halliwell 2016), conforme descrito na seção Resultados e Discussão. Logo, um aumento na MOC poderia implicar em um aumento no transporte de calor, afetando a temperatura na coluna d'água e, consequentemente, a estratificação. A estratificação alteraria a concentração de nitrato integrado, que por sua vez, impactaria na clorofila. Tal cenário explicaria a relação inversa entre MOC do Atlântico Sul (NEMO) e nitrato integrado observada nas regiões A, B e C. Portanto, um aumento (diminuição) no transporte de volume da MOC, implicaria em um aumento (diminuição) no transporte de calor e que aumentaria (diminuiria) a estratificação na coluna d'água, e diminuindo (aumentando) o nitrato integrado chegando na camada fótica. Outra variável dentro desta "hipótese do transporte de calor" para explicar este padrão inverso MOC-nitrato integrado/concentração de clorofila seria o efeito do grazing do zooplâncton. Um aumento (diminuição) na temperatura da coluna d'água implica em um aumento (diminuição) no metabolismo dos organismos do zooplâncton, que levaria a um aumento (diminuição) no 
grazing. Esse efeito seria análogo ao da estratificação, tendo uma relação direta com a temperatura. Há na literatura a relação da advecção de calor e estratificação/clorofila (Dave and Lozier 2015) como também a relação de uma MOC mais estratificada, aumento do grazing e o impacto na clorofila (Olonscheck et al. 2013), entretanto é necessário um estudo mais profundo do transporte de calor, estratificação e metabolismo do zooplâncton para avaliar se este cenário é válido.

Portanto, enquanto o cenário 2 é inconclusivo temos que o cenário 1 apresenta um explicação direta (MOC-NITRATO-CLOROFILA) e válida. Além disso, o cenário 1 corrobora com outros estudos recentes como o de Panassa et al. (2018) que analisaram o mecanismo de transporte de nutrientes no ramo superior da MOC e seu impacto na clorofila pela análise de variáveis físicas e biogeoquímicas na Água Intermediária Antártica. As tendências interanuais da MOC do Atlântico Sul provenientes de saídas do modelo NEMO foram contrárias aos resultados de Panassa et al. (2018), uma vez que não mostraram um cenário de aceleração da MOC, mas sim, um declínio (Figura 50).

Como última parte deste estudo, foi analisada a influência de fenômenos remotos através de teleconexão atmosférica na MOC do Atlântico Sul. Foram escolhidos dois fenômenos climáticos (El Niño e Oscilação Antártica (AAO)) cujos índices foram decompostos e componentes em escalas maiores que a interanual foram analisadas. Concluímos que dentro de um intervalo de confiança de $90 \%$ o transporte de volume da MOC em $34.5^{\circ} \mathrm{S}$ está correlacionada em escala interanual com variações ditadas pela AAO, com correlação de - 0,75. As análises relacionadas com o El Niño não conduziram à uma correlação significativa, levando a conclusão deste estudo que suas componentes em períodos interanuais são nulas ou não significantes para a SAMOC em $34,5^{\circ} \mathrm{S}$.

Em suma, as principais conclusões deste estudo foram:

- Observamos uma tendência interanual positiva na concentração de clorofila localizada na porção mais austral da área de estudo e se distribui pela porção leste da bacia do Atlântico Sul sentido noroeste passando por toda a bacia;

- A partir de análises do modelo ECCO, a MOC modula este pulso de tendência positiva na clorofila através do transporte de nutrientes presentes na Água Modal Subantártica (SAMW);

- Ocorre uma defasagem de 2 a 4 anos para a concentração de clorofila responder ao aporte de nutrientes na região pelo transporte desses pela MOC do Atlântico Sul;

- Há indícios que existe uma defasagem de 7 anos entre uma taxa negativa do nitrato integrado com uma diminuição na concentração de clorofila;

- Do pulso entrar no Atlântico Sul e chegar na região equatorial leva em torno de 7 a10 anos. Isto porque é observado pelo modelo ECCO um crescimento da MOC 
desde 1992, enquanto que vemos o aumento de nitrato integrado e MOC a partir de 2002 na região C. Pelo Hovmöller ao longo da linha de distribuição de alta tendência (Figura 38) também conseguimos observar o começo das tendências positivas na concentração de clorofila em 2004 e chegando na região equatorial próximo de 2011, levando assim 7 anos. Esse valor é condizente com o valor achado por Castellanos et al. (2017);

- A região oligotrófica do giro subtropical vem experimentando uma tendência positiva desde 2010;

- Há indícios que este aumento na região central do giro subtropical é decorrência deste mecanismo de transporte de nutrientes pela MOC do Atlântico Sul pela recirculação da matéria orgânica remineralizada oriunda da produção nova;

- Há indícios que oscilações interanuais na Oscilação Antártica influenciem a MOC do Atlântico Sul e que este impacto ocorra próximo de cinco anos depois da perturbação.

Vale ressaltar que pelo padrão de variação das tendências interanuais, é esperado que nos próximos anos o sinal da tendência diminua na porção sul da parte leste da bacia enquanto a região equatorial continue com uma tendência alta. Se de fato ocorrer, compreender e prever sinais biológicos será mais viável.

Como considerações finais gostaríamos de expressar nossas recomendações de como melhorar este estudo. A primeira destas é obter séries mais longas da MOC do Atlântico Sul. Isto garante entender melhor suas flutuações e poder quantificar melhor o período do mecanismo de transporte de nutrientes pela mesma e seu impacto na concentração de clorofila. Uma série mais longa também permitirá a decomposição da série temporal em mais IMF's, entendendo melhor a variabilidade da MOC em outras escalas de tempo e como estas se relacionam com a AAO (ou outros índices climáticos). A avaliação da saída de outros modelos para quantificar a MOC do Atlântico Sul seria recomendável. Mais séries temporais garantem mais indícios de qual cenário (1 ou 2) se aproxima mais da realidade, além de ajudar a compreender melhor como os fenômenos atmosféricos impactam a MOC do Atlântico Sul, se sua correlação é positiva ou negativa, já que o ECCO e o NEMO concordaram na escala de decorrelação mas discordaram no sinal da correlação. Por fim, uma análise do transporte de calor, estratificação e do zooplâncton conseguiriam estruturar melhor um veredito para qual forçante está explicando o padrão espaço-temporal na clorofila. 


\section{Apêndice}

\subsection{Teste de Significância para o IMF}

O teste de significância adotado para analisar se a Instrinsic Mode Function é significativa estatisticamente é baseado no método desenvolvido por Wu and Huang (2004). Wu and Huang (2004) realizaram um experimento numérico em que aplicaram o Empirical Mode Decomposition para $10^{6}$ ruídos brancos e observaram o seu padrão. O resultado foi que perceberam uma relação constante entre o produto de densidade espectral média dos IMF's com seu período médio:

$$
E \cdot T=\text { constante }
$$

onde $E$ é a densidade espectral do IMF e $T$ o seu período médio. Com essa equação consegue a seguinte relação matemática:

$$
\ln (E)+\ln (T)=\ln (\text { constante })
$$

Por se tratar de ruídos brancos normalizados, pode-se assumir que a constante é igual a 1 (Wu and Huang 2004). Portanto, a equação 8 pode ser reescrita como:

$$
\ln (E)+\ln (T)=0 .
$$

Essa relação se mostrou verdadeira para IMF's com períodos de alta frequência, mas não para IMF's com períodos de baixa frequência. Desta maneira, uma curva foi ajustada percebendo-se verdadeira para qualquer IMF:

$$
\ln (E)=0,12-0,934 \cdot \ln (T)
$$

Com essa relação estabelecida, os autores tentaram entender a probabilidade de distribuição dos IMF's. Wu and Huang (2004) perceberam que os IMF's apresentavam uma função probabilidade densidade com uma distribuição qui-quadrado. Essa descoberta fez com que eles conseguissem determinar como esses IMF's de ruídos brancos se distribuiriam. Como resultado os IMF's de ruídos brancos ficam delimitados a certos valores (Figura 52).

Desta maneira, o teste de significância implica em definir um limite de confiança (e.g. 99\% de confiança) e analisar onde os IMF's da série temporal analisada se encontram dentro do domínio $\ln -\mathrm{E} \times \ln -\mathrm{T}$. Se o IMF estiver entre as curvas de limite confiança, ele se comporta como um ruído branco, e portanto, não é estatisticamente significativo $(\overline{\mathrm{Wu}}$ and Huang 2004; Huang 2014). Por outro lado, se o IMF estiver abaixo ou acima dos limites das curvas de intervalo de confiança, este não se comporta como um ruído branco 


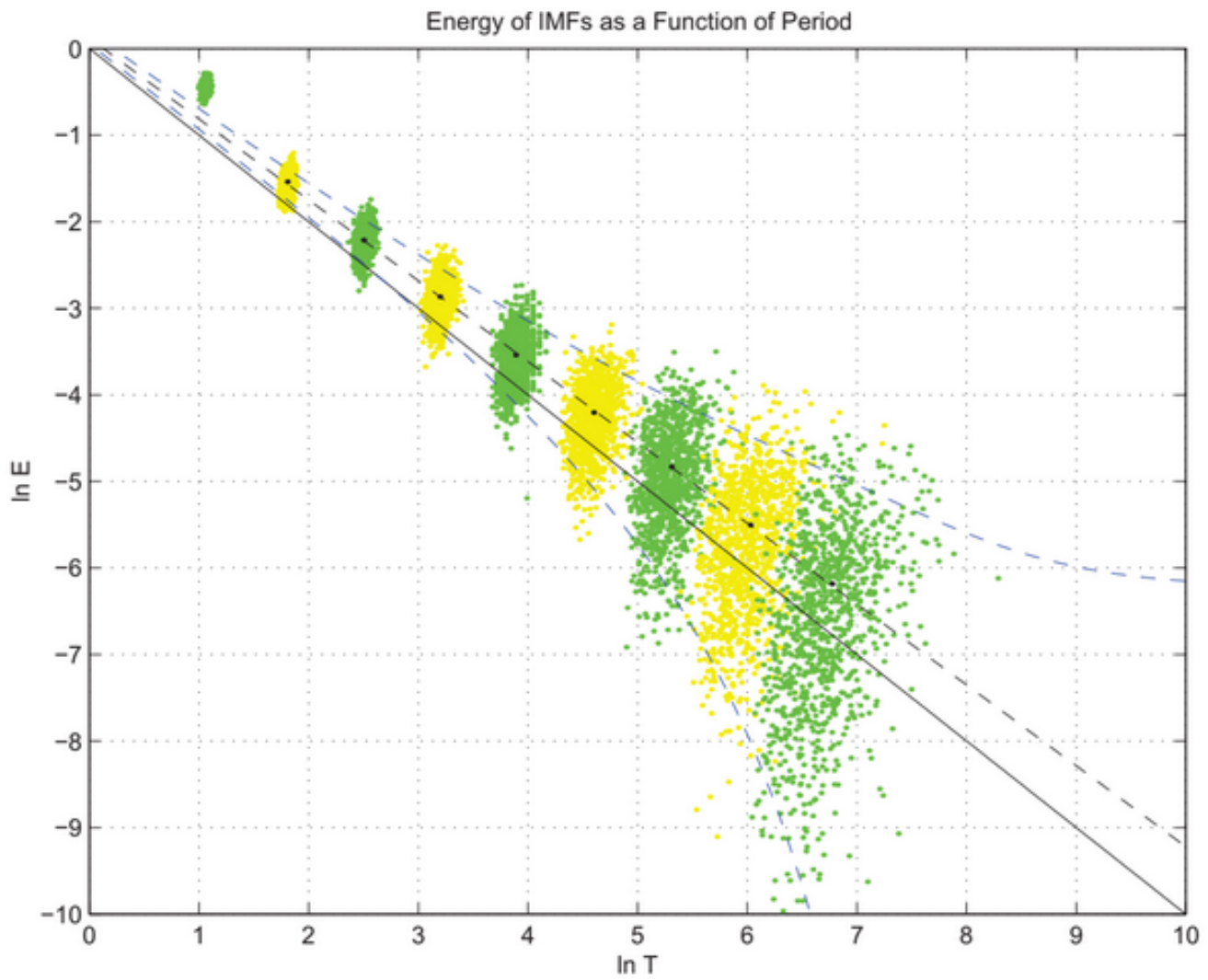

Figura 52: Os pontos amarelos e verdes são IMF's de 1024 séries temporais de ruídos brancos. Os IMF's estão em função de sua densidade espectral média pelo seu período médio. A linha preta sólida é a curva da equação 9 enquanto a linha preta tracejada é a curva da equação 10 . Os tracejados azuis localizados na extremidade dos pontos se referem ao $5^{\circ}$ e $95^{\circ}$ percentil. Fonte: (Huang 2014). 
e, portanto, é estatisticamente significativo (Wu and Huang 2004; Huang 2014).

\subsection{Teste de significância para as tendências decadais}

Para definir se as tendências decadais apresentaram significância estatística, um teste de significância análogo a um teste de Monte Carlo foi realizado. O método se baseia nos seguintes passos:

1. Selecionar uma tendência de uma série temporal que apresente baixo grau de complexidade matemática, isto é, a tendência se assemelha a uma reta;

2. Ajustar um polinômio de grau 1 para essa tendência;

3. Gerar séries randômicas com distribuição normal e contendo média e desvio padrão da série temporal escolhida;

4. Ajustar um polinômio de grau 1 para cada série randômica gerada;

5. Armazenar o coeficiente angular desse polinômio;

6. Analisar o coeficiente angular da reta ajustada da tendência com a média dos coeficientes angulares das retas ajustadas das séries randômicas.

Se o coeficiente angular da reta ajustada da tendência escolhida diferir da média $\pm 2,5$ desvios padrão dos coeficientes angulares calculados, a sua tendência é estatisticamente significativa. A premissa por trás deste teste de significância é que, se as curvas das tendências que apresentam baixa complexidade matemática conseguem ser um sinal não randômico, então menor será a probabilidade das tendências que apresentem padrões mais complexos representarem um sinal aleatório sem significado físico.

Para aplicar o teste, as tendências decadais da concentração de clorofila e nitrato integrado da região A, como também a tendência da MOC calculada proveniente de saídas do modelo NEMO e ECCO em $34,5^{\circ} \mathrm{S}$, foram escolhidas pelo padrão das tendências ser análogo a um polinômio de primeiro grau. Foram geradas $10^{5}$ séries randômicas com mesma média e desvio padrão que as séries temporais de cada variável. A tendência decadal da MOC proveniente de saídas do modelo NEMO apresentou um padrão próximo a uma parábola, então foram ajustados polinômios de segundo grau nas séries randômicas e o segundo coeficiente da equação foi escolhido, pois esse se refere a inclinação da parábola com o eixo y, indicando assim uma taxa positiva ou negativa. Os resultados se encontram nas Figuras 53 a 56. 


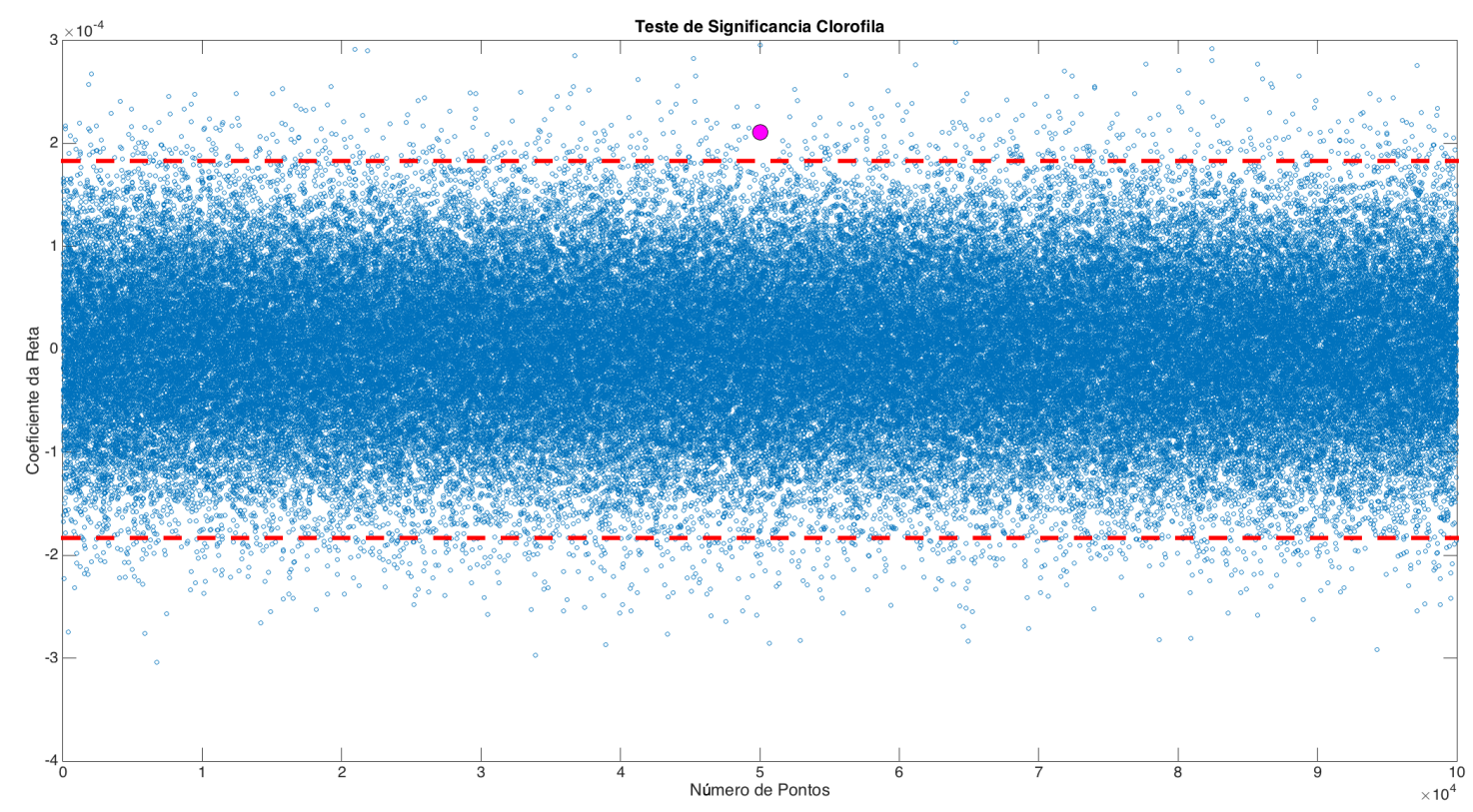

Figura 53: Teste de significância para a tendência da concentração de clorofila na região A. Os pontos azuis são os coeficientes angulares das retas ajustadas para as séries randômicas. As linhas tracejadas se referem a valores da média $\pm 2,5$ desvios padrão. $O$ ponto em magenta é o coeficiente angular do polinômio ajustado para a tendência.

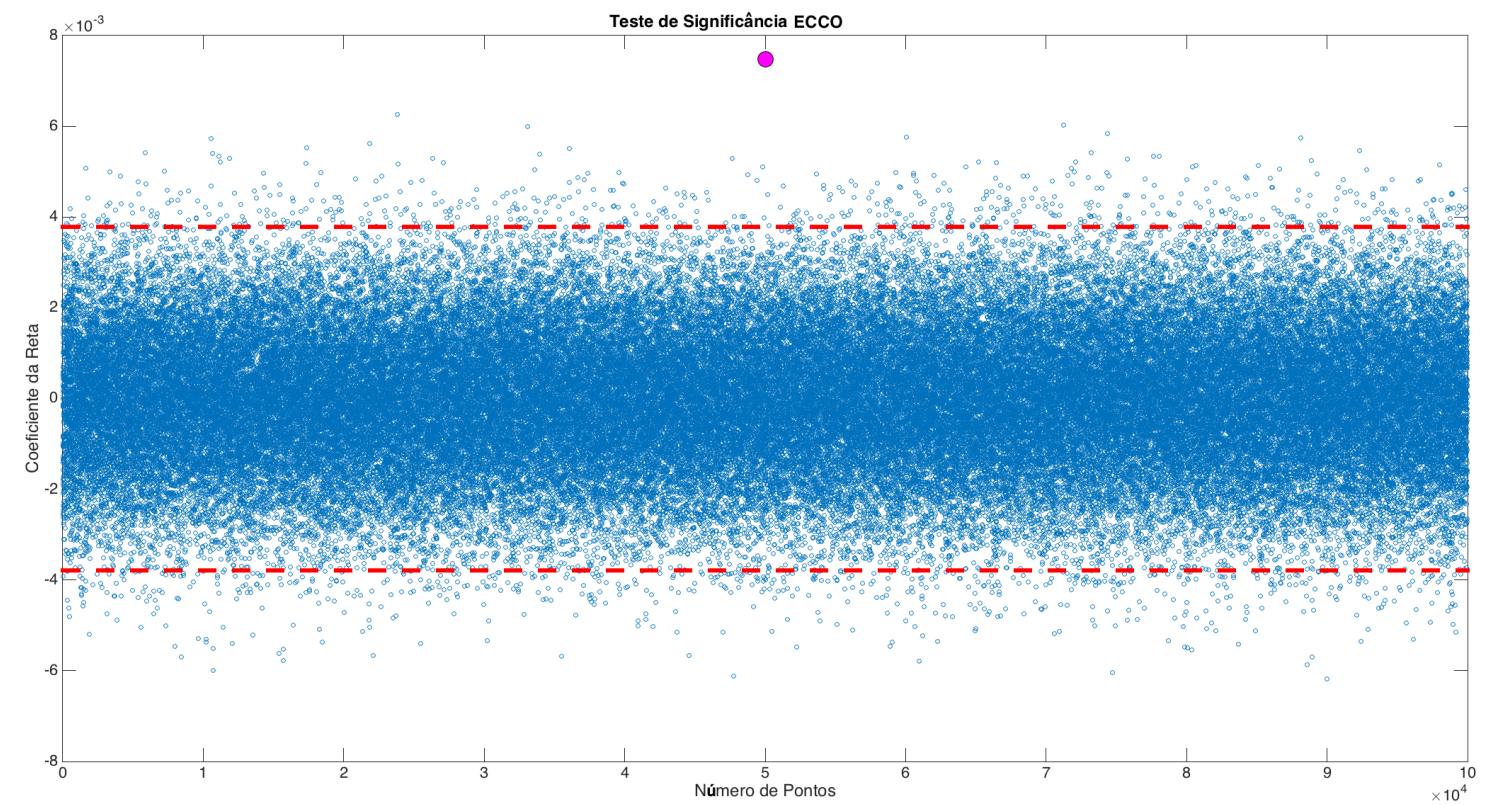

Figura 54: Similar a Figura 53, porém com a MOC proveniente de saídas do modelo ECCO 


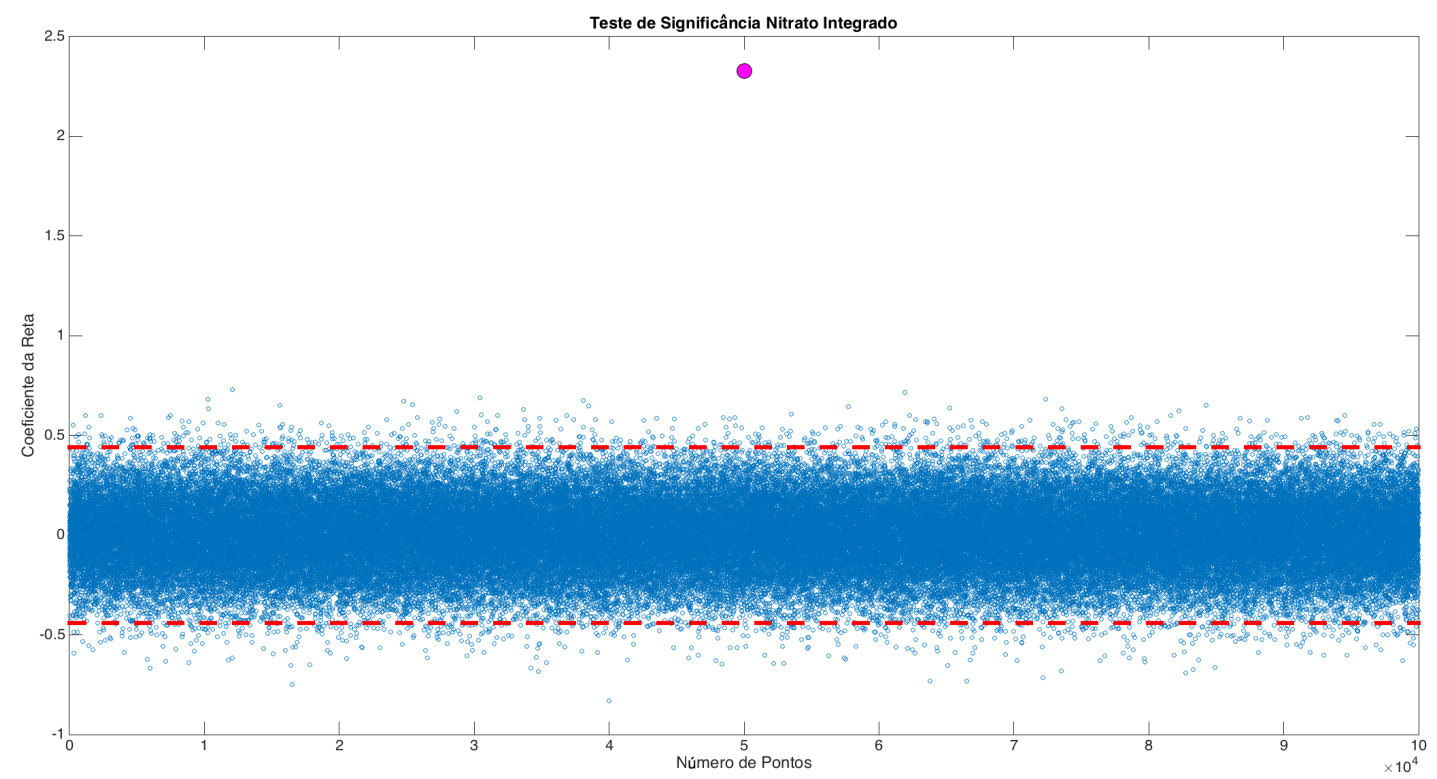

Figura 55: Similar a Figura 53, porém com ao nitrato integrado

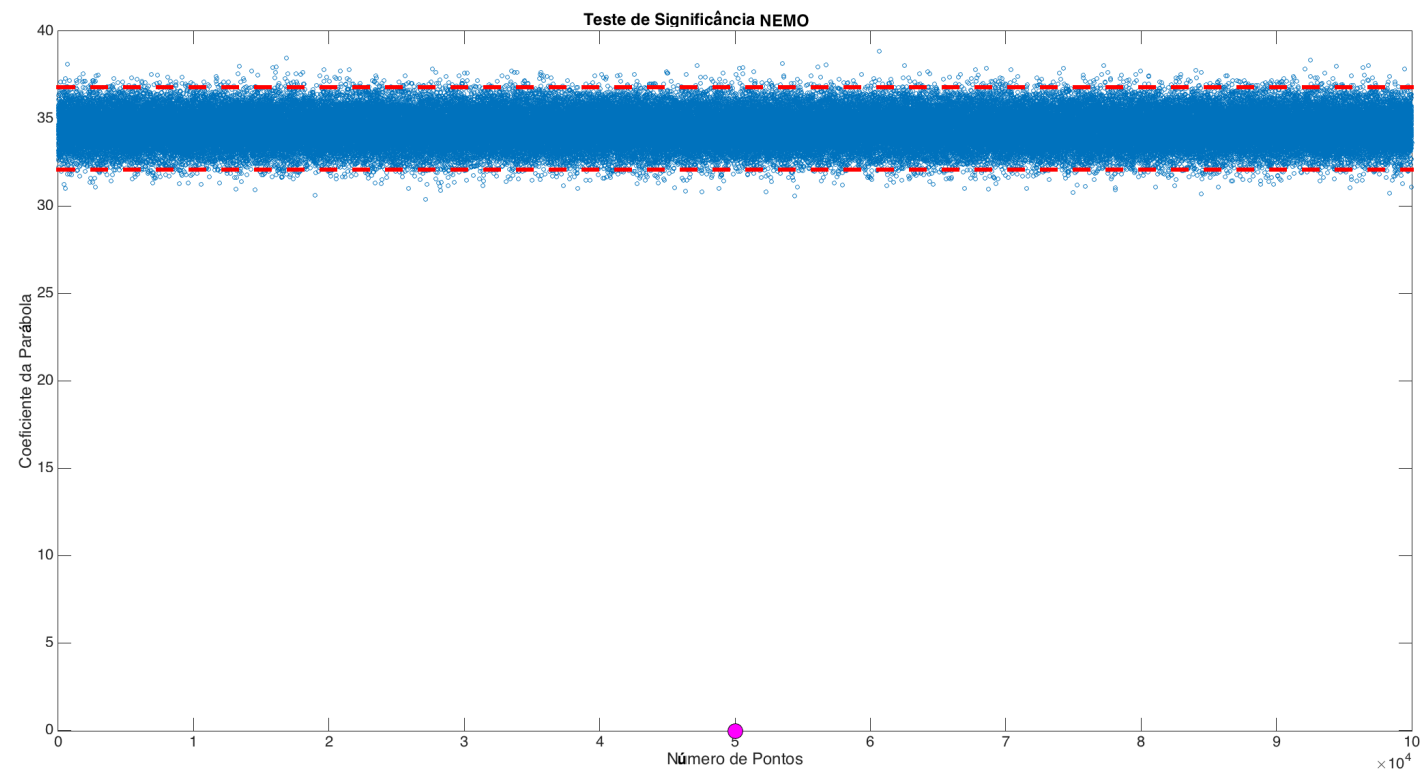

Figura 56: Similar a Figura 53, porém com a MOC proveniente de saídas do modelo NEMO 


\section{Referências}

Amante, C, and BW Eakins. 2009. "ETOPO1 Global Relief Model converted to PanMap layer format." NOAA-National Geophysical Data Center, doi, vol. 10.

Anderson, RF, S Ali, LI Bradtmiller, SHH Nielsen, MQ Fleisher, BE Anderson, and LH Burckle. 2009. "Wind-driven upwelling in the Southern Ocean and the deglacial rise in atmospheric CO2." science 323 (5920): 1443-1448.

Aumont, O. 2005. "PISCES biogeochemical model description." Technical Report, Internal report, 36 pages.

Aumont, Oliver, and Laurent Bopp. 2006. "Globalizing results from ocean in situ iron fertilization studies." Global Biogeochemical Cycles 20, no. 2.

Ayers, Jennifer M, and M Susan Lozier. 2010. "Physical controls on the seasonal migration of the North Pacific transition zone chlorophyll front." Journal of Geophysical Research: Oceans 115, no. C5.

Ayers, Jennifer M, and Peter G Strutton. 2013. "Nutrient variability in subantarctic mode waters forced by the southern annular mode and ENSO." Geophysical Research Letters 40 (13): 3419-3423.

Barrot, G, A Mangin, and S Pinnock. 2010. "GlobColour: An EO Based Service Supporting Global Ocean Carbon Cycle Research: Product User Guide.” ESA, Ref: GC-UM-ACR-PUG-01, v1 4:56.

Beal, Lisa M, Wilhelmus PM De Ruijter, Arne Biastoch, Rainer Zahn, Meghan Cronin, Juliet Hermes, Johann Lutjeharms, Graham Quartly, Tomoki Tozuka, Sheekela Baker-Yeboah, et al. 2011. "On the role of the Agulhas system in ocean circulation and climate." Nature 472 (7344): 429.

Becker, JJ, DT Sandwell, WHF Smith, J Braud, B Binder, Jl Depner, D Fabre, J Factor, S Ingalls, SH Kim, et al. 2009. "Global bathymetry and elevation data at 30 arc seconds resolution: SRTM30_PLUS.” Marine Geodesy 32 (4): 355-371.

Biastoch, Arne, and Claus W Böning. 2013. "Anthropogenic impact on Agulhas leakage." Geophysical Research Letters 40 (6): 1138-1143.

Biastoch, Arne, Claus W Böning, and JRE Lutjeharms. 2008. "Agulhas leakage dynamics affects decadal variability in Atlantic overturning circulation." Nature 456 (7221): 489.

Bristow, Laura A, Wiebke Mohr, Soeren Ahmerkamp, and Marcel MM Kuypers. 2017. "Nutrients that limit growth in the ocean." Current Biology 27 (11): R474-R478.

Castellanos, Paola, EJD Campos, Jaume Piera, OT Sato, and MAF Silva Dias. 2017. "Impacts of Agulhas Leakage on the Tropical Atlantic Western Boundary Systems." Journal of Climate 30 (17): 6645-6659. 
Cerovečki, Ivana, Lynne D Talley, Matthew R Mazloff, and Guillaume Maze. 2013. "Subantarctic mode water formation, destruction, and export in the eddy-permitting Southern Ocean state estimate." Journal of physical oceanography 43 (7): 14851511.

Charlson, Robert J, James E Lovelock, Meinrat O Andreae, and Stephen G Warren. 1987. "Oceanic phytoplankton, atmospheric sulphur, cloud albedo and climate." nature 326 (6114): 655.

Chassot, Emmanuel, Sylvain Bonhommeau, Nicholas K Dulvy, Frédéric Mélin, Reg Watson, Didier Gascuel, and Olivier Le Pape. 2010. "Global marine primary production constrains fisheries catches." Ecology letters 13 (4): 495-505.

da Silveira, Ilson Carlos Almeida, André Campos Kersten Schmidt, Edmo José Dias Campos, Sueli Susana de Godoi, and Yoshimine Ikeda. 2000. "A corrente do Brasil ao largo da costa leste brasileira." Revista Brasileira de Oceanografia 48 (2): 171183.

Dave, Apurva C, and M Susan Lozier. 2013. "Examining the global record of interannual variability in stratification and marine productivity in the low-latitude and mid-latitude ocean.” Journal of Geophysical Research: Oceans 118 (6): 3114-3127.

2015. "The impact of advection on stratification and chlorophyll variability in the equatorial Pacific." Geophysical Research Letters 42 (11): 4523-4531.

de Baar, Hein JW, Anita GJ Buma, Rob F Nolting, Gerhard C Cadée, Guy Jacques, and Paul J Tréguer. 1990. "On iron limitation of the Southern Ocean: experimental observations in the Weddell and Scotia Seas." Marine ecology progress series, pp. $105-122$.

Dee, Dick P, S M Uppala, AJ Simmons, Paul Berrisford, P Poli, S Kobayashi, U Andrae, MA Balmaseda, G Balsamo, d P Bauer, et al. 2011. "The ERA-Interim reanalysis: Configuration and performance of the data assimilation system." Quarterly Journal of the royal meteorological society 137 (656): 553-597.

Dong, Shenfu, Molly Baringer, Gustavo Goni, and Silvia Garzoli. 2011. "Importance of the assimilation of Argo float measurements on the Meridional Overturning Circulation in the South Atlantic." Geophysical Research Letters 38, no. 18.

Dong, Shenfu, Silvia Garzoli, Molly Baringer, Christopher Meinen, and Gustavo Goni. 2009. "Interannual variations in the Atlantic meridional overturning circulation and its relationship with the net northward heat transport in the South Atlantic." Geophysical Research Letters 36, no. 20.

Dong, Shenfu, Gustavo Goni, and Francis Bringas. 2015. "Temporal variability of the South Atlantic meridional overturning circulation between $20 \mathrm{~S}$ and 35 S." Geophysical Research Letters 42 (18): 7655-7662. 
Elipot, Shane, and Lisa M Beal. 2018. "Observed Agulhas Current sensitivity to interannual and long-term trend atmospheric forcings." Journal of Climate 31 (8): 3077-3098.

Falkowski, Paul G. 1994. "The role of phytoplankton photosynthesis in global biogeochemical cycles." Photosynthesis research 39 (3): 235-258.

Fauchereau, Nicolas, S Trzaska, Yves Richard, Pascal Roucou, and Pierre Camberlin. 2003. "Sea-surface temperature co-variability in the Southern Atlantic and Indian Oceans and its connections with the atmospheric circulation in the Southern Hemisphere." International Journal of Climatology 23 (6): 663-677.

Field, Christopher B, Michael J Behrenfeld, James T Randerson, and Paul Falkowski. 1998. "Primary production of the biosphere: integrating terrestrial and oceanic components." science 281 (5374): 237-240.

Forget, GAEL, J-M Campin, P Heimbach, CN Hill, RM Ponte, and C Wunsch. 2015. "ECCO version 4: An integrated framework for non-linear inverse modeling and global ocean state estimation."

Franzke, Christian LE. 2014. "Warming trends: Nonlinear climate change." Nature Climate Change 4 (6): 423.

Frouin, Robert, and Rachel T Pinker. 1995. "Estimating photosynthetically active radiation (PAR) at the earth's surface from satellite observations." Remote Sensing of Environment 51 (1): 98-107.

Fukumori, Ichiro, Ou Wang, Ian Fenty, Gael Forget, Patrick Heimbach, and Rui M Ponte. 2017. "ECCO version 4 release 3." Technical Report.

Garcia, Hernan E, Timothy P Boyer, Ricardo A Locarnini, John I Antonov, Alexey V Mishonov, Olga K Baranova, Melissa M Zweng, James R Reagan, Daphne R Johnson, and Sydney Levitus. 2013a. "World ocean atlas 2013. Volume 3, Dissolved oxygen, apparent oxygen utilization, and oxygen saturation."

Garcia, Hernan E, Ricardo A Locarnini, Timothy P Boyer, John I Antonov, Olga K Baranova, Melissa M Zweng, James R Reagan, Daphne R Johnson, Alexey V Mishonov, and Sydney Levitus. 2013b. "World ocean atlas 2013. Volume 4, Dissolved inorganic nutrients (phosphate, nitrate, silicate)."

Garric, Gilles, and Laurent Parent. 2013. "Quality Information Document GLORYS2v4.” Change 2:14.

Garzoli, Silvia L, and Molly O Baringer. 2007. "Meridional heat transport determined with expandable bathythermographs-Part II: South Atlantic transport.” Deep Sea Research Part I: Oceanographic Research Papers 54 (8): 1402-1420. 
Garzoli, Silvia L, Molly O Baringer, Shenfu Dong, Renellys C Perez, and Qi Yao. 2013. "South Atlantic meridional fluxes." Deep Sea Research Part I: Oceanographic Research Papers 71:21-32.

Garzoli, Silvia L, and Ricardo Matano. 2011. "The South Atlantic and the Atlantic meridional overturning circulation.” Deep Sea Research Part II: Topical Studies in Oceanography 58 (17): 1837-1847.

Gilles Garric, Laurent Parent. 2017. Technical Report.

Hall, Alex, and Martin Visbeck. 2002. "Synchronous variability in the Southern Hemisphere atmosphere, sea ice, and ocean resulting from the annular mode." Journal of Climate 15 (21): 3043-3057.

Hanawa, Kimio, and Lynne D Talley. 2001. “4. Mode waters.” In International Geophysics, Volume 77, 373-386. Elsevier.

Hofmann, M, Boris Worm, S Rahmstorf, and HJ Schellnhuber. 2011. "Declining ocean chlorophyll under unabated anthropogenic CO2 emissions.” Environmental Research Letters 6 (3): 034035.

Hogg, Nelson G, and W Brechner Owens. 1999. "Direct measurement of the deep circulation within the Brazil Basin.” Deep Sea Research Part II: Topical Studies in Oceanography 46 (1-2): 335-353.

Hoppema, Mario, Karel Bakker, Steven MAC van Heuven, Jan C van Ooijen, and Hein JW de Baar. 2015. "Distributions, trends and inter-annual variability of nutrients along a repeat section through the Weddell Sea (1996-2011)." Marine chemistry 177:545-553.

Hu, Zeng-Zhen, Bohua Huang, James L Kinter, Zhaohua Wu, and Arun Kumar. 2012. "Connection of the stratospheric QBO with global atmospheric general circulation and tropical SST. Part II: Interdecadal variations.” Climate dynamics 38 (1-2): 2543.

Huang, Norden E, Zheng Shen, Steven R Long, Manli C Wu, Hsing H Shih, Quanan Zheng, Nai-Chyuan Yen, Chi Chao Tung, and Henry H Liu. 1998. "The empirical mode decomposition and the Hilbert spectrum for nonlinear and non-stationary time series analysis." Proceedings of the Royal Society of London A: mathematical, physical and engineering sciences, Volume 454. The Royal Society, 903-995.

Huang, Norden E, Man-Li C Wu, Steven R Long, Samuel SP Shen, Wendong Qu, Per Gloersen, and Kuang L Fan. 2003. "A confidence limit for the empirical mode decomposition and Hilbert spectral analysis." Proceedings of the royal society of london a: Mathematical, physical and engineering sciences, Volume 459. The Royal Society, 2317-2345. 
Huang, Norden Eh. 2014. Hilbert-Huang transform and its applications. Volume 16. World Scientific.

Iida, T, T Odate, and M Fukuchi. 2013. "Long-Term Trends of Nutrients and Apparent Oxygen Utilization South of the Polar Front in Southern Ocean."

Ji, Fei, Zhaohua Wu, Jianping Huang, and Eric P Chassignet. 2014. "Evolution of land surface air temperature trend." Nature Climate Change 4 (6): 462.

Kahru, Mati, Zhongping Lee, and B Greg Mitchell. 2017. "Contemporaneous disequilibrium of bio-optical properties in the Southern Ocean." Geophysical Research Letters 44 (6): 2835-2842.

Kuhlbrodt, Till, Alexa Griesel, Marisa Montoya, Anders Levermann, Matthias Hofmann, and Stefan Rahmstorf. 2007. "On the driving processes of the Atlantic meridional overturning circulation." Reviews of Geophysics 45, no. 2.

Longhurst, Alan R. 2007a. "Chapter 12 - THE SOUTHERN OCEAN." In Ecological Geography of the Sea (Second Edition), edited by Alan R. Longhurst, Second Edition, 51 - 70. Burlington: Academic Press.

. 2007b. "Chapter 4 - PHYSICAL CONTROL OF ECOLOGICAL PROCESSES." In Ecological Geography of the Sea (Second Edition), edited by Alan R. Longhurst, Second Edition, 51 - 70. Burlington: Academic Press.

. 2007c. "Chapter 6 - BIOMES: THE PRIMARY PARTITION." In Ecological Geography of the Sea (Second Edition), edited by Alan R. Longhurst, Second Edition, 51 - 70. Burlington: Academic Press.

. 2007d. "Chapter 9 - THE ATLANTIC OCEAN." In Ecological Geography of the Sea (Second Edition), edited by Alan R. Longhurst, Second Edition, 51 - 70. Burlington: Academic Press.

Lozier, M Susan, Apurva C Dave, Jaime B Palter, Lisa M Gerber, and Richard T Barber. 2011. "On the relationship between stratification and primary productivity in the North Atlantic." Geophysical Research Letters 38, no. 18.

Majumder, Sudip, Claudia Schmid, and George Halliwell. 2016. "An observation and model-based analysis of meridional transports in the South Atlantic." Journal of Geophysical Research: Oceans 121 (8): 5622-5638.

Marini, Camille, Claude Frankignoul, and Juliette Mignot. 2011. "Links between the southern annular mode and the Atlantic meridional overturning circulation in a climate model." Journal of Climate 24 (3): 624-640.

Marinov, I, A Gnanadesikan, JR Toggweiler, and JL Sarmiento. 2006. "The southern ocean biogeochemical divide." Nature 441 (7096): 964. 
Maritorena, Stéphane, and David A Siegel. 2005. "Consistent merging of satellite ocean color data sets using a bio-optical model." Remote Sensing of Environment 94 (4): $429-440$.

Marshall, Gareth J. 2003. "Trends in the Southern Annular Mode from observations and reanalyses." Journal of Climate 16 (24): 4134-4143.

Martin, John H, R Michael Gordon, and Steve E Fitzwater. 1990. "Iron in Antarctic waters." Nature 345 (6271): 156.

Matsushita, Bunkei, Wei Yang, Peng Chang, Fan Yang, and Takehiko Fukushima. 2012. "A simple method for distinguishing global Case-1 and Case-2 waters using SeaWiFS measurements." ISPRS journal of photogrammetry and remote sensing 69:74-87.

McCartney, MS. 1977. "Subantarctic Mode Water. In." A Voyage of Discovery, Deep Sea Research 24:103-119.

Misra, Vasubandhu, H Li, Z Wu, and S DiNapoli. 2014. "Global seasonal climate predictability in a two tiered forecast system: part I: boreal summer and fall seasons." Climate dynamics 42 (5-6): 1425-1448.

Mitchell, B Greg, Eric A Brody, Osmund Holm-Hansen, Charles McClain, and James Bishop. 1991. "Light limitation of phytoplankton biomass and macronutrient utilization in the Southern Ocean.” Limnology and Oceanography 36 (8): 1662-1677.

Mo, Kingtse C. 2000. "Relationships between low-frequency variability in the Southern Hemisphere and sea surface temperature anomalies." Journal of Climate 13 (20): 3599-3610.

Moore, C Mark, Matthew M Mills, Eric P Achterberg, Richard J Geider, Julie LaRoche, Mike I Lucas, Elaine L McDonagh, Xi Pan, Alex J Poulton, Micha JA Rijkenberg, et al. 2009. "Large-scale distribution of Atlantic nitrogen fixation controlled by iron availability." Nature Geoscience 2 (12): 867.

Munk, Walter, and Carl Wunsch. 1998. "Abyssal recipes II: Energetics of tidal and wind mixing." Deep Sea Research Part I: Oceanographic Research Papers 45 (12): 1977-2010.

Nelson, David M, and Walker 0 Smith Jr. 1991. "Sverdrup revisited: Critical depths, maximum chlorophyll levels, and the control of Southern Ocean productivity by the irradiance-mixing regime.” Limnology and Oceanography 36 (8): 1650-1661.

Olonscheck, D, M Hofmann, Boris Worm, and HJ Schellnhuber. 2013. “Decomposing the effects of ocean warming on chlorophyll a concentrations into physically and biologically driven contributions." Environmental Research Letters 8 (1): 014043. 
Pachori, Ram Bilas. 2008. "Discrimination between ictal and seizure-free EEG signals using empirical mode decomposition." Research Letters in Signal Processing 2008:14.

Palter, Jaime B, M Susan Lozier, Jorge L Sarmiento, and Richard G Williams. 2011. "The supply of excess phosphate across the Gulf Stream and the maintenance of subtropical nitrogen fixation." Global Biogeochemical Cycles 25, no. 4.

Palter, JB, JL Sarmiento, A Gnanadesikan, J Simeon, and RD Slater. 2010. "Fueling export production: Nutrient return pathways from the deep ocean and their dependence on the Meridional Overturning Circulation.” Biogeosciences 7 (11): 3549.

Panassa, Essowe, J Magdalena Santana-Casiano, Melchor González-Dávila, Mario Hoppema, Steven MAC van Heuven, Christoph Völker, Dieter Wolf-Gladrow, and Judith Hauck. 2018. "Variability of nutrients and carbon dioxide in the Antarctic Intermediate Water between 1990 and 2014.” Ocean Dynamics 68 (3): 295-308.

Pardo, Paula Conde, Bronte Tilbrook, Clothilde Langlais, Thomas William Trull, and Stephen Rich Rintoul. 2017. "Carbon uptake and biogeochemical change in the Southern Ocean, south of Tasmania.” Biogeosciences 14 (22): 5217-5237.

Perruche, Coralie, Julien Paul, and Marie Drévillon. 2018. “Quality Information Document Global Reanalysis Bio 001 029.” Technical Report.

Perruche, Coralie, Camille Szczypta, Julien Paul, and Marie Drévillon. 2013. "Product User Guide Global Reanalysis Bio 001 029.”

Platt, Trevor, Heather Bouman, Emmanuel Devred, César Fuentes-Yaco, and Shubha Sathyendranath. 2005. "Physical forcing and phytoplankton distributions." Scientia Marina 69 (S1): 55-73.

Polovina, Jeffrey J, Fei Chai, Evan A Howell, Donald R Kobayashi, Lei Shi, and Yi Chao. 2008. "Ecosystem dynamics at a productivity gradient: a study of the lower trophic dynamics around the northern atolls in the Hawaiian Archipelago." Progress in Oceanography 77 (2-3): 217-224.

Polovina, Jeffrey J, Evan A Howell, Donald R Kobayashi, and Michael P Seki. 2017. "The Transition Zone Chlorophyll Front updated: Advances from a decade of research.” Progress in Oceanography 150:79-85.

Prézelin, Barbara B, Max M Tilzer, Oscar Schofield, and Clivia Haese. 1991. "The control of the production process of phytoplankton by the physical structure of the aquatic environment with special reference to its optical properties." Aquatic Sciences 53 (2-3): 136-186.

Rahmstorf, Stefan. 2002. "Ocean circulation and climate during the past 120,000 years." Nature 419 (6903): 207. 
Raitsos, Dionysios E, Xing Yi, Trevor Platt, Marie-Fanny Racault, Robert JW Brewin, Yaswant Pradhan, Vassilis P Papadopoulos, Shubha Sathyendranath, and Ibrahim Hoteit. 2015. "Monsoon oscillations regulate fertility of the Red Sea." Geophysical Research Letters 42 (3): 855-862.

Riding, Robert. 1992. “The algal breath of life.” Nature 359 (6390): 13.

Rodrigues, Regina R, Edmo JD Campos, and Reindert Haarsma. 2015. "The impact of ENSO on the South Atlantic subtropical dipole mode." Journal of Climate 28 (7): 2691-2705.

Sabine, Christopher L, Richard A Feely, Nicolas Gruber, Robert M Key, Kitack Lee, John L Bullister, Rik Wanninkhof, CSL Wong, Douglas WR Wallace, Bronte Tilbrook, et al. 2004. "The oceanic sink for anthropogenic CO2." science 305 (5682): 367-371.

Saenko, Oleg A, John C Fyfe, and Matthew H England. 2005. "On the response of the oceanic wind-driven circulation to atmospheric CO 2 increase." Climate dynamics 25 (4): 415-426.

Sanchez-Franks, A, and R Zhang. 2015. "Impact of the Atlantic meridional overturning circulation on the decadal variability of the Gulf Stream path and regional chlorophyll and nutrient concentrations." Geophysical Research Letters 42 (22): 98899887.

Sarmiento, J áL, N Gruber, MA Brzezinski, and JP Dunne. 2004. "High-latitude controls of thermocline nutrients and low latitude biological productivity." Nature 427 (6969): 56.

Schlotthauer, Gastón, María Eugenia Torres, and Hugo L Rufiner. 2009. "A new algorithm for instantaneous $\mathrm{F} 0$ speech extraction based on ensemble empirical mode decomposition." Signal Processing Conference, 2009 17th European. IEEE, 23472351.

Schmid, Claudia. 2014. "Mean vertical and horizontal structure of the subtropical circulation in the South Atlantic from three-dimensional observed velocity fields." Deep Sea Research Part I: Oceanographic Research Papers 91:50-71.

Schmittner, Andreas. 2005. "Decline of the marine ecosystem caused by a reduction in the Atlantic overturning circulation." Nature 434 (7033): 628.

Shi, Yingni, Xuan Zhou, Xiaofeng Yang, Lijian Shi, and Sheng Ma. 2015. "Merging satellite ocean color data with Bayesian maximum entropy method." IEEE Journal of Selected Topics in Applied Earth Observations and Remote Sensing 8 (7): 3294 3304. 
Siegenthaler, U, and JL Sarmiento. 1993. "Atmospheric carbon dioxide and the ocean." Nature 365 (6442): 119.

Stramma, Lothar, and Matthew England. 1999. "On the water masses and mean circulation of the South Atlantic Ocean." Journal of Geophysical Research: Oceans 104 (C9): 20863-20883.

Talley, Lynne D. 2011. Descriptive physical oceanography: an introduction. Academic press.

Tanhua, Toste, Mario Hoppema, Elizabeth M Jones, Tim Stöven, Judith Hauck, Melchor González Dávila, Magdalena Santana-Casiano, Marta Álvarez, and Volker H Strass. 2017. "Temporal changes in ventilation and the carbonate system in the Atlantic sector of the Southern Ocean.” Deep Sea Research Part II: Topical Studies in Oceanography 138:26-38.

Thompson, David WJ, Susan Solomon, Paul J Kushner, Matthew H England, Kevin M Grise, and David J Karoly. 2011. "Signatures of the Antarctic ozone hole in Southern Hemisphere surface climate change." Nature Geoscience 4 (11): 741.

Toggweiler, JR. 1995. "What are upwelling systems contributing to the ocean's carbon and nutrient budgets?" Upwelling in the ocean: modern processes and ancient records, pp. 337-360.

Toggweiler, JR, and B Samuels. 1995. "Effect of Drake Passage on the global thermohaline circulation.” Deep Sea Research Part I: Oceanographic Research Papers 42 (4): $477-500$.

Trenberth, KE. 2016. "The climate data guide: Nino SST indices (Nino 1+ 2, 3, 3.4, 4; ONI and TNI)." Online, February.

Wei, Wei, Gerrit Lohmann, and Mihai Dima. 2012. "Distinct modes of internal variability in the global meridional overturning circulation associated with the Southern Hemisphere westerly winds." Journal of Physical Oceanography 42 (5): 785-801.

Weijer, Wilbert, Wilhelmus PM De Ruijter, Andreas Sterl, and Sybren S Drijfhout. 2002. "Response of the Atlantic overturning circulation to South Atlantic sources of buoyancy." Global and Planetary Change 34 (3-4): 293-311.

Williams, Richard G, Vassil Roussenov, and Michael J Follows. 2006. "Nutrient streams and their induction into the mixed layer." Global Biogeochemical Cycles 20, no. 1.

Wu, Zhaohua, and Norden E Huang. 2004. "A study of the characteristics of white noise using the empirical mode decomposition method." Proceedings of the Royal Society of London A: Mathematical, Physical and Engineering Sciences, Volume 460. The Royal Society, 1597-1611. 
_ 2009. "Ensemble empirical mode decomposition: a noise-assisted data analysis method." Advances in adaptive data analysis 1 (01): 1-41.

Wu, Zhaohua, Norden E Huang, and Xianyao Chen. 2009. “The multi-dimensional ensemble empirical mode decomposition method." Advances in Adaptive Data Analysis 1 (03): 339-372.

Wu, Zhaohua, Norden E Huang, Steven R Long, and Chung-Kang Peng. 2007. "On the trend, detrending, and variability of nonlinear and nonstationary time series." Proceedings of the National Academy of Sciences 104 (38): 14889-14894.

Zhang, Min, Yuanling Zhang, Qi Shu, Chang Zhao, Gang Wang, Zhaohua Wu, and Fangli Qiao. 2018. "Spatiotemporal evolution of the chlorophyll a trend in the North Atlantic Ocean." Science of The Total Environment 612:1141-1148.

Zhu, Jieshun, Bohua Huang, and Zhaohua Wu. 2012. "The role of ocean dynamics in the interaction between the Atlantic meridional and equatorial modes." Journal of Climate 25 (10): 3583-3598. 
São Paulo, 14 de Maio de 2019

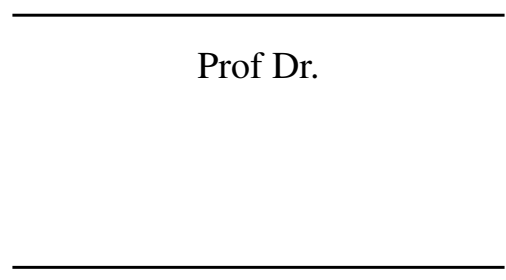

Prof. Dr.

Prof. Dr. 